\title{
WEATHERING STEELS: FROM EMPIRICAL DEVELOPMENT TO SCIENTIFIC DESIGN. A REVIEW
}

\author{
M. Morcillo , I. Díaz, B. Chico, H. Cano, D. de la Fuente \\ National Centre for Metallurgical Research (CENIM-CSIC), Avda. Gregorio del Amo, 8, 28040- \\ Madrid, Spain
}

\begin{abstract}
The design of the first weathering steels was purely empirical and focused on a small number of conventional alloying elements such as manganese, silicon, chromium, nickel, copper and phosphorus, mainly. The environmental conditions that promote the formation of protective rust layers: existence of wet/dry cycling, absence of very long wetness times, atmospheres without a marine component, etc., were identified by trial and error. This paper makes a bibliographic review of the abundant literature that has been published on the atmospheric corrosion of weathering steels, setting out in chronological order the advances made in the scientific knowledge of important matters such as: atmospheric corrosion mechanisms of weathering steel, formation of protective rust layers, and the role played by alloying elements. The work ends with an overview of the scientific design of new weathering steels, placing special emphasis on the new compositions developed for application in marine atmospheres.
\end{abstract}

Keywords: C. Atmospheric corrosion; C. Rust; A. Low alloy steel

\section{Introduction}

Weathering steels (WS), also known as low-alloy steels, are mild steels with a carbon content of less than $0.2 \% \mathrm{wt}$, to which mainly $\mathrm{Cu}, \mathrm{Cr}, \mathrm{Ni}, \mathrm{P}, \mathrm{Si}$, and $\mathrm{Mn}$ are added as alloying elements totalling a few percent maximum [1]. The development of the first WS in the early 20th Century was essentially empirical, based on results obtained in wide-scale research programmes undertaken by ASTM [2] and the steelmaker US Steel Corporation [3].

The enhanced corrosion resistance of WS is due to the formation of a dense and well-adhering corrosion product layer known as the patina. Besides possessing greater mechanical strength and corrosion resistance than mild steel or plain carbon steel (CS), the patina is also valued for its attractive appearance and self-healing abilities. The main applications for WS include civil

\footnotetext{
* Corresponding author: Tel. +34 91553 8900, Fax. +34 915347425.

e-mail: morcillo@cenim.csic.es (M. Morcillo)
} 
structures such as bridges and other load-bearing structures, road installations, electricity posts, utility towers, guide rails, ornamental sculptures, façades and roofing, etc.

The environmental conditions which promote the formation of protective rust layers: existence of wet/dry cycling, absence of very long wetness times, absence of a marine component in the atmosphere, etc., were also initially identified by means of trial and error. Extensive research work has subsequently thrown full light on the requisites for a protective rust layer to form, and it is now well accepted that wet/dry cycling is essential to form a dense and adherent rust layer, with rainwater washing the steel surface well, accumulated moisture draining easily, and a fast drying action (low time of wetness) [4]. Surfaces protected from the sun and rain (sheltered) tend to form loose and poorly compacted rust, while surfaces freely exposed to the sun and rain produce more compact and protective rust layers. Structures should be free of interstices, crevices, cavities, and other places where water can collect, which are vulnerable to corrosion due to the absence of a protective patina. It is also inadvisable to use bare WS in continuously moist exposure conditions due to the lack of alternate wetting and drying cycles which are necessary to physically consolidate the rust film, or in marine atmospheres where the protective patina does not form [5-6].

Matsushima et al. [7] studied the effect of a large number of variables on WS behaviour in architectural applications and verified the decisive influence on the formation of the protective patina of whether or not the surface was wetted by rainwater, and whether or not the points where moisture tended to collect were well drained. These effects are most pronounced in atmospheres with high pollution levels, where the protective patina may never get to form. An exhaustive bibliographic review on the effect of exposure conditions on atmospheric corrosion of conventional WS (Cor-Ten) has been published in a previous paper [8].

Since the first studies by Copson [2] and Larrabee and Coburn [3], great advances have been made in scientific knowledge of the mechanisms that govern WS behaviour.

This paper presents a bibliographic review of the abundant literature that has been published on the atmospheric corrosion of WS, setting out in chronological order the advances made in the scientific knowledge on important matters such as the atmospheric corrosion mechanisms of WS, the formation of protective rust layers, and the role played by alloying elements.

It ends with an overview of the scientific design of new WS, placing special emphasis on the new compositions developed for application in marine atmospheres, one of the main limitations of conventional WS. 


\section{Empirical development of WS.}

\subsection{Brief historical development}

Albrecht and Hall [9] made an exhaustive study of the historical development of WS. By way of summary, the following milestones represent the most important advances in the empirical development of WS.

1910 (Buck [10])

Buck, of US Steel Corporation, conducted a large-scale atmospheric exposure test of copper steel in the industrial coke regions (sulphurous fumes) of Pennsylvania, Atlantic City (marine) and Kittanning (rural). This research showed the beneficial effect of copper in steels for atmospheric exposure. Most of the effect due to the presence of copper was achieved with the first $0.03 \%$ wt or so added.

\section{6 (Committee A-5 ASTM [11])}

The first major exposure study was conducted on large 260 corrugated sheets, with copper contents varying between 0.01 and $0.25 \%$ wt, at three USA locations: Fort Pitt in Pittsburgh, Fort Sheridan and Annapolis. The findings indicated that with $0.04 \%$ wt copper the atmospheric corrosion rate slowed down considerably, and that a copper level of $0.15 \% \mathrm{wt}$ was ample.

\section{6 (Committee A-5 ASTM [12])}

The second major exposure study was conducted in four USA locations: Altoona, State College, Sandy Hook and Key West. Larrabee [12] summarised the results of these two major studies and concluded on behalf of Committee A-5 that the ratios of time to perforation varied depending upon the type of steel and location. The average life of all sheets with $0.20 \% \mathrm{wt}$ minimum copper was about twice that of sheets with residual copper. The more copper the steel contained, the longer its life. A higher phosphorus content contributed to corrosion resistance.

\section{9 (V.V. Kendall and E.S. Taylerson [13])}

In the sulphurous industrial atmosphere of Pittsburgh, copper and especially a combination of copper and phosphorus had a strongly beneficial effect on corrosion resistance. This influence was greater in steels than in irons. In the rural atmosphere of Fort Sheridan the attack was much less severe, but in general the indications from Pittsburgh were valid here as well. 


\section{3 (US Steel Corporation)}

US Steel launched the first commercial WS under the name of USS Cor-Ten steel.

\section{1 (Committee A-5 ASTM $[2,14]$}

71 low-alloy steels were exposed to an industrial atmosphere at Bayonne and to marine atmospheres at Block Island and Kure Beach $(250 \mathrm{~m})$. It was found that rust coatings in the industrial atmosphere were more protective, with the corrosion rate dropping to lower values than in the marine atmospheres.

\section{2 (United States Steel Co. [3])}

Different steels were exposed in the following atmospheres: Kearny (industrial), South Bend (semi-rural) and Kure Beach, $250 \mathrm{~m}$ (marine). It was found that the rust film developed during the first four years of exposure in the industrial atmosphere was more protective than the film developed in the marine atmosphere. The corrosion rates for all three materials (mild steel, copper steel and Cor-Ten steel) in the industrial atmosphere decreased markedly after one to two years of exposure, as was shown by the flatness of their corrosion/time curves indicating more and more protective rust, whereas the rust had a lesser effect on the corrosion rates of mild steel and even copper steel in the marine atmosphere.

\subsection{Effect of alloying elements}

The development of the first WS compositions was initially an empirical task based on steel mass loss results in atmospheric exposure, and not on scientific knowledge of the influence of alloying elements. The early studies of Copson [2] and Larrabee and Coburn [3], the former beginning in 1941 by ASTM Committee A-5 and the latter in 1942 by US Steel Corporation, represented an important step forward in the empirical development of WS based on a knowledge of the effect of different alloying elements. There follows a short summary of the effect of the main alloying elements in atmospheric corrosion of WS.

\subsubsection{Phosphorus}

Phosphorus is not essential for protective patina formation, but its addition to a copperbearing steel leads to a marked improvement in corrosion resistance. As an alloying element, phosphorus has a notable effect on the mechanical properties of steel, and may be beneficial or harmful depending on its content in the alloy and on the processing method. It is one of the most powerful solid solution ferrite hardeners, raising the yield strength and tensile strength by approximately $62 \mathrm{MPa}$ with just a $0.17 \%$ wt phosphorus addition [15]. However, it presents high solubility and low diffusion in steel at the thermal treatment temperatures, and as a 
result tends to segregate at austenite grain boundaries, severely reducing both fracture toughness and ductility, and thus embrittling the steel. A common example is the embrittlement experienced by low-alloy steels for tempering when they are thermally treated during processing.

It is estimated that a proportion of more than $0.1 \%$ wt phosphorus can promote brittle fracture in steel when subjected to vibratory forces or blows, as a result of either solid dissolution of the phosphorus in ferrite, which reduces ductility, or the formation of $\mathrm{Fe}_{3} \mathrm{P}$. The latter, along with austenite and cementite, forms a ternary eutectic known as steadite, which is highly fragile, hard, and has a relatively low melting point $\left(960^{\circ} \mathrm{C}\right)$, appearing at the grain boundaries and causing embrittlement of the steel [16].

From the viewpoint of atmospheric corrosion, phosphorus notably improves the resistance of WS, reducing the average mass loss or thickness loss as the phosphorus content in the steel composition rises. However, as has been seen above, its upper limit is controlled by its adverse effect on the mechanical properties of steel, and so phosphorus should not exceed $0.1 \%$ wt in the composition of structural steels intended for atmospheric exposure.

Fig. 1 shows the results obtained by Copson [2] and Larrabee and Coburn [3] in the industrial atmospheres of Bayonne and Kearny respectively, for steels with different $\mathrm{P}$ contents as a function of the copper content. It can be seen that corrosion decreased as the phosphorus and copper contents increased.

\subsubsection{Copper}

Copper is the most relevant alloying element in the composition of WS. It was the first to be incorporated and led to the birth of weathering steels. Copper is also the most beneficial alloying element in terms of cost/performance. As has been noted above, Buck [17] revealed that alloying mild steel with copper improved its resistance to atmospheric corrosion; the presence of just $0.04 \%$ wt copper perceptibly improved its anticorrosive behaviour in the atmosphere, and concentrations above $0.25 \%$ wt barely led to any further improvement. Later, in 1962, Larrabee and Coburn confirmed Buck's results, setting a lower limit of 0.05\% wt and an upper limit of $0.20 \% \mathrm{wt}$ [3], and noting that the greatest benefit occurred with the first $0.05 \%$ wt. The beneficial effect of copper in marine environments was lower than in rural and industrial atmospheres (Fig. 2).

Larrabee [18] reported that the presence of copper in steel B buffered the harmful effect of sulphur in the steel A (Table 1). If the steel had practically no $S$, the effect of $\mathrm{Cu}$ was not observed (steels C and D). Larrabee and Coburn [3] attributed this improvement to the 
possible interaction of $\mathrm{Cu}$ with $\mathrm{S}$ in the steel to prevent the formation of iron sulphide [19]. It is known that in slightly acid solution FeS can give rise to $\mathrm{H}_{2} \mathrm{~S}$, a highly aggressive product from the corrosion viewpoint, through the following reaction

$$
\mathrm{FeS}+2 \mathrm{H}^{+} \leftrightarrow \mathrm{Fe}^{2+}+\mathrm{H}_{2} \mathrm{~S}
$$

Acidification could be produced by hydrolysis of the cation in the rust pores. However, the presence of copper would lead to the formation of copper sulphides (instead of iron sulphide), which are highly insoluble compounds that require a very low $\mathrm{pH}$ to generate $\mathrm{H}_{2} \mathrm{~S}$. This theory was questioned by Horton [20], as Mn, which also forms part of the composition of any steel, has a greater thermodynamic affinity for sulphur than copper. In fact, $\mathrm{Mn}$ is added during steel manufacturing to prevent the formation of $\mathrm{FeS}$, which has a low melting point at $981^{\circ} \mathrm{C}$ and can melt during the hot processing of steel. In its place MnS, which has a higher melting point, forms.

Carius [21] suggested in 1930 that as a consequence of the corrosion process the copper in steel may accumulate on the surface to form a metallic copper deposit that reduces corrosion. In this respect, Tomashov [22]stated that copper, once concentrated on the metallic surface of the steel, is able to induce anodic passivity due to its cathodic nature with respect to iron. This statement was supported by the fact that the effect of copper is present from the initial stages of corrosion, when the corrosion product layer is not yet visible on the steel surface. Nevertheless, Copson [23] also pointed out that the existence of such a copper film was never analytically proven.

Different researchers have tried to attribute the protective effect of copper to the modification it makes to the structure and properties of rust, associating the decrease in the corrosion rate with an increase in rust density, and thus a greater barrier effect. According to Copson [23], the corrosion product of mild steel in an industrial atmosphere is basic iron sulphate, with the stoichiometry $\left[\mathrm{Fe}_{2} \mathrm{O}_{3} \cdot \mathrm{Fe}_{2}\left(\mathrm{SO}_{4}\right)_{3} \cdot \mathrm{H}_{2} \mathrm{O}\right.$ ], due to the interaction of rust with $\mathrm{SO}_{2}$ pollution in the atmosphere. Copson suggested that the addition of copper leads to a change in the rust characteristics, favouring the formation of insoluble basic copper complexes, $\left[\left\{\mathrm{Cu}\left[(\mathrm{OH})_{2} \mathrm{Cu}\right]_{x}\right\} \mathrm{SO}_{4}\right]$, which plug the rust pores and thus increase corrosion resistance. According to Horton [20], the presence of such basic copper sulphates has never been identified in the corrosion products of WS or copper steels.

\subsubsection{Chromium}

The effect of chromium on the atmospheric corrosion of WS has been probably the best understood of all the alloying elements. According to the early works of Copson [2] and 
Larrabee and Coburn [3], the addition of chromium to mild steel leads to a significant improvement in atmospheric corrosion resistance, though the presence of at least $0.1 \%$ wt $\mathrm{Cu}$ is necessary in order for its effect to be more appreciable. Thus, the thickness loss of copper steels decreases with chromium concentrations of up to $1.2 \%$ wt (Fig. 3). However, for copper contents lower than $0.04 \% \mathrm{wt}$, the presence of $0.6-1.3 \% \mathrm{wt} \mathrm{Cr}$ is slightly detrimental, especially in industrial atmospheres (Fig. 4) [3, 24].

\subsubsection{Nickel}

Nickel was incorporated in the composition of WS in order to minimise hot embrittlement during the rolling process, due to copper enrichment of the steel surface layer, and mainly to improve atmospheric corrosion resistance in marine atmospheres [2] (Fig. 5). Although its presence improves atmospheric corrosion resistance in industrial and marine environments, a higher proportion of nickel is necessary to obtain similar results to copper steels. Thus, after 15.5 years of exposure in marine and industrial environments, $1 \%$ wt $\mathrm{Ni}$ addition achieved similar increases in the atmospheric corrosion resistance of CS to a $0.5 \%$ wt $\mathrm{Cu}$ addition.

As in the case of chromium, the beneficial effect of nickel is greatly strengthened by the presence of a small proportion of copper [25]. Thus, $1 \%$ Ni together with a small percentage of copper leads to notable improvements in the atmospheric corrosion resistance of WS exposed in marine and industrial environments [3] (Fig. 6).

\subsection{Effect of exposure conditions}

The enhanced corrosion resistance of WS is due to the formation of a dense and well-adhering corrosion product layer. Extensive research work has thrown light on the requisites for the protective rust layer to form. It is now well accepted that wet /dry cycling is necessary to form a dense and adherent rust layer, with rainwater washing the steel surface well, accumulated moisture draining easily, and fast drying action (absence of very long wetness times). Therefore, the ability of weathering type steels to fully develop their anticorrosive action is dependent on the climate and exposure conditions of the metallic surface.

In a recent publication in this journal [8] the authors provided an exhaustive bibliographic review of the effect of exposure conditions on WS behaviour, in particular with regard to ASTM A-242 WS specification [26], which is traditionally the most widely used. There follows below a short summary of that review.

The corrosion characteristics of WS depend in a complex way on climate parameters, pollution levels, exposure conditions (open air, shelter, etc.) and the composition of the steel. 
The literature contains abundant references and representations of outdoor corrosion versus time for WS exposed in atmospheres of different types: rural, urban, industrial and marine. Such information, however, presents a factor of uncertainty in that the atmospheres are classified in a purely qualitative way according to the location of the testing station and its surroundings, based on a subjective assessment of climate and pollution factors.

According to Knotkova et al. [27], in rural areas the corrosion rate is usually low, and the time needed to develop a protective and nice-looking patina may be quite long. In urban environments with $\mathrm{SO}_{2}$ levels not exceeding about $90 \mathrm{mg} \mathrm{SO} \mathrm{S}_{2} / \mathrm{m}^{2} \cdot \mathrm{d}$, WS usually show stabilised corrosion rates in the range of 2-6 $\mu \mathrm{m} / \mathrm{year}$, i.e. only slightly higher than in rural atmospheres. In more polluted industrial atmospheres with $\mathrm{SO}_{2}$ levels exceeding $90 \mathrm{mg}$ $\mathrm{SO}_{2} / \mathrm{m}^{2}$.d, significantly higher corrosion rates are also found for WS, indicating that the rust layer formed at very high $\mathrm{SO}_{2}$ pollution is not altogether protective.

In a study carried out recently by the authors [28] it was seen that a WS steady-state corrosion rate of $\leq 6 \mu \mathrm{m} /$ year, where WS may be used without protective coatings, was obtained for atmospheric $\mathrm{SO}_{2}$ contents of less than $20 \mathrm{mg} \mathrm{SO} / \mathrm{m}^{2}$.day. Above this $\mathrm{SO}_{2}$ level WS corrosion is accelerated. These results seem to confirm the opinion of Leygraf and Graedel that large amounts of deposited $\mathrm{SO}_{2}$ result in intense acidification of the aqueous layer existing on WS during the corrosion process, triggering dissolution and hindering precipitation [6]. WS sculptures can be damaged due to the effect of environmental stresses in polluted urban atmospheres [29].

In marine environments polluted with chlorides a protective patina does not develop and the corrosion rate may be high, especially close to the shore. This applies especially to rainsheltered surfaces, where the corrosion rate may be very high due to the accumulation of chlorides which are never washed away.

Data analysing the effect of atmospheric salinity in marine atmospheres is very scarce. The only rigorous study found in the literature was carried out in Japan on 41 bridges through longterm exposure tests (9 years) [30]. There seems to be a critical air-borne salinity concentration of around $3 \mathrm{mg} \mathrm{Cl} / \mathrm{m}^{2}$.day $\left(0.05 \mathrm{mg} \mathrm{NaCl} / \mathrm{dm}^{2}\right.$.day) below which the steady-state corrosion rate of conventional WS is less than $6 \mu \mathrm{m} /$ year, the criterion already mentioned for allowing the use of unpainted WS.

Finally, continuously moist exposure does not allow the formation of protective rust layers due to the lack of the necessary wet/dry cycles. Furthermore, as in indoor exposure, WS corrosion 
is not so different to that experienced by plain carbon steel, and thus the use of WS is not justified.

\subsection{Corrosion testing and performance evaluation}

Early progress in the development of WS came through the performance of extensive outdoor exposure tests $[2,3]$ involving a large number of steels in a range of rural, urban, industrial and marine atmospheres. Field studies of atmospheric corrosion provide real data on materials corrosion and are the most important method for atmospheric corrosion research.

The most important advances in the design of the first WS were based on results obtained in natural atmospheric exposure tests. In the same way, as will be seen later, the main steps forward in the understanding of the atmospheric corrosion mechanisms of WS and the formation of protective rust layers have been due to studies of test specimens exposed for long periods in atmospheric testing stations.

However, atmospheric testing has the disadvantage of being costly and time consuming (usually taking about $10-20$ years or more), making it very slow to evaluate new materials. In the late 1960's the interest of steel-makers in developing new WS encouraged researchers to use accelerated laboratory tests to investigate the effect of alloy composition on performance [31]. It is well established that a wetting and drying cycle should be an integral part of any laboratory test in which the characteristic properties of WS are assessed [32].

Over the years many accelerated cyclic corrosion tests have been used for studies on WS, but few of them have followed in general terms the standard wet/dry cyclic testing methods of ASTM [33] and ISO [34].

The characteristics of these wet/dry cyclic tests have varied widely, making it impossible to compare the results obtained by different researchers. Basically these tests consist of a wetting stage and a drying stage, though each has its own particular characteristics in terms of the way in which the metallic surface is wetted and the characteristics of the wetting solution employed (nature of the solution, concentration, and volume used per unit of surface area), $\mathrm{RH}$ and $\mathrm{T}$ conditions of the testing cabinet during the wetting and drying steps, drying conditions for the surface after the wetting stage, duration of each step in the cycle and total duration of the cycle, number of cycles, etc.

The matter is further complicated by the fact that no accelerated test can be consistent with the different kinds of atmospheric exposure: for instance, the relative merits of steels in marine atmospheres may not be same as in industrial atmospheres [35]. Other disadvantages include the sophistication of some accelerated tests and a lack of commercial testing 
equipment. Many of these studies with accelerated wet/dry cyclic tests were complemented by electrochemical measurements [36].

Thus it would be very important to standardise a simple wet/dry cyclic corrosion test for WS that would allow the comparison of results obtained by different researchers in the laboratory studies carried out with this type of materials. However, when assessing the laboratory behaviour of a given material, it should not be forgotten that the results obtained in accelerated tests often fail to match real-life exposure tests.

In a recent paper [37] the authors studied the possibility of applying to WS the accelerated wet/dry cyclic corrosion tests commonly used to evaluate organic and metallic coatings on ferrous metals: Kesternich test [38,39] (for $\mathrm{SO}_{2}$ polluted atmospheres), and Prohesion test [40] (for marine atmospheres). These laboratory wet/dry cyclic tests made it possible to shorten the testing time to assess the protective capacity of rust formed on WS.

In 1966 the Belgian Centre for Corrosion Study (CEBELCOR) developed an electrochemical method [41-43], known in the literature as the "CEBELCOR" test, which uses the alternating condition of immersion in a test solution, emersion and drying following a prescribed cycle. In addition to CEBELCOR itself [42-44], other researchers have applied this cyclic test to the case of WS $[37,44-48]$.

\section{Atmospheric corrosion products}

Atmospheric corrosion products of iron and its alloys, referred to as "rust", comprise various types of oxides, hydrated oxides, oxy-hydroxides and miscellaneous crystalline and amorphous substances that form as a result of the reaction between iron and their environment. Such substances may originate from the substrate itself (endogenous products) or from the atmosphere (exogenous products).

The proportion in which each type of component occurs depends on the composition of the iron material and the environment to which it is exposed. The exposure time is also highly influential.

\subsection{Nature of atmospheric corrosion products}

Table 2 lists the corrosion products found most frequently in the layers formed on CS and WS exposed to the atmosphere. A group of Fe(II/III) hydroxyl salts, known as green rusts because of their greenblue - greyish colour, are also often detected among atmospheric corrosion products on steel, and it is habitual to find non-crystalline (amorphous) and non-stoichiometric phases in iron corrosion product layers $[49,50]$. 
In addition to the above compounds, iron can also form a number of different substances and be found in other minerals, some of which contain sulphur and can play a significant role in corrosion in urban and industrial atmospheres. Such compounds include iron(II) sulphur heptahydrate (melanterite), tetrahydrate (rozenite) or monohydrate; and iron(III) sulphate or $\mathrm{Fe}\left(\mathrm{SO}_{4}\right)_{3}$ hydrated to a variable extent. In corrosion in marine atmospheres, chloridecontaining compounds such as iron(II) chloride or $\mathrm{FeCl}_{2}$ (lawrencite), iron(II) chloride tetrahydrate or $\mathrm{FeCl}_{2} .4 \mathrm{H}_{2} \mathrm{O}$, and iron(III) chloride hexahydrate or $\mathrm{FeCl}_{3} .6 \mathrm{H}_{2} \mathrm{O}$ can also play an active role [49].

\subsection{Dependence on environmental conditions}

The composition of the rust layer depends on the conditions in the surface electrolyte and thus varies according to the type of atmosphere [51]. Reported rust compositions vary widely as a result of differences in exposure conditions, identification techniques and data interpretation [49].

Hiller [52] considers lepidocrocite $(\gamma-\mathrm{FeOOH})$ to be the primary crystalline corrosion product. In mildly acidic solutions lepidocrocite is transformed into goethite $(\alpha-\mathrm{FeOOH})$ in a process that is dependent on the sulphate concentration and the temperature. Goethite seems to be the most stable of ferric oxy-hydroxides.

Magnetite $\left(\mathrm{Fe}_{3} \mathrm{O}_{4}\right)$ is also formed as one of the main constituents. Magnetite is usually detected in the inner part of rust adhering to the steel surface of specimens that have been subjected to prolonged exposure, where oxygen depletion may occur $[53,54]$.

In marine atmospheres, where the surface electrolyte contains chlorides, akaganeite ( $\beta$ $\mathrm{FeOOH}$ ) is found [55]. As shown by Keller [55], rust can contain up to $6 \%$ chloride and be formed at an early corrosion stage in chloride-containing solutions by hydrolysis of $\mathrm{FeCl}_{3}$ or oxidation of $\mathrm{FeCl}_{2}$ in the presence of iron.

Maghemite $\left(\gamma-\mathrm{Fe}_{2} \mathrm{O}_{3}\right)$ and hematite $\left(\alpha-\mathrm{Fe}_{2} \mathrm{O}_{3}\right)$ have also been found on steel surfaces exposed in different types of atmospheres [56]. Hydrated maghemite $\left(\gamma-\mathrm{Fe}_{2} \mathrm{O}_{3} \cdot \mathrm{H}_{2} \mathrm{O}\right)$ was identified by Nasrazadani and Raman [57] as a goethite precursor in wet and dry cycles at room temperature. It is not common to find hematite among steel atmospheric corrosion products, nevertheless, Antunes et al. [56] and de la Fuente et al. [58] have found this compound on plain carbon steel exposed in industrial atmospheres. 
At industrial and urban sites a common feature is the presence of lepidocrocite, goethite and magnetite. Reflection lines corresponding to hydrated maghemite have also been detected [59].

Ferrihydrite $\left(\mathrm{Fe}_{5} \mathrm{HO}_{8} .4 \mathrm{H}_{2} \mathrm{O}\right)$ is also observed in atmospheric corrosion layers on steels. It is generally the first precipitate resulting from rapid hydrolysis of Fe (III) solutions. It presents lower crystallinity, so its identification has been confirmed by X-ray absorption spectroscopy (XAS) under synchrotron radiation [60]. Marco et al. [61] found the presence of large amounts of ferrihydrite on steel after one year of exposure to the atmosphere, and Leidheiser et al. [62] reported that the first solid oxide component formed on steel in an artificial polluted atmosphere at $100 \%$ RH contained significant amounts of lepidocrocite and ferrihydrite.

Although there is general agreement about the presence of lepidocrocite and goethite in the rust composition, other authors assign prevalence to amorphous ferric oxy-hydroxide [63] or feroxyhyte $(\delta-\mathrm{FeOOH})[64]$.

\subsection{Characterisation techniques for identification of corrosion products}

The corrosion products formed on the surface of metals exposed to natural weathering are directly related to the corrosion mechanisms of their formation. Thus, a fine characterisation of corrosion product layers identifying the oxide phases on a metal surface yields valuable information on the evolution of the corrosion process in a given atmosphere. Not only it is important to identify the different oxides but also the fraction of each corrosion product and its distribution in the rust layer in order to gain a better understanding of the corrosion process. The distribution of the phases can drastically influence local corrosion mechanisms.

Numerous studies have been dedicated to the characterisation of rust. Atmospheric corrosion product layers are heterogeneous and can be described as multiphase systems composed of a mixture of different iron oxides and oxy-hydroxides with various physical and chemical properties. Over the years, rust studies have taken advantage of the technical means available at the time.

Element compositions can be determined by Scanning electron microscopy (SEM) - Energy dispersive X-ray (EDX) analysis and Electron probe microanalysis (EPMA).

Several macroscopic techniques such as X-ray diffraction (XRD), Infrared spectroscopy (IR) and Mössbauer spectroscopy (MS) are commonly used at macroscopic scale for structural characterisation. However, it may be very important to obtain a fine and local determination of the structure of corrosion products in order to understand corrosion mechanisms. In such 
cases the local structure of the corrosion layers must be characterised with the help of microprobes: Raman microspectroscopy (micro Raman), X-ray microdiffraction (micro XRD), (XAS), etc. The specifities of each analysis method strongly influence the type of phase identified.

\subsubsection{Powder X-ray diffraction (XRD)}

XRD is the preferred procedure for crystalline samples. As the number of phases present in the sample rises, their identification becomes increasingly difficult. It is also difficult to obtain quantitative results. In addition to crystalline phase identification, XRD provides information on the crystal (size, perfection, etc.).

The sum of the crystalline phases found during a quantitative X-ray analysis of rust is usually less than $100 \%$ due to the existence of amorphous phases. Amorphous products do not yield defined peaks but broad bands that are difficult to assign, while quasi-amorphous or badly crystallised products yield "intermediate" diffractograms between amorphous and crystalline material. It is practically impossible to identify the different species in the former case and difficult in the latter. Furthermore, XRD cannot easily differentiate between closely related phases with similar crystal structures, such as maghemite and magnetite. XRD diffraction patterns for these two oxides, maghemite and magnetite, are very similar and it is difficult to determine whether a mixture or just one compound is present.

Powder XRD quantitative measurements are not very precise (about 10-20 relative percent error [60]). For this reason, IR spectroscopy has usually been used to complete XRD observations.

\subsubsection{Infrared spectroscopy (IR)}

This is by far the best identification technique for solids, allowing the obtainment of each solid's "fingerprint". It can also detect non-crystalline and not well crystallised phases, even in trace amounts (1-2\%). IR spectroscopy has proven to be the most versatile and accurate technique to detect changes in most phases.

In principle it is capable of identifying the different iron oxides and oxyhydroxides. However, it should also be taken into account that IR spectra for microcrystalline solids -and the oxides and hydroxides resulting from the corrosion of iron often appear in this form- may differ considerably to the IR spectra of the bulk solids. This is attributed to the fact that the vibration modes of atoms on the surface are different to those of atoms in the interior of the solid. 
IR spectroscopy is the habitual technique to detect $\mathrm{OH}$ groups, which give rise to characteristic IR bands in the 3000-3500 ( $\left.\mathrm{cm}^{-1}\right)$ region. Thus, IR spectroscopy has been found to be extremely useful for the identification of rust phases and their subsequent stability or transformations. It can easily differentiate between closely related phases with similar crystal structures and between different amorphous phases.

However, according to Antony et al. [65] it must be noted that Fourier transform infrared (FTIR) spectroscopy is not very appropriate to precisely identify magnetite. Moreover, it is generally difficult to determine the presence or absence of amorphous phases such as ferrihydrite since the corresponding responses are broad and are located in the low frequency range.

\subsubsection{Mössbauer spectroscopy (MS)}

In general terms, MS supplies information on the oxidation state, distribution of atoms at different lattice sites and their corresponding surroundings (coordination, symmetry, etc.), as well as other properties related with magnetic interactions (magnetic ordering temperature, superparamagnetism, surface magnetism, etc.). Each chemical species yields a characteristic Mössbauer spectrum, and the spectrum for a mixture is equal to the sum of the spectra of all the species it contains. In principle the spectral contribution of each species is proportional to its relative concentration in the sample, and can be calculated by deconvoluting the spectrum. The main advantage of MS in this field is that it allows both qualitative and quantitative analysis, even of amorphous products, both in the bulk and on the surface [66].

MS has the great advantage of being specific for iron, so it is very suitable for the analysis of iron corrosion products. When working with ferrous materials, MS also provides information on particle size, magnetic properties, etc. which it is difficult to obtain using other procedures.

Over the past decade the extensive application of MS in studies of the atmospheric corrosion of structural steels has shown that XRD often provides highly incorrect information on the composition of rust formed on weathering and carbon steels [67]. One common example of this is the separate identification of magnetite and maghemite, as has been commented before. Both oxides have a cubic structure and nearly identical lattice parameters at room temperature, making them nearly indistinguishable by XRD [68]. However, their magnetic and electric properties are quite different, thereby allowing MS to uniquely identify each one. For corrosion research, these two oxides are known to form in different exposure conditions, and often with lattice defects or substituted impurities that do not noticeably change the lattice 
parameters. MS has proven invaluable by identifying magnetite and maghemite and providing information on impurity concentration and the exposure conditions in which they formed.

MS has now become a required analytical technique in corrosion research, and when used in conjunction with other techniques can provide a very accurate correlation between the corrosion process and the local environment [69]. It is important to underline the utility of MS to identify and quantify the nanophasic iron oxides that form on steels, and are practically transparent to most other spectroscopic techniques, which is one of the best advances in the understanding of protective rust layers on WS [70]. According to Cook [67] MS is an indispensable tool in atmospheric corrosion studies.

Nevertheless, this technique has two important limitations: it lacks lateral resolution and is difficult to apply in the study of thin films. Monnier et al. also note that this technique has difficulty in discriminating phases of the same oxidation state that have similar local environments, particularly in the case of complex mixes [71]. This is the case of two iron oxides reported in atmospheric corrosion studies: magnetite and /or maghemite. Both oxides can be present in the corrosion patterns, but their presence is sometimes difficult to detect in the case of mixture of phases.

\subsubsection{Micro-Raman spectroscopy (micro Raman)}

According to Monnier et al [71] iron oxides and mainly iron oxy-hydroxides are identified in the corrosion products formed on low alloy steels or weathering steels exposed to atmospheric corrosion. A more controversial matter is the presence and nature of amorphous or less crystallised phases. Moreover, despite numerous papers dealing with the characterisation of corrosion products, very few descriptions of the organisation of these rust layers at a microscopic scale are available. This could be because most studies have been performed on powder samples that were taken from the corroded surfaces or very thin layers. Analyses at the macroscopic scale are then carried out on phase mixtures. This makes it more difficult to detect amorphous or poorly crystallised phases.

Rust composition studies using micro Raman usually demand a high laser power for the excitation of spectra because some of the most common iron oxides and oxy-hydroxides are poor light scatters. Sample degradation frequently occurs under intense sample illumination and may lead to the misinterpretation of spectra. Low laser power minimises the risks of spectral changes due to sample degradation [72].

Neff et al. have used this technique for the structural characterisation of corrosion products on archaeological iron artefacts subjected to very long-term exposure in soils [73] or in indoor 
atmospheres [74]. Thanks to the fine beam of the micro Raman and the acquisition of hyperspectral images of the corrosion scales, detailed structural mapping (Raman imaging) of the corrosion layer can be obtained.

In some cases, particularly when phases are less crystallised, it is difficult to discriminate one phase from another only by micro Raman because the Raman shift of these phases are in the $700 \mathrm{~cm}^{-1}$ range. This is the case with maghemite, ferrihydrite and feroxyhyte phases. Thus, in the reference spectrum of maghemite three broad bands can be identified around 380, 500 and $700 \mathrm{~cm}^{-1}$. The broad band at around $700 \mathrm{~cm}^{-1}$ can also be observed on other iron components, feroxyhyte and ferrihydrite.

As the type of phases formed during the corrosion process and their distribution inside the corrosion layer is of great importance to know the corrosion mechanisms, it is worth combining appropriate microstructural analysis techniques in order to elucidate this point. For this reason, the use of complementary analytical techniques will be needed to obtain accurate Raman phase characterisation (micro XRD, XAS and MS). Each technique provides complementary information. Micro XRD is more sensitive to crystallised phases and micro Raman presents a higher spatial resolution and allows the detection and location of crystallised phases (goethite, lepidocrocite, maghemite, akaganeite) from less crystallised ones (feroxyhyte, ferrihydrite). Discrimination of maghemite, feroxyhyte and ferrihydrite could be partially solved by the use of XAS [71].

\section{Atmospheric rusting mechanisms of WS}

The most common characteristic of metallic atmospheric corrosion is the localised nature of its nucleation. Preferential nucleation sites depend on the metal structure and are associated to the presence of different phases or environmental pollutants on discrete areas of the metallic surface.

According to Kucera and Mattsson [5], in principle the corrosion mechanism is similar for WS and mild steel. On the former, however, rust forms a more dense and compact layer which more effectively screens the steel surface form the corrosive components of the atmosphere.

The corrosion process, which is electrochemical in nature, takes place in cells of macroscopic dimensions with very distinct anodic and cathodic areas. According to de Meybaum and Ayllon, the initiation of attack on WS occurs in both urban-industrial atmospheres [75] and marine atmospheres [76] at discrete areas on the surface and nucleates in the ferritic matrix near cementite nodules. Selective ferrite dissolution gives rise to geometrical pitting, leaving 
the cementite phase unattacked. Chen et al. [77] note the effect of the micro-area pH on the formation of different rust phases on a WS in the initial corrosion period. In this way they justify the occurrence of corrosion in slightly acid conditions, where lepidocrocite is formed in the initial period and then gradually transforms into goethite.

In the early days, extensive work was carried out to determine WS corrosion rates in different atmospheres. Gaining a knowledge of the atmospheric rusting mechanisms of WS has been a gradual process, and the following are some of the main contributions that have been made over time set out in chronological order under headings that highlight the main contributions made by each research group.

\subsection{Vernon et al.: "Critical relative humidity for atmospheric rusting”}

Vernon essentially showed that atmospheric corrosion required both wetness and pollutants. This conclusion was confirmed by extensive exposure testing in the years 1930-1960.

Vernon [78-81] conducted experiments that showed the effect of relative humidity on rusting, revealing that little corrosion occurred in pure air below $100 \%$ relative humidity. He first showed the effect of sulphur dioxide, in conjunction with relative humidity, on the corrosion of iron (Fig. 7) [82]. Serious rusting was found on a specimen in air with a certain critical RH and even a small amount of $\mathrm{SO}_{2}$. When the $\mathrm{SO}_{2}$ content was raised to $0.01 \%$, the critical relative humidity dropped to $60 \%$ and corrosion increased substantially. Corrosion was also much higher if the metal surface was coated with solid particles (dust, dirt, soot), as moisture and salts were retained for a longer time.

\subsection{Schikorr: "Acid regeneration cycle"}

Schikorr demonstrated that rusting iron rapidly absorbs sulphur dioxide from the atmosphere and that this absorption continues irrespective of $\mathrm{RH}$ or temperature. The pollutant is stored in the corrosion product as ferrous sulphate, and produces appreciable corrosion at sufficiently high humidity (critical RH).

Schikorr [83] proposed a theory of the atmospheric corrosion of steel based on an "acid regeneration cycle", consisting of the following steps:

(a) Sulphuric acid forms in the presence of rust, with rust acting as a catalyst.

$$
\mathrm{SO}_{2}+\mathrm{H}_{2} \mathrm{O}+1 / 2 \mathrm{O}_{2} \rightarrow \mathrm{H}_{2} \mathrm{SO}_{4}
$$

(b) The chemical action of the sulphuric acid forms ferrous sulphate.

$$
2 \mathrm{H}_{2} \mathrm{SO}_{4}+2 \mathrm{Fe}+\mathrm{O}_{2} \rightarrow 2 \mathrm{H}_{2} \mathrm{O}+2 \mathrm{FeSO}_{4}
$$


(c) Ferrous sulphate is oxidised to ferric sulphate and hydrated ferric oxide.

$$
6 \mathrm{FeSO}_{4}+\mathrm{H}_{2} \mathrm{O}+3 / 2 \mathrm{O}_{2} \rightarrow 2 \mathrm{Fe}_{2}\left(\mathrm{SO}_{4}\right)_{3}+2 \mathrm{FeOOH}
$$

(d) Ferric sulphate then hydrolyses to additional rust

$$
\mathrm{Fe}_{2}\left(\mathrm{SO}_{4}\right)_{3}+4 \mathrm{H}_{2} \mathrm{O} \rightarrow 2 \mathrm{FeOOH}+3 \mathrm{H}_{2} \mathrm{SO}_{4}
$$

The last equation shows that all the dissipated acid is theoretically regenerated.

Even when Schikorr's theory does not explain the detailed mechanism of the rusting process, according to Barton oxidative hydrolysis seems to be very important in the atmospheric corrosion of steel [84]. However, it should be mentioned that according to Evans and Taylor [85] the oxidative hydrolysis of $\mathrm{FeSO}_{4}$ is very slow and this reaction should affect corrosion only during the initiation stage.

\subsection{Horton: "Dual layer structure of the atmospheric rust"}

Using samples of Mayari-R WS that were exposed for up to 17 years in the atmospheres of Rankin (industrial) and Kure Beach, 250 (marine), Horton in his M.S. Thesis [86] and Ph.D dissertation [87] in 1964 made a number of important contributions to knowledge of the atmospheric rusting mechanisms of WS which are literally transcribed below:

(a) "The dual layer structure of the rust: a loose outer portion and an adherent inner portion". Fig. 8 shows a figure reproduced from a copy of the figure 19 in his doctoral thesis, which presented for the first time the characteristic dual layer structure of the rust formed on WS.

(b) "Rust layers grow by several mechanisms: (i) by iron ions diffusing outward through the rust to form fresh rust at the air-rust interface, (ii) at the steel-rust surface and (iii) within the rust layer to fill pores and cracks". It was also the first time this observation was reported in scientific literature.

(c) "Moisture conditions in the rust at a given time may determine where rust deposition occurs".

(d) "The existence of thin areas where there seemed to be little attack of the steel, and thick areas which covered broad-based pits into the steel".

(e) "The presence of pores and cracks and a tendency for stratification of the rust layers. Such pores and cracks would provide access for oxygen to reach the steel base. Sometimes these cracks or pores seemed to fill up with fresh rust which is darker than inner layer rust, and became blocked".

(f) "The rust layers show a tendency to flake". 
(g) "Chromium may accumulate strongly in the inner half of rust layers, while sulphur appears throughout the rust layer".

Trying to explain the formation of rust at the rust/air interface, at the metal/rust interface and inside the rust layer, Horton by means of thermodynamic considerations suggests that at any given time there is a membrane in the rust layer that separates $\mathrm{Fe}^{2+}$ ions from the dissolved oxygen. Fresh rust formation must occur at this membrane. Iron ions diffuse outwardly through the rust during wet periods and react at the surface giving rise to fresh rust formation.

$$
2 \mathrm{Fe}^{2+}+1 / 2 \mathrm{O}_{2}+5 \mathrm{H}_{2} \mathrm{O} \rightarrow 2 \mathrm{Fe}(\mathrm{OH})_{3}+4 \mathrm{H}^{+}
$$

This reaction zone gradually moves toward the steel surface during each drying cycle. In Fig. 9 a simplified diagram is shown according to Horton's considerations [87].

Unfortunately Horton did not disseminate his results and conjectures through the most appropriate scientific channels [20,86-88], which may explain why his important observations on the growth of rust layers went almost unnoticed to many researchers.

\subsection{Evans et al.: "First electrochemical model for atmospheric rusting"}

With regard to the mechanism of the rust formation cycle (acid regeneration cycle) in the presence of $\mathrm{SO}_{2}$ mentioned above, Evans developed an electrochemical model to explain the observed influence of changing wetness on the atmospheric corrosion of iron [85, 89-91]. According to Evans [91], the fact that a single $\mathrm{SO}_{2}$ molecule can produce many rust molecules makes this interpretation difficult to accept, except perhaps in the very early stages of rusting. Evans considers that if it were true, it would expect to find plenty of acid and ferric sulphate in the rust, which was not the case. It seems more likely that once a rust layer containing $\mathrm{FeSO}_{4}$ has established itself, the mechanism will be electrochemical. The situation in the steady state is a lower layer of magnetite beneath the ferric rust $(\mathrm{FeOOH})$, with the $\mathrm{FeSO}_{4}$ solution extending up to the boundary between the two layers (Fig. 10).

Evans postulated that in periods of high water content within the porous structure of the rust the oxidation of iron (Eq. 7) (level $x^{\prime}$ in Fig. 10) is balanced by the reduction of ferric rust to magnetite (Eq. 8) (level yy' in Fig. 10). Later, after partial drying of the pore structure, magnetite is reoxidised by oxygen that now has free access through the pores due to gas diffusion (Eq. 9). After wetting, the cycle of $\mathrm{FeOOH}$ reduction and magnetite oxidation can start again.

$$
\begin{gathered}
\mathrm{Fe} \rightarrow \mathrm{Fe}^{2+}+2 \mathrm{e}^{-} \\
\mathrm{Fe}^{2+}+2 \mathrm{FeOOH} \rightarrow \mathrm{Fe}_{3} \mathrm{O}_{4}+2 \mathrm{H}^{+}
\end{gathered}
$$




$$
3 \mathrm{Fe}_{3} \mathrm{O}_{4}+1.5 \mathrm{O}_{2} \rightarrow 4.5 \mathrm{Fe}_{2} \mathrm{O}_{3}
$$

The electronic path in the atmospheric electrochemical corrosion process is provided by magnetite. The autocatalytic cycle responsible for the fact that rust promotes further rusting involves alternate reduction and re-oxidation of the pre-existing rust.

In the same paper, Evans [91] conjectures that this mechanism may perhaps serve to explain why the addition of certain elements $(\mathrm{Cu}, \mathrm{Cr}$, etc.) yields a low-alloy steel that builds a protective rust layer, so that these alloys (WS), in some climates at least, do not require painting, considering that spinels containing these other metals are likely to conduct electricity much less well than magnetite.

\subsection{Okada et al.: "Behaviour of dual rust layer"}

As has been noted above, Horton (1957-1964) established for the first time the dual nature of rust layers on weathering steels. However, Okada et al. were the first to widely publicise his results in 1969-1970 through appropriate scientific channels [92-95], and it is they who are generally attributed with showing the dual nature of rust layers. Okada et al. saw that the use of reflected polarised light and crossed nicols in the microscopic observation of polished crosssections of rust made it possible to distinguish optically active and optically isotropic layers in the rust on WS. This dual nature of the rust layer was not observed on CS, where the optically active layer was partly mixed with the optically isotropic layer adjacent to the steel surface. The optically isotropic layer formed on plain carbon steel which is free from beneficial elements contains crystallised magnetite and amorphous oxide (Fig. 11). Nowadays, however, it is generally accepted that this dual structure of the rust layer is not specific to WS $[28,48,96]$.

According to Okada et al. [92-95], in the case of rust layers on WS: (i) the optically isotropic layer is mainly composed of amorphous spinel-type iron oxide and the optically active layer is $\mathrm{FeOOH}$, (ii) the amorphous iron oxide is believed to be beneficial in preventing the penetration of water and oxygen to the steel surface, and (iii) alloying elements, such as $\mathrm{Cu}, \mathrm{Cr}$ and $\mathrm{P}$ are possibly beneficial to the formation of this amorphous iron oxide.

By electrochemical measurements, Okada et al. [92] showed that the main reaction of rusted steel in a neutral solution is not the reduction of dissolved oxygen but other reactions, such as reduction of $\mathrm{FeOOH}$ to magnetite, a mechanism that had already been formulated by Evans [89-91] a few years earlier. The significant corrosion resistance of WS in the atmosphere was attributed to the fact that the anodic reaction is prevented owing to the masking of active sites on the steel surface by the formation of a dense amorphous spinel-type iron oxide layer. The 
cathodic reaction is suppressed by the compactness of the outer part of the $\mathrm{FeOOH}$ surface oxide layer.

Matsushima and Ueno [97] also confirmed that corrosion of rusted steel under wet conditions proceeds by a cathodic reaction depolarised mainly by the reduction of ferric rust to lower oxides. As a result, the dissolution rate of iron under wet conditions is high, and the dissolved $\mathrm{O}_{2}$ contributes only to a minor extent.

\subsection{Misawa et al.: "Identification of feroxyhyte in the rust"}

The consensus in the early 1970's was that the main corrosion products formed on CS and WS in atmospheric rusting were goethite, lepidocrocite, magnetite and X-ray amorphous matter, with akaganeite also being often found in the rust layer on steels exposed in marine atmospheres. Misawa et al. noted in that time that the mechanism of the formation of goethite, lepidocrocite and amorphous matter in atmospheric rusting was not completely understood, and in particular the composition of amorphous matter [98].

Studies by Misawa et al. [63,98-100] shed some light on the oxidation processes of $\mathrm{Fe}(\mathrm{II})$ hydroxo-complexes to lepidocrocite and goethite. They stated that one of the main components of the rust, fine amorphous ferric oxy-hydroxide $\left[\mathrm{FeO}_{x}(\mathrm{OH})_{3-2 x}\right]$ particles, which cannot be identified by XRD measurement and had previously been reported as X-ray amorphous matter, probably played the most important role in decreasing the atmospheric corrosion of low alloy steels.

Misawa et al. [63] characterised by XRD and IR X-ray amorphous matter as amorphous ferric oxyhydroxide (feroxyhyte), formulating the following mechanism of atmospheric rusting:

(a) In the first stage of rusting the aerial oxidation of ferrous ions, dissolved from the steel into a slightly acidic thin water layer formed by rain on the steel surface, leads to the precipitation of lepidocrocite. Fine weather accelerates the precipitation and crystallisation of lepidocrocite by drying.

$$
\mathrm{Fe} \stackrel{\text { dissolution }}{\longrightarrow} \mathrm{Fe}^{2+} \stackrel{\text { hydrolisis }}{\longrightarrow} \mathrm{FeOH}^{+} \stackrel{\text { oxidation and precipitation }}{\longrightarrow} \gamma-\mathrm{FeOOH}
$$

(b) The lepidocrocite content is higher in inner rust layers than in outer layers, which contain large amounts of amorphous ferric oxyhydroxide and goethite. This suggests that lepidocrocite is formed on the steel surface and transformed to amorphous ferric oxyhydroxide and goethite during the atmospheric rusting process. It is known that fresh rainwater often contains dissolved atmospheric impurities like $\mathrm{SO}_{2}$ and has a low $\mathrm{pH}$ value, dissolving lepidocrocite and resulting in the precipitation of amorphous ferric 
oxyhydroxide upon drying. The amorphous ferric oxyhydroxide transforms to goethite by deprotonation using hydroxyl ions provided by the rainwater.

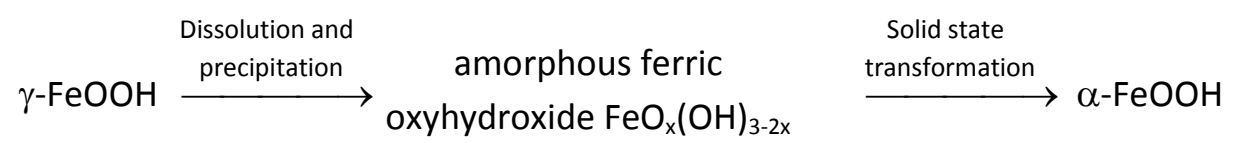

The rust layer which is formed on steel after exposure to the atmosphere for long periods can be assumed to have the structure shown in Fig. 12. The difference in the feroxyhyte content of rust layers on CS and WS is not remarkable, and it is likely that differences in rust composition do not have an important impact on the corrosion rate, which is largely influenced by the compactness or adhesiveness of the rust layer.

Feroxyhyte formed on CS was probably produced from Fe(II)-complexes by rapid oxidation with $\mathrm{H}_{2} \mathrm{O}_{2}$ or dehydration-oxidation. The feroxyhyte thus formed was not necessarily concentrated near the metal surface. Therefore, the rust layer formed on CS consists of a mixture of amorphous feroxyhyte and coarse grains of magnetite or goethite, akaganeite, or lepidocrocite, and cracks giving rise to paths for water and $\mathrm{O}_{2}$ (Fig. 12). Rust layers of this type cannot be protective against atmospheric corrosion.

However, the feroxyhyte formed on low alloy steels containing $\mathrm{Cu}, \mathrm{P}$, or $\mathrm{Cr}$ was transformed from $\mathrm{Fe}(\mathrm{II})$-complexes to amorphous feroxyhyte by the catalytic action of $\mathrm{Cu}$ and $\mathrm{P}$ concentrated at the metallic surface. The amorphous feroxyhyte rust forms a cohesive and compact crack-free protective layer (Fig. 12) which constitutes a protective barrier during atmospheric exposure. The superior corrosion resistance of WS in atmospheres containing $\mathrm{SO}_{2}$ is supported by the fact that $\mathrm{H}_{2} \mathrm{SO}_{4}$ accelerates the corrosion rate, and so the concentration of $\mathrm{Cu}$ or $\mathrm{P}$ on the metal surface rapidly increases.

\subsection{Stratmann et al.: "Advanced electrochemical model for atmospheric rusting"}

Stratmann et al. [101] in an electrochemical study of phase transitions in rust layers experimentally showed that the oxidation of magnetite to lepidocrocite, as proposed by Evans [85, 89-90], was not possible. Stratmann et al. [101] used a combination of magnetic and volumetric measurements to show that when a prerusted iron sample is wetted, iron dissolution is not immediately balanced by a reaction with oxygen, but rather by the reduction of pre-rusting oxide with later reoxidation of the reduced species. Thus, Stratmann et al. [101107] proposed dividing the atmospheric corrosion mechanism of pure iron into the following three stages (Fig. 13): 
Stage 1: wetting of the dry surface

As proposed by Evans [89-90] and Evans and Taylor [85], a corrosion cell starts where the anodic dissolution of iron is balanced by the cathodic reduction of lepidocrocite in the rust layer

$$
\gamma-\mathrm{FeOOH}+\mathrm{H}^{+}+\mathrm{e}^{-} \rightarrow \gamma-\mathrm{Fe} . \mathrm{OH} . \mathrm{OH}
$$

with the transformation of lepidocrocite into an iron (II) oxidation state transition phase of $\gamma$-Fe.OH.OH, also called "reduced lepidocrocite". Stratmann and Hoffman [108] propose that this new phase presents a structure similar to a conductive hydrogel on the lepidocrocite surface.

During this stage the cathodic $\mathrm{O}_{2}$ reduction reaction is very slow compared to anodic iron dissolution. The metal dissolution rate is high, but the amount of dissolved iron is restricted to the amount of reducible $\mathrm{FeOOH}$ in the rust layer [101].

\section{Stage 2: wet surface}

Once the reducible $\mathrm{FeOOH}$ has been used up, the $\mathrm{O}_{2}$ reduction reaction becomes the cathodic reaction

$$
1 / 2 \mathrm{O}_{2}+\mathrm{H}_{2} \mathrm{O}+2 \mathrm{e}^{-} \rightarrow 2 \mathrm{OH}^{-}
$$

The metal dissolution rate is determined by the diffusion-limited current density of the $\mathrm{O}_{2}$ reduction reaction on the pore surfaces. Because the pores in the rust layer are filled with electrolyte, the corrosion rate is quite slow during stage 2 , as the diffusion rate is lower in the electrolyte than in the gas phase.

Electrochemical studies by Stratmann and Müller [103] showed for the first time that oxygen is reduced within the oxide scale and not at the metal/electrolyte interface. This implies that the electronic structure of the oxides will strongly influence the reduction of oxygen and therefore also the corrosion rate. The atmospheric corrosion rate is determined for thin films by the electronic properties of the rust layer, and the corrosion rate immediately decreases as the oxides are reoxidised [104].

\section{Stage 3: drying-out of the surface}

During drying out, the rate of the diffusion-limited $\mathrm{O}_{2}$ reduction reaction is extremely fast due to thinning of the electrolyte film on the inner surface of the rust layer. Accordingly, the corrosion rate is very high, $\mathrm{O}_{2}$ reduction again being the cathodic reaction (reaction 13). 
In addition to this, reoxidation of the $\mathrm{Fe}^{2+}$ intermediate formed $(\gamma$-Fe.OH.OH) in stage 1 can take place:

$$
2 \gamma \text {-Fe.OH.OH }+1 / 2 \mathrm{O}_{2} \rightarrow 2 \gamma-\mathrm{FeOOH}+\mathrm{H}_{2} \mathrm{O}
$$

As a consequence of the high corrosion rate, stage 3 seems to dominate the metal loss during the whole wet-dry cycle. The third stage leads to the formation of goethite and the regeneration of lepidocrocite. When the electrolyte film is used up, the corrosion process stops completely. It is during this final stage that the rust layer composition changes, leading to a different intensity in the corrosion process for the next wet-dry cycle (Fig. 13).

\subsection{Dillmann et al.: "Recent advances in the understanding of atmospheric corrosion mechanisms"}

In the last decade great advances has been made in the understanding of atmospheric corrosion mechanisms. Many of these advances have been due to Legrand et al. [65,109-111] and Dillmann et al. $[60,71,112-115]$. The basic research carried out on this field is related with a greater knowledge of the electrochemical reactivity of the ferric phases that constitute atmospheric rust, the coupling or decoupling of anodic and cathodic reactions, and knowing at which interface (metal/corrosion product layer ( $\mathrm{CPL}$ ) or $\mathrm{CPL} / \mathrm{environment)}$ the different phases are formed. These research groups have also dedicated considerable effort to the characterisation of long-term (several centuries) complex corrosion layers in order to better understand the mechanisms of outdoor and indoor atmospheric corrosion.

\subsubsection{The electrochemical reactivity of the ferric phases that constitute rust}

Studies by Stratmann et al. [101] highlighted the importance of the lepidocrocite phase in the atmospheric corrosion mechanism; during the first stage (wetting) the anodic dissolution of iron was mainly balanced by the reduction of lepidocrocite:

$$
\gamma-\mathrm{FeOOH}+\mathrm{H}^{+}+\mathrm{e}^{-} \rightarrow \gamma-\mathrm{Fe} . \mathrm{OH} . \mathrm{OH}
$$

This reduction was understood to be the rate-limiting step of the corrosion process. The amount of oxidised metal depended on the quantity of reduced lepidocrocite.

Important studies by Antony et al. [65,109-110] and Lair et al. [111] have contributed to a greater knowledge of the electrochemical reactivity of the ferric phases that constitute rust; one paper was devoted to the development of synthesis ways to obtain reproducible thin lepidocrocite films [109], and other one to the confirmation that galvanic coupling between lepidocrocite and iron oxidation is possible [110]. 
Lepidocrocite is not the only reducible ferric component. In a study on the electroreduction behaviour of seven synthesised ferric products, their reduction reactivity (from greater to lesser) was as follows: ferrihydrite, green rusts > akaganeite and feroxyhyte > lepidocrocite > goethite. According to Antony et al., the reduction of goethite by iron is not favoured and if it occurs it should be an extremely slow rate reaction. All of the other ferric products will undergo a galvanic coupling reaction with metallic iron. These results are consistent with the goethite enrichment of corrosion layers with time [111].

These researchers aimed to obtain the electrochemical responses of several selected indoor atmospheric corrosion layers (800 years old) formed on ancient iron artefacts [65]. Reduction reactivity decreased with time, suggesting a progressive stabilisation of the corrosion layer, but the electrochemical responses of a synthetic ferric reference powder mixture did not allow simulation of the electrochemical responses of the ancient iron artefacts.

In very recent work, Monnier et al. studied the electrochemical reduction of lepidocrocite and ferrihydrite by analysing in situ by XRD and XAS the compounds formed [115]. Both phases evolved during reduction through a dissolution-re-precipitation process and the reduced phases were identified in situ as magnetite and iron (II) hydroxide, two phases that can play a key role in corrosion mechanisms because of their conductivity properties. The reoxidation of the reduced phase was also studied, and led to the formation of magnetite/maghemite and to the formation of the initial reducible phases lepidocrocite and ferrihydrite.

\subsubsection{Decoupling of the anodic and cathodic reaction}

To improve the existing modelling of corrosion mechanisms it is crucial to highlight the real mechanisms occurring during long-term exposure to the atmosphere. A key point of these mechanisms is the localisation of oxygen reduction sites in order to know if anodic and cathodic reactions are located at the same place or if they are delocalised [114].

In the case of non-conductive phases constituting the corrosion layer, the anodic and cathodic oxygen reduction reactions can only take place at the metal/corrosion product interface. With conductive phases in electrical contact with the metallic substrate, however, a decoupling of the anodic and cathodic reactions may occur. Furthermore, electrochemically reactive and locally present Fe(III) phases, such as lepidocrocite, ferrihydrite and feroxyhyte $[65,111]$, may cause metallic iron oxidation and may be reduced to conductive phases that could also enable the decoupling of the anodic and cathodic reactions. Such decoupling would make the transport of oxygen through the layer entirely unnecessary [114]. 
To answer these questions, Monnier et al. conducted an experiment that involved the corrosion of rusted ancient samples in a specific ${ }^{18} \mathrm{O}$-labelled atmosphere [114]. The results obtained by these researchers provide analytical proof that the parameters controlling the corrosion mechanisms differ fundamentally according to the layer type connected to the metallic substrate. The mechanisms involved seem to be quite close to those proposed by Stratmann et al. [101] for synthetic corrosion product layers. Their electrochemical studies underlined a decoupling of anodic iron oxidation and cathodic oxygen reduction on both sides of the conductive reduced lepidocrocite phase. In the case of phases connected to the metal base through the corrosion layer, studies in an ${ }^{18} \mathrm{O}$-marked medium provide analytical proof of the reaction delocalisation.

As the authors note, further research needs to be performed in order to define parameters like the diffusion coefficient of dissolved oxygen in pore water and the phase conductivity or reactivity in order to establish reliable corrosion models [114].

\subsubsection{Knowledge of the interfaces where corrosion products are formed}

It is a very important matter to know at which interface the different phases are formed, differentiating between outward cationic diffusion and inward diffusion of oxygen and/or hydroxyl anions ( $\mathrm{OH}-)$, and to evaluate their evolution with time. For this purpose, Burger et al. [113], using the gold marker method and micro Raman mappings, revealed a significant contribution of inward diffusion of oxidant through the corrosion product layer. Due to the expansive nature of the corrosion products, mechanical stresses develop in the material, thus inducing two opposing effects: pore blocking and formation of cracks/spalling.

With regard to the structural evolution of the corrosion product layer, it is pointed out that after wet/dry cycling the initial lepidocrocite layer seems to have evolved to a system composed of a mixture of lepidocrocite, goethite and ferrihydrite.

The continuous decrease in the reactivity of the corrosion layer over centuries seems to be related to a two-step process in the corrosion mechanisms: the preliminary formation of ferrihydrite close to the metal/corrosion product layer interface, followed by its progressive transformation into goethite, a more stable oxy-hydroxide [60].

\subsubsection{Characterisation of ancient rust scales on archaeological iron artefacts}

Dillmann et al. [60] and Monnier et al. [71] have also made important efforts to characterise complex corrosion layers for a better understanding respectively of outdoor [60] and indoor [71] atmospheric corrosion mechanisms on low carbon steels over periods of several centuries. The complexity of the corrosion layers formed, with phases in various crystallinity states, called 
for the combined use of several techniques providing complementary information: SEM-EDS, EPMA, XRD, micro XRD, micro Raman, X-ray microfluorescence (micro XRF) and XAS. The main phase of the corrosion layer is goethite, but lepidocrocite and akaganeite are also present locally in the corrosion layer. The presence of low crystallinity phases (feroxyhyte and/or ferrihydrite) is also shown.

As these researchers note, there is still a long way to go before long-term atmospheric corrosion mechanisms are fully clarified. Vital questions such as the specific area of the rust layer, porosity, tortuosity and connectivity need to be more precisely determined in the future [60]. The chemical stability (crystallinity and grain size of the phases, reactive surface due to the presence of other elements such as $\mathrm{P}, \mathrm{Ca}$ or $\mathrm{S}$, etc.) and the localisation and connectivity of the phases inside the corrosion layer are also of primary importance in the determination of corrosion mechanisms. All of these parameters, and the relations between them, have to be studied in the future.

\section{Advances in scientific knowledge of protective rust layers on WS}

The protective ability of the rust layer emerges after a few years of exposure. The stable rust is composed of an inner and an outer layer. Okada et al. [93] and Kihira et al. [116] pointed out that the inner layer, which is responsible for protection against atmospheric corrosion, consists of an X-ray amorphous spinel type iron oxide containing a number of effective elements such as $\mathrm{Cr}, \mathrm{Cu}$ and P. Misawa et al. [63], using IR, later reported that amorphous ferric oxyhydroxide containing a significant amount of water acts as a protective barrier against atmospheric rusting. According to Misawa [117], in 1988 a consensus had not yet been reached on the structure of the rust layer responsible for the protection of WS from atmospheric attack.

There follows a presentation in chronological order of the main advances that have taken place in the scientific knowledge of protective rust layers formed on WS. As in section 4, the subheadings highlight the main contributions made by each research group.

\subsection{Yamashita et al.: "Nano-size chromium substituted goethite (Cr-FG)"}

In 1994 Yamashita et al. [69] characterised the corrosion products formed on CS and ASTM A242 WS exposed for 26 years in an industrial atmosphere, long enough to form a stable and protective rust layer on the WS.

The rust formed on WS consisted of an outer layer of loosely aggregated component particles with a mean diameter of approximately $0.5 \mu \mathrm{m}$ and an inner layer of densely packed fine 
particles. In contrast, the corrosion product formed on CS contained a number of voids and microcracks.

The outer layer on WS was composed mainly of lepidocrocite and an inner layer mainly of goethite. Like Okada et al. [92], Yamashita et al. noted that the corrosion products formed on CS had a mottled structure consisting of lepidocrocite and goethite parts; the former was illuminated under observation with reflected polarised light and the latter corresponded to the darkened region.

The most striking feature was the high $\mathrm{Cr}$ concentration observed only in the inner layer. This $\mathrm{Cr}$ enrichment agrees with the results reported by Okada et al [92], who pointed out that the inner corrosion product layer on WS exposed for a few years contained a considerable amount of $\mathrm{Cr}, \mathrm{P}$ and $\mathrm{Cu}$. Neither $\mathrm{P}$ nor $\mathrm{Cu}$ were concentrated in the corrosion products, although they may both play an important role in the formation of the uniform protective rust layer on the surface of WS, especially at the early stages of atmospheric corrosion.

The most significant result of this research of Yamashita et al. [69] was that the protective rust layer covering the WS surface consisted mainly of nano-size goethite. This is not consistent with the results for several-year protective rusts reported by Okada et al. [92], who concluded that the protective rusts were composed of X-ray amorphous spinel type iron oxide, and by Misawa et al. [63], who found considerable amounts of amorphous ferric oxyhydroxide in the protective rust layers.

Yamashita et al. concluded that the main constituent of the rust layers formed on low-alloy steels was altered from lepidocrocite (less than a few years), via an amorphous substance (several years), to goethite (decades) [69]. Following the aforementioned atmospheric rusting mechanism proposed by Misawa et al. [99-100] (see section 4.6), a new step in the rusting process of a WS was proposed:

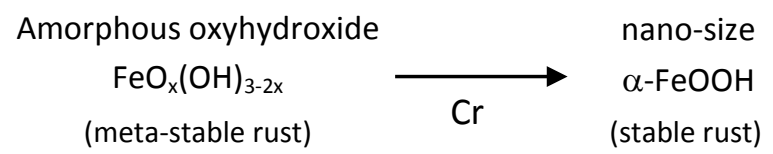

It was proposed that lepidocrocite, as the initial rust layer on WS, was transformed into the final stable, protective, $\mathrm{Cr}$-enriched inner rust layer consisting of densely packed nano-size particles of goethite, via amorphous ferric oxyhydroxide $\left[\mathrm{FeO}_{x}(\mathrm{OH})_{3-2 x}\right]$ in long-term atmospheric exposure.

Fig. 14 shows the proposed scheme of the transformation into a stable and protective rust layer on WS in an industrial atmosphere. Lepidocrocite forms on the steel surface in the initial 
stage of corrosion. After this, the inner portion of the initial corrosion product changes via the dissolution of lepidocrocite and the precipitation of the X-ray amorphous substance in wet/dry cycles. Finally, during long-term exposure the X-ray amorphous substance is transformed into a densely packed aggregate of $\mathrm{Cr}$-substituted goethite, $\alpha-\left(\mathrm{Fe}_{1-x} \mathrm{Cr}_{x}\right) \mathrm{OOH}$, which is stable both electrochemically and thermodynamically. It is inferred that the coexistence of $\mathrm{Cr}$ in the final protective rust provides the fine particles of goethite that yield the retardation effect for both metal dissolution and oxygen reduction due to its strongly aggregated structure.

In 1996 Yamashita et al. [118] reported that the stable and protective inner rust layer covering the surface of WS exposed for more than a quarter of a century in the atmosphere consisted mainly of nano-particles of $\mathrm{Cr}$-substituted goethite ( $\mathrm{Cr}-\mathrm{FG})$.

The Raman spectra of spontaneously formed Cr-substituted goethite shown in Fig. 15 were measured at several points at different distances from the rust/steel interface, $\Delta d$, in both the inner and outer layers. The strong peak in the vicinity of $255 \mathrm{~cm}^{-1}$ observed in the outer layer was clearly due to the presence of lepidocrocite as the major constituent. On the other hand, the intensity peak found in the vicinity of $397 \mathrm{~cm}^{-1}$ in the inner layer was due to goethite, the main constituent of the inner layer. Fig. 15 clarifies that the goethite peak intensity gradually decreases as the $\Delta d$ decreases at some places in the inner layer, even though the spectrum can be identified as goethite only. Yamashita et al. concluded that the $\mathrm{Cr}$ content and the crystal size of the inner layer changed as the $\Delta \mathrm{d}$ decreased closer to the rust/steel interface [118]. It may be pointed out that the Raman peak intensity is influenced by the crystallographic feature, i.e. less crystallised materials show a weaker intensity.

Looking at Fig. 15 it is interesting to note the presence of a band at $700 \mathrm{~cm}^{-1}$ in the Raman spectra. This kind of feature could correspond to maghemite, and/or feroxyhyte, and/or ferrihydrite, not easy to determine by micro Raman, as was seen before in subsection 3.3.4.

Then, in 2002, Yamashita and Uchida performed Raman spectra on synthetic Cr-substituted goethite, showing that the goethite peak intensity also gradually decreased with an increasing $\mathrm{Cr}$ content [119]. Transmission electron microscopy (TEM) observation revealed that the increase in the $\mathrm{Cr}$ content yielded rather small crystals. The crystal size of the goethite decreased as the amount of $\mathrm{Cr}$ substituting the Fe lattice points increased (Fig. 16).

This increase in the $\mathrm{Cr}$ content and the resulting aggregation of smaller crystals leads to a denser $\mathrm{Cr}$-substituted goethite rust layer which affords greater protection against atmospheric corrosion. The Raman intensity comparison between spontaneously formed and synthetic 
goethite implies that the $\mathrm{Cr}$ content in the vicinity of the spontaneously formed goethite /steel interface may be estimated at approximately 5-10\% wt [119].

Yamashita et al. also studied the effect of the $\mathrm{Cr}$ content on the ion selectivity of goethite [118]. In order to examine the cation and anion selectivity of the $\mathrm{Cr}$-substituted goethite, a study of the membrane potentials of the synthetic Cr-substituted goethite and the varied concentration of $\mathrm{KCl}$ solution was carried out.

Fig. 17 shows $\mathrm{t}_{\mathrm{Cl}}$, the transport number of $\mathrm{Cl}^{-}$, as a function of the $\mathrm{Cr}$ content in the $\mathrm{Cr}$ substituted goethite membrane. It is clearly shown that $\mathrm{t}_{\mathrm{Cl}}$ - decreases as the $\mathrm{Cr}$ content increases. This means that the ion selectivity of the $\mathrm{Cr}$-substituted goethite changes from anion selective to cation selective by increasing the $\mathrm{Cr}$ content, probably due to a fixed charge change from positive to negative in the $\mathrm{Cr}$-substituted goethite. The point of iso-selectivity, where $t_{k+}$ is equal to $t_{C l-}$, is estimated to be approximately $\mathrm{Cr} 3 \%$ wt. Thus it can be said that the cation selective property appears when the $\mathrm{Cr}$ content exceeds approximately $3 \% \mathrm{wt}$. As was discussed above, the $\mathrm{Cr}$ content in the spontaneously formed goethite depended on $\Delta \mathrm{d}$ and was higher than $3 \% \mathrm{wt}$ in the vicinity of the rust/steel interface. It is considered that the spontaneously formed $\mathrm{Cr}$-substituted goethite possesses the cation selective ability at least in the vicinity of the rust/steel interface where the $\mathrm{Cr}$ content can be estimated to be approximately $5-10 \%$ wt. Thus, the final stable protective rust layer of the Cr-substituted goethite impedes the penetration of aggressive corrosive anions such $\mathrm{Cl}^{-}$and $\mathrm{SO}_{4}{ }^{2-}$, besides the physical effect of its dense aggregation [118].

Thus, the protective effect of the rust layer formed on WS after long-term exposure is derived from the dense aggregation of ultrafine goethite (Cr-UFG) which contains a certain amount of $\mathrm{Cr}$. Cr- goethite also possesses cation selectivity which prevents the penetration of corrosive anions.

In studies carried out at that time at Bethlehem Steel Corporation, USA, by Townsend et al. [120] on rusts formed over 11 years, the results differed to those found by Yamashita et al. [69]. Townsend et al. reported that rust formed on WS during long-term exposure to industrial and rural environments was composed mostly of two crystallographic forms of ferric oxyhydroxides, namely lepidocrocite and goethite, and a thin, light-coloured, discontinuous outer layer composed of two other iron oxides: hematite and possibly magnetite [120]. Moreover, they reported that lepidocrocite was located in an inner layer and goethite in an outer layer.

To help to resolve these differences, Yamashita and Townsend exchanged samples of rusted WS so that both parties in Japan and the USA could conduct parallel, comparative studies of 
identical materials. In conclusion, they reported a mutual understanding of the final form of the rust layers formed on WS exposed in Japan and USA, in the following terms (Fig. 18) [121]:

(a) The main constituents of the Japanese and US rusts were Cr-substituted goethite, lepidocrocite, and a small amount of maghemite and/or magnetite.

(b) The dark $\mathrm{Cr}$-substituted goethite area was located in the inner layer, while the bright lepidocrocite area was in the outer layer. In some cases, however, the goethite was also located in the outer layer and this detached goethite consequently formed a third layer.

(c) The innermost $\mathrm{Cr}$-substituted goethite layer may be the final form of the protective rust layer that suppresses corrosive species penetration through the rust layer, and therefore further slows corrosion.

\subsection{Cook et al.: "Distribution and mean particle size of Cr-FG"}

In 1999 Cook et al. [122], using a wide range of high resolution spectroscopic instrumentation (XRD, IR, MS, micro Raman, EPMA, EDX, and SEM), analysed the mass fraction of each oxide present in ASTM A-588 WS [123] exposed in a rural atmosphere for 16 years. In particular, the use of MS turned out to be of great importance. This data provided a significant insight into the protective rust layer formed on WS, and a better understanding of the mechanism by which the corrosion product layer is able to successfully protect the steel from further corrosion through the formation of an adherent protective layer of nano-phase goethite at the steel surface.

The authors found that the outer layer contained nearly equal fractions of lepidocrocite and goethite and its formation and composition were most likely controlled by the local exposure conditions. The inner layer was entirely goethite, containing very small islands of maghemite and magnetite. The inner layer had a distribution in $\mathrm{Cr}-\mathrm{FG}$ of particle size 5-30 nm, with a mean particle size of $12 \mathrm{~nm}$, and about $60 \%$ of Cr-UFG, with a particle size of less than $15 \mathrm{~nm}$. The formation of the latter fraction of small-particle goethite was predominantly controlled by the steel chemistry. Cr-FG was obtained by ripening of Cr-UFG.

According to Yamashita and Uchida $[119,124]$ the exposure-time dependence of the fractions of all three constituents (goethite, lepidocrocite and X-ray amorphous substance) in the rusts could be summarised in the model shown in Fig. 19. There are three regions, namely the lepidocrocite-rich initial region (region I), less than a few years; the X-ray amorphous-rich region (region II), after several years; and the goethite-rich region (region III), after decades. The WS corrosion rate decreased with this long-term phase transformation. 
In 1999 Oh, Cook and Townsend [70] characterised by MS, micro Raman and XRD the corrosion behaviour of different steels (plain carbon steel, Cu-bearing steel, A-242 WS [26], and A-588 WS [123]) as a function of the steel composition and the environmental conditions (rural, moderate industrial and moderate marine atmospheres) after 16 years of exposure. They found that magnetic and superparamagnetic goethite and lepidocrocite were present in the corrosion products formed on all the samples, irrespective of the environmental conditions and steel composition. The inner layer consisted of interdispersed goethite in large fractions and superparamagnetic maghemite in small fractions, and the outer layer was composed of interdispersed goethite in small fractions and lepidocrocite in large fractions. The decrease in particle size due to the increase in the superparamagnetic goethite fraction probably enhanced the protective ability of the rust layer, and resulted in a lower corrosion rate of the steel samples.

These researchers found that the large amounts of silicon and smaller amounts of phosphorus in the steel increased the superparamagnetic goethite fraction, irrespective of the environmental conditions, however, different amounts of nickel did not affect the formation and development of iron oxides after sixteen years of exposure. They also pointed out the following conjectures for a long-term lifetime of steel structures: (i) increasing the silicon content in the steel substrate would be helpful to enhance corrosion resistance caused by increasing the relative fraction of superparamagnetic goethite in atmospheric conditions, and (ii) the large goethite and magnetic maghemite particles were a possible cause of the increase in the corrosion rate of plain carbon steel exposed at the marine site [70].

\subsection{Yamashita et al.: "Nanostructure of Cr-FG"}

It is important to clarify why the increase in the $\mathrm{Cr}$ concentration causes the aggregation of small goethite particles.

To answer this question it is necessary to elucidate the nanostructure and thus the atomic arrangement of $\mathrm{Cr}$ - goethite. For this purpose, Yamashita et al. used X-ray absorption fine structure (XAFS) [125-126]. According to Yamashita the structural unit of a goethite crystal is an $\mathrm{FeO}_{3}(\mathrm{OH})_{3}$ octahedron where each $\mathrm{Fe}^{3+}$ is surrounded by three $\mathrm{O}^{2-}$ and three $\mathrm{OH}^{-}$. The network of the octahedra gives the goethite structure. Double chains of the octahedra formed by edge-sharing run parallel to the (001) direction. These chains are linked to adjacent double chains by corner-sharing, which leads to the orthorhombic symmetry. Therefore, the goethite structure consists of double chains of octahedra alternating with double chains of vacant sites [68]. 
By considering a spatial site in the network of octahedra, there are considered to be two possible sites for $\mathrm{Cr}^{3+}$ in the goethite structure: one is the substitutable $\mathrm{Fe}^{3+}$ site and the other is in the double chains of vacant sites. Based on the extended XAFS (EXAFS) results, Yamashita et al. concluded that $\mathrm{Cr}^{3+}$ in the $\mathrm{Cr}$-goethite in the rust layer can be positioned in the double chains of vacant sites with coordinating $\mathrm{O}^{2-}$, probably forming a $\mathrm{CrO}_{x}{ }^{3-2 x}$ complex anion. The latter may expand and probably break the double chains of vacant sites [125-126]. This collapse of the double chains of vacant sites causes the formation of the ultrafine crystals resulting in the presence of closely packed aggregates of ultrafine crystals with cation selectivity. In the research carried out with a Fe-5\%Cr alloy, Yamashita et al. [126] found that increasing the $\mathrm{Cr}$ content gave rise to the faster formation of Cr-UFG.

Almost at the same time, Kimura et al. quantitatively analysed the atomic nanostructure of rusts formed on a WS surface using a combination of techniques (XAFS, XRD and TEM) [127128]. Time-evolution of the atomic structure of the rust was discussed in terms of an $\mathrm{Fe}(\mathrm{O}, \mathrm{OH})_{6}$ network. According to these researchers, chromium addition results in the formation of $\operatorname{Cr}(\mathrm{O}, \mathrm{OH})_{6}$ units with different structures to $\mathrm{Fe}(\mathrm{O}, \mathrm{OH})_{6}$. Thus, $\operatorname{the} \operatorname{Cr}(\mathrm{O}, \mathrm{OH})_{6}$ units may influence the evolution of $\mathrm{Fe}(\mathrm{O}, \mathrm{OH})_{6}$, so as to distort the $\mathrm{Fe}(\mathrm{O}, \mathrm{OH})_{6}$ network. This is related to the fact that the final size distribution of goethite formed on WS is smaller than on CS. In particular, this tendency may be remarkable in the inner rust layer formed on WS, where chromium is considerably enriched.

\subsection{Yamashita et al.: " $\alpha / \gamma$ index to evaluate the protective ability of the rust layer"}

Yamashita et al. found that the mass ratio of the goethite to lepidocrocite amounts on WS, $\alpha / \gamma$, determined by XRD is a function of the exposure time, as is shown in Fig. 20a. The $\alpha / \gamma$ ratio increased proportionally with the exposure time due to the long-term phase transformation. The relation between $\alpha / \gamma$ and the corrosion rate is shown in Fig. 20b. It can be said that the WS corrosion rate decreased as the $\alpha / \gamma$ increased, and that $\alpha / \gamma>2$ was a necessary condition for the final protective rust layer. $\alpha / \gamma$ can be considered as an index to evaluate the protective ability of the rust layer [124].

Asami and Kikuchi [129-130] characterised by XRD, SEM, EPMA and TEM/Electron diffraction (ED) the rusts formed on CS and WS exposed for 17 years in an industrial coastal atmosphere. They found that $\mathrm{Cu}, \mathrm{Cr}$ and $\mathrm{Si}$ were concentrated in the inner layer while $\mathrm{P}$ and Ni were mostly distributed uniformly throughout the entire rust layer.

The rust layer consisted of the following phases: goethite, akaganeite, lepidocrocite, magnetite and amorphous matter. These researchers found that: 
(a) The main rust constituent in all specimens was goethite that appeared almost homogeneously throughout the rust layer. Its concentration was higher in the rust on WS than on CS.

(b) Amorphous rust was located at the bottom of the rust layer irrespective of the steel type.

(c) Akaganeite existed in the thick parts of the rust layer, but was scarce in the thin parts. Its concentration was much lower in the rust on WS than on CS.

(d) The magnetite concentration was negatively correlated with the akaganeite concentration.

The mass ratio of goethite to akaganeite + lepidocrocite + magnetite, the $\alpha / \gamma^{*}$ ratio, determined by TEM/ED, was larger than 1 on WS, and less than 1 on CS. That ratio could be used as a new index to evaluate the protective value of a rust layer [131,132], in the same way as the $\alpha / \gamma$ ratio determined by the conventional XRD technique, mentioned before.

\subsection{Dillmann et al.: "New $\alpha^{*} / \gamma^{*}$ index to evaluate the protective ability of the rust layer"}

Dillmann et al. [60], examining very old rusts formed on archaeological irons (several hundred years old) did not find amorphous phases in the inner rust layer. They attributed to the old age of the rust its apparent absence. This hypothesis was also shared by Yamashita and Uchida [119], who suggested that during long exposure the amorphous inner layer may be transformed into a densely packed aggregate of goethite nanoparticles.

Despite of the fact that magnetite is a conducting phase, Dillmann et al. [60] consider it as protective because of its relatively good stability, suggesting a new protective ability index $\left(\alpha^{*} / \gamma^{*}\right)$

$$
\frac{\alpha^{*}}{\gamma^{*}}=\frac{C_{\alpha}+C_{M}}{C_{\gamma}+C_{\beta}}
$$

where $C_{\alpha}$ is the mass $\%$ of goethite, $C_{M}$ is the mass $\%$ of magnetite, $C_{\gamma}$ is the mass of lepidocrocite and $C_{\beta}$ is the mass $\%$ of akaganeite. The older the rust layers, the higher the protective ability index.

A new method to evaluate the protective ability of the rust layer was recently proposed, which considers the mass fraction of each of the phases constituting the corrosion layer weighted according to their intrinsic reactivity [133]. 


\section{Role of alloying elements}

The scientific literature has accumulated a great number of studies on the influence of different alloying elements on the corrosion resistance of WS exposed to the atmosphere. The most ambitious and significant are probably the aforementioned studies carried out by Copson [2] and Larrabee and Coburn [3].

However, despite this volume of information, only a relatively small number of relevant scientific conclusions have been drawn regarding the direct effect of alloying elements on the atmospheric corrosion resistance of WS. The information that has been gathered is above all empirical, deducing that certain compositions generated lower mass losses due to atmospheric corrosion than CS in certain environments, and not based on scientific knowledge of the influence of the alloying elements.

In section 2.2 we analysed the effect of the main alloying elements in WS in the light of such empirical knowledge. This section 6 now seeks to briefly set out the main contributions that have appeared over the years in scientific knowledge of the effect of different alloying elements on the corrosion resistance of WS in atmospheric exposure.

\subsection{Phosphorus}

In 1971 Misawa et al. [98] studied the effect of phosphorus on the formation of natural rust on (0.13\% P-0.40\% Cu-0.40\% Ni-1.00\% Cr) WS in two industrial atmospheres. IR studies of the rust generated in these environments indicated the presence of an amorphous feroxyhyte phase which was difficult to identify by XRD.

At the same time, the authors synthesised Fe (II) hydroxide in the laboratory and oxidised it in a solution containing known concentrations of phosphate ions by means of air bubbling, noting that irrespective of the $\mathrm{pH}$ value of the solution, the Fe (II) hydroxide oxidised to the feroxyhyte amorphous phase, unlike in the absence of phosphate ions. Misawa et al. concluded that the feroxyhyte phase must form the amorphous iron oxide layer, attributing its formation on WS to oxidisation catalysed by the presence of $\mathrm{PO}_{4}{ }^{-3}$ ions, mainly concentrated on its metallic surface.

In 1990 Kihira et al. [116] reported the exposure of a WS composition ( $0.1 \%$ P- $0.26 \%$ Cu- $0.56 \%$ $\mathrm{Cr}-0.16 \% \mathrm{Ni}$ ) to an urban atmosphere for 19 years. The rust generated during this exposure time presented good protective properties. Using X-ray microanalysis the authors found evidence of phosphorus enrichment in the intermediate portion of the rust. Using Raman spectroscopy (RS) they also managed to identify and attribute some bands of iron phosphate, 
whose stoichiometry was not specified. They concluded that phosphorus must be converted into an iron phosphate compound during the rust formation process.

At the same time, the authors used a light microscope fitted with a video camera to monitor the corrosion process experienced by WS (with and without $0.1 \% \mathrm{P}$ ) immersed in $0.5 \mathrm{M} \mathrm{NaCl}$. After generating the coagulation of colloidal rust particles in the bulk solution, the authors saw that a considerable amount of these particles migrated slowly towards the interface of the steel with $0.1 \% \mathrm{P}$ in its composition, leading to the accumulation of a precipitate layer. This was not observed in the absence of phosphorus, in which case the particles migrated without any preferential direction. They concluded that the phosphate layer may perhaps form as a result of a colloidal process during the initial stages of corrosion.

Later, Balasubramaniam et al. [134-136] carried out in India an in-depth study into the effect of phosphorus in the composition of ancient irons exposed for approximately 950 and 1600 years in the atmospheres of Dhar and Delhi respectively, which surprisingly had barely corroded. Although these ancient irons possessed a considerably different composition to that of a WS (heterogeneous microstructure due to the presence of second phase particles and an average $\mathrm{P}$ content of approximately $0.25 \% \mathrm{wt}$ ), their characterisation may help to understand the role of phosphorus in the rust generated in atmospheric corrosion.

XRD identified the presence in the rust of hydrated iron phosphate $\left(\mathrm{FePO}_{4} \cdot \mathrm{H}_{3} \mathrm{PO}_{4} \cdot 4 \mathrm{H}_{2} \mathrm{O}\right)$ of a crystalline nature and low porosity. FTIR also confirmed its presence, along with goethite, lepidocrocite, feroxyhyte, and magnetite, which were not detected by XRD and must therefore be of a nanophase size. MS confirmed the amorphous nature of the iron oxy-hydroxides, and provided information on the $\mathrm{Fe}^{3+}$ oxidation state in the hydrated phosphate.

Dillmann et al. [137] proposed the following mechanism: the presence of second phase particles initially raised the iron corrosion rate, which theoretically led to an increase in the phosphorus concentration on the metallic surface, catalysing the formation of a continuous layer of amorphous feroxyhyte, a phase which is difficult to identify by XRD. Subsequently, as exposure continued, phosphorus continued to accumulate, leading to the precipitation of an insoluble phosphate. This insoluble phosphate, of a crystalline nature, presented very low porosity and was considered to be responsible for the good atmospheric corrosion behaviour of that steel over so many centuries of exposure.

More recently, Monnier et al. [138] characterised ancient iron-based world heritage structures containing phosphorus in their metallic substrate by means of complementary techniques: optical microscopy (OM), micro Raman, and micro XRF and micro X-ray absorption near edge 
structure (micro XANES) spectroscopies under synchrotron radiation. Among the corrosion products, neither crystallised nor amorphous iron phosphate, nor any specific phase enrichment were observed; phosphate ions were mainly complexed with all the oxidised iron phases present in the layers.

\subsection{Copper}

In 1980 Schwitter and Bohni [139] proposed that the retarding effect of alloying elements in WS upon the corrosion rate was due to a slower activation of the corrosion process after wetting of the surface. Suzuki et al. [140], on the other hand, observed differences in the reduction behaviour of rust on pure iron and on WS. Both papers hint that stage 1 "wetting of the dry surface (see section 4.7)" was predominantly affected by copper addition, as rust reduction is only of special importance in that stage.

In 1987 Stratmann et al. [102] carried out a major research project to electrochemically determine the effect of $\mathrm{Cu}$ in Fe-Cu $0.5 \%$ wt and compare it with pure iron. They showed for the first time that the influence of copper addition to the metal is limited to the drying out period of the rust layer (stage 3), whereas during the wet period (stages 1 and 2) pure iron and a $\mathrm{Fe}-\mathrm{Cu} 0.5 \%$ wt alloy behave very much in the same way (see section 4.7$)$. Using a magnetic and a gas volumetric technique, they demonstrated that during the wet period the metal loss was very much the same for both metallic materials, whereas during the drying out period the metal loss of $\mathrm{Fe}-\mathrm{Cu} 0.5 \%$ wt was much less than in the case of pure iron, the difference between the two becoming larger with higher numbers of wet/dry cycles. This also confirms the importance of wet/dry cycles in WS behaviour.

For the Fe-Cu $0.5 \%$ wt alloy the electrolyte film became extremely thin during the drying out period and transportation of $\mathrm{O}_{2}$ to the reaction site was increased. This acceleration of $\mathrm{O}_{2}$ transportation did not result in a higher corrosion rate. This fact may be explained by two models, based on different assumptions:

Model 1: Cu changes the kinetics of the cathodic reaction. If the addition of copper were to retard the kinetics of the $\mathrm{O}_{2}$ reduction until the overall reaction is under kinetic control, then the enhancement of $\mathrm{O}_{2}$ transportation during the drying out period would have no influence on the corrosion rate. The incorporation of $\mathrm{Cu}$ in the rust phases would change the electronic conductivity $\left(\mathrm{Fe}_{3} \mathrm{O}_{4}\right.$ vs $\mathrm{Fe}_{2} \mathrm{CuO}_{4}$, insulating) and/or its electro-catalytic properties.

Model 2: Cu changes the kinetics of the anodic reaction. $\mathrm{Cu}$ is enriched at the metal/electrolyte interface and changes the kinetics of metal dissolution. The low rate of the anodic reaction 
could be explained by passivation or by the formation of a dense corrosion film that blocks the surface to a great extent.

Three years later, Stratmann and Streckel observed with a Scanning Kelvin Probe (SKP) that the $\mathrm{Fe}-\mathrm{Cu} 0.5 \%$ wt alloy showed rather negative corrosion potentials during drying, which was interpreted as a slow oxygen reduction rate (Model 1 ) in the oxide scale formed on this alloy [105].

\subsection{Chromium}

The important role of $\mathrm{Cr}$ at microstructural level in the rust layer has been thoroughly examined in section 5. The only thing to add at this point is to mention the major electrochemical study carried out by Kamimura and Stratmann on the role of $\mathrm{Cr}$ in the atmospheric corrosion of WS [141].

Kamimura and Stratmann studied the influence of chromium in the initial stages of the atmospheric corrosion of steel [141]. Tests were carried out on Fe and three Fe-Cr alloys with $\mathrm{Cr}$ concentrations of 1,2 and $4.6 \%$ wt respectively. The surface of these alloys was subjected to 20 wetting and drying cycles using a $0.01 \mathrm{M} \mathrm{Na}_{2} \mathrm{SO}_{4}$ electrolyte in order to simulate neutral atmospheric environments without chlorides. The authors simultaneously monitored the evolution of the corrosion potential by SKP and the corrosion rate by means of the oxygen consumption technique during each of the 20 wetting and drying cycles. They saw that the addition of $\mathrm{Cr}$ enormously lowered the steel corrosion rate during the drying stage, as the oxygen consumption decreased notably during this stage, while it remained practically constant during the wetting stage.

However, XRD and RS measurements failed to show any difference in the composition, quantity or microstructure of the corrosion products on the $\mathrm{Fe}$ and $\mathrm{Fe}-\mathrm{Cr} 4.6 \%$ wt surfaces. In contrast, EPMA and EDX revealed $\mathrm{Cr}$ enrichment in direct contact with the metallic surface of the $\mathrm{Fe}-4.6 \mathrm{Cr}$ alloy, showing a maximum $\mathrm{Cr} / \mathrm{Fe}$ ratio of $10-15 \%$, while the outer rust layer presented a ratio of just $1 \%$. Therefore, the presence of $\mathrm{Cr}$ was again the only difference between the rusts formed on Fe and on the steels containing $\mathrm{Cr}$. The authors concluded that the presence of $\mathrm{Cr}$ inhibits the reduction of rust (cathodic reaction) during the wetting stage, decreasing the formation of $\mathrm{Fe}^{2+}$ intermediate states inside the lepidocrocite structure, thus reducing the oxygen reduction rate during the drying stage by limiting the electron transfer reaction.

However, the positive effect of chromium is not seen in saline environments, above $5 \mathrm{mg}$ $\mathrm{NaCl} / \mathrm{m}^{2} \mathrm{~d}$, and instead it seems to have a harmful effect by accelerating WS corrosion in 
coastal environments. According to Schwitter and Bohni, the hydrolysis reaction originated by the $\mathrm{Cr}^{3+}$ ion is very notable, lowering the $\mathrm{pH}$ on the metallic surface and accelerating the corrosion process [139].

$$
\mathrm{Cr}^{3+}+3 \mathrm{H}_{2} \mathrm{O} \leftrightarrow \mathrm{Cr}(\mathrm{OH})_{3}+3 \mathrm{H}^{+}
$$

\section{$6.4 \quad$ Nickel}

Kimura et al. [142] exposed a high $\mathrm{Ni}$ content steel ( $\mathrm{Ni} 3 \%-0.4 \% \mathrm{Cu}$ ) to a coastal environment in Kimitsu ( $79 \mathrm{mg} \mathrm{Cl} / \mathrm{m}^{2}$ day) for 9 years. Using EPMA they found that Ni was distributed in both rust layers (outer and inner) with a much higher concentration in the inner layer. The $\mathrm{Na}^{+}$ cation was located in the inner layer, while the $\mathrm{Cl}^{-}$anion was concentrated predominantly in the outer layer. By means of mass loss tests they determined that the steel with $3 \% \mathrm{Ni}$ presented a 20 times lower mean penetration than conventional WS (Fig. 21).

The authors also carried out in situ monitoring of the evolution of rust by synchrotron radiation, simulating atmospheric exposure by means of wetting and drying cycles with diluted sea water. They found that $\mathrm{Ni}^{2+}$ occupied octahedral voids inside the magnetite structure, partly replacing the $\mathrm{Fe}^{2+}$ ions and stabilising the $\mathrm{Fe}_{2} \mathrm{NiO}_{4}$ phase in the rust. They speculate that new units of $(\mathrm{Fe}, \mathrm{Ni}) \mathrm{O}_{6}$ would be initially formed which altered the morphology of the rust, precipitating $\mathrm{Fe}_{2} \mathrm{NiO}_{4}$, which would provide larger sites for the nucleation of the $\mathrm{Fe}(\mathrm{O}, \mathrm{OH})_{6}$ nanostructure, forming a densely packed fine-grain rust.

In addition to this, the ion-exchange properties of the rust are also modified. Thus, when the rust is wetted in highly saline conditions and corrosion progresses, its $\mathrm{pH}$ decreases due to hydrolysis of the metallic cations [59].

$$
2 \mathrm{Fe}^{2+}+3 \mathrm{H}_{2} \mathrm{O}+1 / 2 \mathrm{O}_{2} \rightarrow 2 \mathrm{FeOOH}+4 \mathrm{H}^{+}
$$

The hydroxyl $(-\mathrm{OH})$ groups present in the rust $(\mathrm{FeOOH})$ change to $-\mathrm{OH}^{2+}$, becoming positively charged and facilitating the approach of the $\mathrm{Cl}^{-}$ions to the metal/rust interface. However, in the case of the steel with a high $\mathrm{Ni}$ content, $\mathrm{Fe}_{2} \mathrm{NiO}_{4}$ forms in the inner layer, increasing the negative charge on the surface of the rust compared to that formed only by $\mathrm{FeOOH}$. The incorporation of divalent ions $\left(\mathrm{Ni}^{2+}\right)$ in the inner rust layer brings about a lowering of its isoelectric point, favouring the change to cationic selectivity of the inner rust where $\mathrm{Na}^{+}$ accumulates instead of $\mathrm{Cl}^{-}$. In other words, chloride ions are expelled from the metal/rust interface, protecting the steel for a longer time period in saline environments [59].

Two years later, Chen et al. [143] reached similar conclusions with two steels alloyed with $1 \%$ wt and $4 \% \mathrm{wt} \mathrm{Ni}$ in simulated marine environments. Using SEM they found that the rust 
formed on the steels alloyed with Ni presented two layers. The outer layer was porous, while the inner layer showed great compactness, with a density that increased in line with the proportion of $\mathrm{Ni}$ in the steel. These authors also prepared cross-section composition profiles of the different tested steels by means of EDX. Nickel was found homogenously distributed throughout the rust on the steels alloyed with $4 \% \mathrm{Ni}$, and there was only a small amount of $\mathrm{Cl}$ in the inner rust layer. Thus they concluded that $\mathrm{Ni}$ brings about a change in the ionic selectivity of the rust layer, decreasing its anionic behaviour to the point that it becomes cationic when the $\mathrm{Ni}$ content exceeds $4 \%$. They also found that $\mathrm{Ni}$ restrained the anodic dissolution of iron, shifted the corrosion potential in a noble direction, and increased the corrosion resistance of the rust layer by improving adhesion and compactness and ameliorating the physicochemical properties of the substrate/rust interface.

\section{Scientific design of new WS}

The design of the first weathering steels was purely empirical and focused on a small number of conventional alloying elements such as $\mathrm{Mn}, \mathrm{Si}, \mathrm{Cr}, \mathrm{Ni}, \mathrm{Cu}, \mathrm{Mo}$ and $\mathrm{P}$ in a narrow concentration range. Since the effects of these elements on the corrosion properties of steels have been well known for many decades, only marginal improvements in the weathering performance of these steels could be achieved by adjusting their concentrations.

Modern WS design seeks to overcome the limitations of conventional WS. The main lines of action are focused on the following objectives [119]: a) greater corrosion resistance; b) cutting the formation time of protective layers; and c) applicability in severe environments, mainly marine atmospheres.

On the other hand, WS design should not be based solely on weathering characteristics, but the composition should be optimised with regard to strength, ductility and fracture properties, ease of processing and manufacture, cost, and avoiding adverse health effects. Furthermore, it is important to improve recycling capability.

Nowadays, new WS designs can be tested by means of laboratory-performed accelerated weathering tests [37] and deep studies can be carried out at the laboratory scale to know the effects of new alloying elements on thermodynamic, kinetic, electrochemical, crystallographic and other properties of corrosion product layers on steels; powerful instrumental techniques are now available which allow a better understanding of corrosion mechanisms and corrosion rates [144].

There follows a review of the latest advances that have taken place in the development of WS according to their field of application. Consideration is made of two main groups: non-marine 
atmospheres and marine atmospheres, with greater emphasis on the latter; this being perhaps the most important limitation of conventional WS.

\subsection{Non-marine atmospheres}

From a bibliographic review of the scientific literature, the following new WS alternatives for non-marine atmospheres which have appeared during the last decade are highlighted, along with an indication of their main properties.

\subsubsection{Increasing the phosphorus content}

Low P contents $(0.01 \% \mathrm{wt})$ promote high corrosion rates, so when the $\mathrm{P}$ content is raised the corrosion resistance also increases considerably. A WS composition with a P content of $0.035 \%$ wt [145], known as "economic WS", showed more corrosion resistance than ordinary (copperfree) steels, giving equally good corrosion resistance to ASTM A-242 WS [26] without extra alloying expense.

A wet/dry cyclic corrosion test indicated that a low-cost WS not alloyed with $\mathrm{Cr}$ and $\mathrm{Ni}$, $\mathrm{Mn}(1.38 \% \mathrm{wt})-\mathrm{Cu}(0.32 \% \mathrm{wt})-\mathrm{P} 0.07 \% \mathrm{wt}$, showed high corrosion resistance not only in a simulated industrial atmosphere but also in a simulated coastal atmosphere and a simulated industrial-coastal atmosphere [146].

The increase in $\mathrm{P}(0.15-0.26 \% \mathrm{wt})$ promotes more homogeneous and compact rust layers. $\mathrm{P}$ enrichment at the interface gives rise to the precipitation of phosphates, improving corrosion resistance and delaying the penetration of corrosive agents. A wet/dry cyclic laboratory test in $0.005 \mathrm{M} \mathrm{NaHSO}_{3}$ solution showed a predicted lower corrosion rate than an equivalent WS with a $0.08 \%$ wt phosphorus content [147].

\subsubsection{Increasing the silicon content}

Mejía Gómez et al. studied the behaviour of copper steel with increasing contents of Si, Si (1$3 \% \mathrm{wt})-\mathrm{Cu}(0.3 \% \mathrm{wt})-\mathrm{Mn}(0.5 \% \mathrm{wt})$, in accelerated wet/dry cyclic tests in $0.05 \mathrm{M}$ and $0.5 \mathrm{M}$ $\mathrm{NaCl}$ solutions, comparing the results with the behaviour of carbon steel [148]. Weight loss measurements indicated that corrosion resistance increased with the Si content of the steel, in particular in the case of relatively low chloride environments. MS showed that supermagnetic goethite was the dominant phase in the rust developed on the Si steels, indicating that $\mathrm{Si}$ favours the formation of goethite with a small particle size.

In a more recent work, the same authors [149] synthesised goethite in the presence of Si. XRD results did not give any indication that Si species would substitute for Fe in the goethite 
structure. However it was found that the presence of Si inhibits the growth of the goethite particles, thus positively affecting corrosion resistance.

\subsubsection{Increasing the nickel content}

A synergistic anti-corrosion effect of the two alloying elements, $\mathrm{Cu}(0.3 \% \mathrm{wt})$ and $\mathrm{Ni}$, was especially observed when the nickel content was raised from $1 \%$ wt to $4 \% \mathrm{wt}$, providing better corrosion resistance than in the case of mild steel [150]. Electrochemical impedance spectroscopy (EIS) measurements showed that $\mathrm{Ni}$ alloying facilitated steel passivation at the initial stage and its compactness and blocking ability in the later stage. $\mathrm{Cu}$ alloying promoted the formation of lepidocrocite while Ni alloying delayed the crystallisation of some rust phases and facilitated the formation of amorphous phases.

\subsubsection{Increasing the chromium content}

Qian et al. investigated in a wet/dry cyclic laboratory test the influence of $\mathrm{Cr}$ (from $0.8 \%$ wt to $9 \% \mathrm{wt}$ ) on the atmospheric corrosion resistance of WS in a simulated industrial atmosphere (0.01 $\mathrm{M} \mathrm{NaHSO}_{3}$ solution) [151,152]. The increase in $\mathrm{Cr}$ notably shifted the open circuit potential of the steel in the positive direction and improved the corrosion resistance of WS, which was greater the higher the $\mathrm{Cr}$ content, by promoting the formation of a protective goethite rust layer and enhancing its passivation capability.

\subsubsection{Addition of titanium}

Nakayama et al. artificially synthesised goethite rusts by the addition of Ti with atomic ratios $(\mathrm{Ti} / \mathrm{Fe})$ in the $0-0.1 \%$ wt range [153]. Ti-enriched UFG particles plugged the pores in the rust film and significantly increased the passivation ability of the rust; the rust structure that was produced contributed to the protective properties of the rust layer.

\subsubsection{Nitrogen alloying}

Wang et al. [154], conducting electrochemical tests, found that nitrogen alloying of conventional WS, $\mathrm{N}(0.03 \% \mathrm{wt})-\mathrm{Cr}(0.63 \% \mathrm{wt})-\mathrm{Cu}(0.24 \% \mathrm{wt})$, generated a more effective and stable protective rust layer compared to ASTM A-242 WS.

\subsubsection{Addition of boron}

Zhao et al., in EIS laboratory tests, observed that small additions of B (0.0026\% wt) promoted important changes in the microstructure and mechanical properties of steel, lowering its pearlite content, a harmful phase from an anticorrosive point of view [155]. 


\subsubsection{Addition of rare earths (RE)}

The addition of small amounts of RE $(0.01-0.03 \% \mathrm{wt})$, mainly $\mathrm{Ce}$, significantly improve its weatherability, accelerating the formation of protective layers with better mechanical properties [156]. In these WS, RE (0.01-0.02\% wt) - $\mathrm{Cu}(0.31 \% \mathrm{wt})$ - P $(0.10 \%)$, known as "clean steels", small and dispersive RE inclusions are formed instead of highly corrosion-susceptible MnS. By means of electrochemical methods, Yue et al. [157] found higher corrosion resistances and the formation of more uniform and compact rust layers, observing general uniform corrosion of the steel instead of pitting. Mi et al. also observed a faster lepidocrocite to goethite transformation [158].

\subsubsection{Low-carbon microalloyed bainitic steel}

Zhao et al. [159] and Wang et al. [160] found that ultra-low C micro-alloyed bainitic steels (Mo, $\mathrm{Nb}, \mathrm{Cu}, \mathrm{B})$ with carbon contents in the $0.02-0.05 \% \mathrm{wt}$ range showed greater corrosion resistance than ferrite-pearlite structures. The hardenability and strength of the steel were compensated by the microalloying approach [159].

Based on weight loss measurements they found that the grain refinement and homogeneous structure of the rust layers obtained could effectively increase the corrosion resistance of the steel, giving rise to thinner, denser and more protective layers [160]. Good results were also obtained in accelerated laboratory tests involving cyclic wet/dry conditions [161].

However, low-carbon microalloyed bainitic steels do not show good behaviour in marine atmospheres. The corrosion behaviour of low-carbon bainitic WS in an environment containing chloride ions was studied by Guo et al. applying different constant elastic loads [162]. The results showed that the applied elastic load reduced the resistance of the rust layer to $\mathrm{Cl}^{-}$ diffusion, facilitating the corrosion process and consequently resulting in a loose rust layer. Guo et al. also studied by weight loss and EIS the influence of the carbon content and microstructure on the corrosion behaviour of low alloy steels in $\mathrm{Cl}^{-}$containing environments (outdoor exposure with periodic spraying of a $\mathrm{NaCl}$ solution) [163]. The ultra-low C $(0.0036 \%$ wt) steel behaved much worse than the steel with a higher $C$ content $(0.10 \% \mathrm{wt})$.

\subsection{Marine atmospheres}

One of the main limitations of conventional WS is the non-formation of protective rust layers in marine atmospheres. It is well known that CS presents a higher corrosion rate in marine atmospheres, which is greater the higher the atmospheric salinity [164]. Chloride ions degrade the protective ability of rust layers by enlarging the rust particle size, which means that the 
rust layers which form in severe marine environments are not protective and are easily detached (flaked).

As some researchers have noted, many aspects of atmospheric corrosion in marine environments are not yet sufficiently well known, and little basic research has been carried out on the fundamental mechanism of rusting in salt-rich atmospheric environments. In fact, many points remain unclear regarding the basic mechanisms of rust formation and the effect of alloying elements in salty environments, in particular: the formation conditions of akaganeite and/or other corrosion products containing chlorine and their dependence on the atmospheric chloride content, the akaganeite content in the rust layer and its variation with exposure time, the morphology of akaganeite in natural atmospheric corrosion layers, its location in rust layers and suitable techniques for its identification [55,165-169], etc. Other related matters of interest include the growth of rust particles size in marine atmospheres [170], the formation of thick outer rust layers, and exfoliation mechanisms of these layers. The availability of more mechanistic information on the corrosion of steel in marine atmospheres would undoubtedly be of great assistance in the scientific design of new WS with greater corrosion resistance in such environments.

From a bibliographic review of the scientific literature published over the last decade, the following new WS alternatives for application in marine atmospheres and which represent an improvement over conventional WS are cited. Several notably different design approaches are described below.

\subsubsection{Manganese-copper-phosphorus}

$\mathrm{Mn}(1.89 \% \mathrm{wt})-\mathrm{Cu}(0.29 \% \mathrm{wt})-\mathrm{P}(0.05 \% \mathrm{wt})$ steel is a kind of low cost WS, not alloyed with $\mathrm{Cr}$ or Ni elements, that shows higher resistance to atmospheric corrosion in simulated coastal and coastal-industrial atmospheres containing chlorides and sulphur dioxide [145].

Hao et al. studied the behaviour of this steel in the laboratory by means of wet/dry cyclic corrosion tests simulating coastal (0.05 M NaCl solution) [171] and coastal-industrial (0.05 M $\mathrm{NaCl}+0.01 \mathrm{M} \mathrm{Na}_{2} \mathrm{SO}_{3}$ solution) [172] atmospheres, comparing the results with those obtained for plain carbon steel (CS) and Mn (1.57\% wt) steel. The authors performed weight gain measurements and corrosion monitoring by electrochemical measurements.

In the coastal atmosphere the increased relative amount of goethite and the decreased amount of magnetite in the rust layer indicated the improved corrosion resistance of the rusted steel as the corrosion process proceeds. The rust initially enhances and then stabilises the cathodic process, but the anodic process tends to be inhibited by the protective rust layer. 
In the coastal-industrial atmosphere, the formation of akaganeite in the presence of $\mathrm{Cl}^{-}$can be greatly affected by the coexistence of $\mathrm{SO}_{4}{ }^{2-}$ in the thin liquid film on the steel surface.

\subsubsection{Addition of tungsten}

Itagaki et al. using EIS found that Fe-1\% wt W provided higher corrosion resistance than that corresponding to Co $(3 \% \mathrm{wt})$, $\mathrm{P}(0.1 \% \mathrm{wt})$, Al $(0.8 \% \mathrm{wt})$, Mo $(0.8 \% \mathrm{wt})$ or $\mathrm{Ni}(3 \% \mathrm{wt})$, very potent elements in making steel weatherable [173]. When $\mathrm{W}$ is added to $\mathrm{Fe}$, the anion $\left(\mathrm{WO}_{2}\right)^{2-}$ is formed at a $\mathrm{pH}$ as low as 5 . This anion, when combined with $\mathrm{Fe}^{2+}$ during the early stages of weathering, forms a salt that concentrates in the pores of the rust and acts as a corrosion inhibitor. No ions are formed at high pH values in Fe-W systems, where this alloy is also passive [144]. The high electrochemical impedance of the rust film indicated that the low permeation rate of chloride ions lowered the corrosion rate [173].

\subsubsection{Ultrafine-grained silicon-aluminium steel}

Primarily the high contents of Si $(0.8 \% \mathrm{wt})$ and $\mathrm{Al}(0.8 \% \mathrm{wt})$, and secondarily the ultrafinegrained structure of the steel, afford excellent corrosion resistance [174-176]. This was estimated by a cyclic wet/dry corrosion test using $0.5 \%$ wt $\mathrm{NaCl}$ solution and EIS. Rust resistance and charge-transfer resistance were much higher than that corresponding to Si-Mn carbon steel. Nano-scale complex oxides in the inner rust layer were formed. Extremely high toughness was obtained by grain refinement.

\subsubsection{Chromium steels}

In the 1960's Copson [2] and Larrabee and Coburn [3] observed the beneficial effect of $\mathrm{Cr}$ on the behaviour of steels exposed to marine atmospheres (see Fig. 4). Zhang et al. [177] confirmed in the marine atmosphere of Quingdao ( $35 \mathrm{mg} \mathrm{Cl}^{-} / \mathrm{m}^{2}$ day) the results obtained by Larrabee and Coburn. The thickness loss of steels exposed in marine atmosphere decreased rapidly as their $\mathrm{Cr}$ content was increased. Zhang et al. also carried out another study in the same Quingdao atmosphere [178] in which an important improvement was seen with $\mathrm{Cu}(0.30 \% \mathrm{wt})-\mathrm{Cr}(1.53 \% \mathrm{wt}) \mathrm{WS}$ in comparison to CS.

In the first study carried out by Zhang et al. in 2002 [177], with RE $0.4 \%$ wt-Cr 0-4\% wt WS, the following conclusions were reached:

(a) There were many cracks and voids in the rust layer on the Cr-free steel panels, and the corrosive electrolyte could penetrate directly to contact the substrate steel, leading to a higher corrosion rate. On the other hand $\mathrm{Cr}$-containing steel (the $\mathrm{Cr}$ content more than 
$2 \% \mathrm{wt}$ ) was covered by a uniform compact rust layer composed of fine particles with an average diameter of several nanometres.

(b) With increasing $\mathrm{Cr}$ contents in the synthesised rust film, it was more and more difficult for $\mathrm{Cl}^{-}$ions to reach the surface of the substrate steel. The rust film with a $\mathrm{Cr}$ content of less than 3\% wt showed an anion selective property: chloride ions accumulated in the rust and cations accumulated in the solution. In contrast, the rust film with a $\mathrm{Cr}$ content over $4 \%$ wt showed a cation selective property: chloride accumulation occurred in the solution and cations accumulated in the rust.

(c) The atomic diameter of $\mathrm{Cr}$ is similar to $\mathrm{Fe}$, and both atoms have the same valence electron number, so it is reasonable that $\mathrm{Cr}$ can partly substitute the situation of $\mathrm{Fe}$ in goethite to form a new phase $(\mathrm{Cr}-\mathrm{FG})$. The inner rust layer on $\mathrm{Cr} 2 \%$ wt steel was composed of $\mathrm{Cr}-\mathrm{FG}$, with a $\mathrm{Cr}$ content of about $5 \%$ wt. Such rust layer could depress the entrance of $\mathrm{Cl}^{-}$ion, lowering the corrosion rate, thus confirming the conclusions of Yamashita et al. in 1996 [118].

Yamashita et al. [126] studied by using DRX and MS the structure and protective performance of the atmospheric rust layer on $\mathrm{Fe}-\mathrm{Cr} 5 \%$ wt alloy. It was found that the rust layer contained a large amount of $\mathrm{Cr}$-UFG and lepidocrocite. It was pointed out that the higher $\mathrm{Cr}$ concentration facilitated the formation of Cr-UFG phase. The protective performance of $\mathrm{Cr}$-UFG, due to the presence of closely packed aggregates of ultrafine crystals with cation selectivity, might arise from $\mathrm{Cr}^{3+}$ coordinating with $\mathrm{O}^{2-}$ in the double chains of vacant sites, as was noted above in section 5.3.

In 2005 Yamashita et al. [179] also examined by using micro XRD under synchrotron radiation, the rust layer formation process employing $\mathrm{Fe}-\mathrm{Cr} 5 \%$ wt binary alloy covered with a thin $3.5 \%$ $\mathrm{NaCl}$ electrolyte film during wet/dry cycling. After 9 wet/dry cycles a strong lepidocrocite peak was observed as well as weak peaks originated from goethite and akaganeite. The akaganeite structure consists of double chains of edge-shared $\mathrm{FeO}_{3}(\mathrm{OH})_{3}$ octahedra running parallel to give a tunnel bounded by double rows of corner-shared chains [126]; $\mathrm{Cl}^{-}$ions stabilising the tunnel structure of akaganeite.

\subsubsection{Nickel steels}

According to Kihira et al. [180], alloy design methods of WS for application in marine atmosphere focus on aspects such as $\mathrm{Ca}$ addition, enhanced $\mathrm{Ni}$ prescription and the elimination of $\mathrm{Cr}$.

(a) Ca addition 
This measure seeks to increase the $\mathrm{pH}$ at corroding interfaces, resulting in the stabilisation of iron oxyhydroxides, alteration of the ion-exchange properties of colloidal corrosion products, and maintaining a passive state on locally bare steel surfaces at defects in rust layers,

\section{(b) Enhanced nickel prescription}

Enhanced nickel prescription decreases the active dissolution rates of steel, reducing acidification of the corrosion interface caused by the hydrolysis of metallic ions. Rust formed in this way may contain Ni (II) ions to stabilise Fe (II, III) oxides, which may be beneficial to alter its ion-exchange properties to even facilitate alkalisation at steel/rust interfaces, and

\section{(c) Elimination of chromium}

The elimination of chromium is essential to improve the corrosion resistance of low alloy steels applied to coastal atmospheres because of its acidifying properties. In research recently conducted in a tropical marine environment, Ma et al. [181] observed that under low chloride deposition, $\mathrm{Cr}$ enrichment in the inner layer played an important role in improving weatherability of conventional WS. However, the chloride ion was the main factor to reducing weatherability in high chloride deposition.

Other designs enhance corrosion resistance trying to avoid the penetration of $\mathrm{Cl}^{-}$by the following technologies: (i) Iron substitution type (Ni) or oxide type formation (Al), making spinel double oxides with iron in the inner layers, $\mathrm{Fe}_{\mathrm{e}} \mathrm{NiO}_{4}$ and $\mathrm{FeAl}_{2} \mathrm{O}_{4}$ respectively, and (ii) Oxygen-acid salt type $\left(\mathrm{WO}_{4}\right)$ by formation of insoluble salts $\left(\mathrm{FeWO}_{4}\right)$ on the base metal in defects to act as anodic inhibitor. In 2004 Itagaki et al. [173] performed a laboratory study analysing the electrochemical behaviour and ion-exchange properties of two new alloys: Fe$0.6 \%$ wt Mo and Fe- $1 \%$ wt W. It was seen that the high rust film values compared to those of pure Fe led to a low $\mathrm{Cl}^{-}$permeation rate in the rust films on these alloys and a high corrosion resistance of the WS.

Studies carried out by Nishikata et al. in 1995 [182]in the marine atmosphere of Okinawa (47 $\mathrm{mg} \mathrm{Cl} / \mathrm{m}^{2}$ day) showed a reduction in steel corrosion as the nickel content was increased, with an enormous reduction when the nickel concentration reached $5 \% \mathrm{wt}$, confirming the results found by Copson in 1960 [2](see Fig. 5).

Similarly, Usami et al. [167]and Kimura et al. [142, 183], in 9-year studies carried out in the marine atmosphere of Kimitsu, Chiba (79 $\mathrm{mg} \mathrm{Cl} / \mathrm{m}^{2}$ day), observed an enormous improvement in the corrosion resistance of nickel steels when a nickel content of $3 \%$ wt was reached (Fig. 22). 
There follows a presentation of new Ni-advanced WS compositions for marine atmospheres, along with their main characteristics.

WS composition: $\mathrm{Ni}(3 \% \mathrm{wt})-\mathrm{Cu}(0.4 \% w t)-\mathrm{Ca}(20 \mathrm{ppm} w t)$, elimination of $\mathrm{Cr}$

It was found that the anti airborne salinity WS, 3\% wt Ni-0.4\% wt Cu-20 ppm Ca, showed twice the corrosion resistance of conventional WS exposed for 5 years in a marine atmosphere [180]. This steel was established using various findings in terms of the colloidal function of rusts. The addition of $\mathrm{Ca}$ to the steel is a measure aimed at increasing the $\mathrm{pH}$ at the corroding interface, resulting in the stabilisation of iron oxy-hydroxides, modification of the ion-exchange properties of the colloidal corrosion products, and maintaining the passive state of locally bare steel surfaces at defects in the rust layer. $\mathrm{Ni}$ is considered to decrease the active dissolution rate of the steel, which reduces acidification of the corrosion interface caused by hydrolysis of metallic ions, as a result of which $\mathrm{Ni}$ ions would be contained in the rust layer.

WS composition: $\mathrm{Ni}(3 \% \mathrm{wt})-\mathrm{Cu}(0.4 \% w t)$, elimination of $\mathrm{Cr}$

Different papers $[167,180,184]$ set out the basic design philosophy followed by Nippon Steel on the basis of a $3 \%$ wt $\mathrm{Ni}$ addition and no $\mathrm{Cr}$ addition (Fig. 23) [184].

This advanced WS presents a much lower thickness loss than the conventional WS even in the aggressive marine atmosphere of Kimitsu (79 $\mathrm{mg} \mathrm{Cl}^{-} / \mathrm{m}^{2}$ day) (see Fig. 21). $\mathrm{Cl}^{-}$is concentrated in the outer rust layer while $\mathrm{Ni}$ is concentrated in the inner layer.

According to Kimura et al. [183] high performance was successfully achieved by $\mathrm{Ni}$ and $\mathrm{Cu}$ additions which alter the evolution of the $\mathrm{Fe}(\mathrm{O}, \mathrm{OH})_{6}$ nano-network rust structures formed on the steel surface. A novel technique using synchrotron radiation was developed for in situ observation of rust formation during wet/dry cycles. During an early stage of the reaction, $\mathrm{Fe}_{2} \mathrm{NiO}_{4}$ and $\mathrm{CuO}$ phases precipitate, providing sites for nucleation of an $\mathrm{Fe}(\mathrm{O}, \mathrm{OH})_{6}$ nanonetwork resulting in the formation of rust composed of fine and densely packed grains.

Likewise, in the studies carried out by Kihira et al. [184], XRD and XAFS measurements shown that nickel atoms substitute $\mathrm{Fe}$ sites of $\mathrm{Fe}_{3} \mathrm{O}_{4}$ to form $\mathrm{Fe}_{3-\mathrm{x}} \mathrm{Ni}_{\mathrm{x}} \mathrm{O}_{4}$. Good corrosion resistance of the advanced WS could be attributed to fine grain-size distributions of the inner layers and the formation of $\mathrm{Fe}_{3-\mathrm{x}} \mathrm{Ni}_{x} \mathrm{O}_{4}$. When atmospheric corrosion progresses in a wet condition, its $\mathrm{pH}$ becomes low because of hydrolysis. In conventional WS the rust made of only $\mathrm{FeOOH}$ is positively charged by attached $\mathrm{H}^{+}$ions. However, the inner rust of advanced WS contains $\mathrm{Fe}_{3-\mathrm{x}} \mathrm{Ni}_{x} \mathrm{O}_{4}$ and is negatively charged. The rusts "breath out" chloride ions from the rust/steel interface. 
The existence of $\mathrm{Fe}_{2} \mathrm{NiO}_{4}$ in the nano-network changes the ion-exchange properties of the rust from anion to cation selective, whereby chloride ions concentrate in the outer rust layer and sodium ions in the inner rust layer, as shown in Fig. 23 , the penetration of chloride ions to the interface with the steel substrate, their enrichment there, and the lowering of the $\mathrm{pH}$ value will all be inhibited and as a result the dissolution of the steel substrate will be reduced.

This ion-exchange function is presumed to be due to $\mathrm{Ni}$ and $\mathrm{Cu}$ distributed in the inner rust layer. It is considered that the inner rust layer and its interface with the steel substrate are in a high-alkali (thanks to the ion-exchange function) and low $\mathrm{Cl}^{-}$environment, forming a compact and highly protective rust layer. Kihira et al. report that the inner rust layer on $3 \% \mathrm{Ni}$ WS, considered responsible for its excellent weathering performance and which had been considered to be amorphous as a result of DRX analyses, consists of ultra fine magnetite, this information obtained through ED analysis [184]. However, Yamashita et al. [179, 185] in a laboratory study carried out with a Fe-9\% Ni alloy in contact with a $3.5 \% \mathrm{NaCl}$ solution, did not observe any magnetite diffraction peak. It was clearly found that formation of akaganeite was predominant. The predominant formation of akaganeite in the rust layer on the Fe-Ni alloy (the mass fraction of akaganeite is usually less than that of goethite after long-term exposure of a conventional WS to high salinity environments) is very probably caused by a relatively larger amount of $\mathrm{Ni}$ addition as an alloying element.

On other side, Yamashita et al. [186] pointed out that the rust layer formed on a WS containing $\mathrm{Ni}$ immersed in $\mathrm{NaCl}$ solution presents monoclinic akaganeite. This fact implies that the coexistence of $\mathrm{Ni}^{2+}$ and $\mathrm{Cl}^{-}$ions on the atmospheric corroding surface of an Fe-based alloy might result in the formation of a considerable amount of monoclinic akaganeite. Since monoclinic akaganeite intrinsically contains $\mathrm{Cl}^{-}$ion in its crystal structure [187], the formation of monoclinic akaganeite is expected to make the aggressively corrosive $\mathrm{Cl}^{-}$ion inactive by fixing it in the rust layer. This may result in a higher corrosion resistance of the Fe-Ni alloy, and therefore of the advanced WS containing $\mathrm{Ni}$, in a saline environment.

A study of the magnetic properties of rust samples carried out by Mizoguchi et al. [188] using a Superconducting Quantum Interference Device (SQUID) magnetometer and MS revealed two important factors for this advanced $\mathrm{WS}$ : (i) $\mathrm{Ni}^{2+}$ ions in the inner rust layer had the electrochemical effect of repelling anions, especially $\mathrm{Cl}^{-}$, from the steel/rust interface, and (ii) the inner rust layer was composed of grains that can be densely packed because of their particular volume distribution. 
Sugimoto and Kita [189] carried out a 5-year field study in three areas of different salinities (18, 42 and $103 \mathrm{mg} \mathrm{Cl}^{-} / \mathrm{m}^{2}$ day) with different WS compositions: conventional ( $\mathrm{Cu} 0.30 \% \mathrm{wt}$ - $\mathrm{Cr}$ $0.50 \% \mathrm{wt}$ ), Ni-advanced WS A (Ni 3.0\% wt - Cu 0.4\% wt) and Ni-advanced WS B (Ni 1.5\% wt Mo $0.3 \% \mathrm{wt}$ ). They always found the best behaviour with Ni-advanced WS A, which showed no rust flaking, an indication of a protective rust layer, but only in the least aggressive atmosphere (18 $\mathrm{mg} \mathrm{Cl} / \mathrm{m}^{2}$ day). In this atmosphere they found an attack penetration of $<0.5 \mathrm{~mm}$ in the long-term (100 years) thickness loss prediction done by applying the well known power function, widely used to predict the atmospheric corrosion behaviour of metallic materials [190]:

$$
C=A t^{n}
$$

where $C$ is the corrosion after time $t$, and $A$ and $n$ are constants.

Recently, Diaz et al. [191] found by MS the formation of nanophasic goethite on this Niadvanced WS exposed in a marine atmosphere of moderate salinity $\left(75 \mathrm{mg} \mathrm{Cl} / \mathrm{m}^{2}\right.$ day). This phase could be responsible, as in the case of $\mathrm{Cr}$ in conventional WS, for the formation of denser and more compact inner rust sublayers with improved protective properties.

Thus, there has been in the last decade extensive research done on new compositions of WS, mainly in Japan and China, mostly at laboratory scale. Long-term experimentation in different type of atmospheres will confirm or not the good expectations generated in the laboratory.

\section{Conclusions}

From the review that has been carried out it is possible to draw a number of general conclusions:

(a) It is necessary to continue furthering knowledge of the atmospheric corrosion mechanisms of carbon steels and particularly weathering steels. In this respect, the matters of greatest interest are the precise identification of the corrosion products formed, the presence of reactive and/or conductive phases, and the structure of the rust layers formed. For this purpose, Mössbauer and microRaman spectroscopies should continue to play a key role, along with other powerful instrumental techniques now available.

(b) Many aspects of atmospheric corrosion in marine environments are not yet sufficiently well known. These aspects include the following: the formation conditions of akaganeite, the enlarging of rust particle size, and exfoliation mechanisms of thick rust layers. The availability of more mechanistic information on steel corrosion in marine atmospheres would undoubtedly be of great assistance in the scientific design of new WS with greater corrosion resistance in such environments. 
(c) Advances have taken place in the development of new weathering steels over the last decade, mainly at laboratory level through the performance of accelerated wet/dry cyclic corrosion tests. The wide variety of these cyclic tests used by researchers in this field makes it impossible to compare the results obtained, and thus it would be of great interest to define standard cyclic tests designed specifically for the laboratory study of this type of materials.

(d) Modern WS design seeks to overcome the limitations of conventional WS. The main lines of action are focused on the following objectives: (i) greater corrosion resistance, (ii) cutting the formation time of protective rust layers, and (iii) applicability in severe environments (industrial and marine atmospheres).

(e) In non-marine atmospheres the following alternatives to conventional WS are being studied: (i) increasing the content of some alloying components $(\mathrm{P}, \mathrm{Si}, \mathrm{Ni}, \mathrm{Cr})$, (ii) addition of new elements ( $\mathrm{Ti}, \mathrm{N}, \mathrm{B}, \mathrm{RE}$ ), and (iii) low carbon microalloyed bainitic steel. In the case of marine atmospheres the design approaches are: $\mathrm{Mn}-\mathrm{Cu}-\mathrm{P}$, addition of $\mathrm{W}$, ultrafinegrained Si-Al steel, $\mathrm{Cr}$ steels, and $\mathrm{Ni}$ steels, in particular $\mathrm{Ni}(3 \%$ wt.)-Cu(0.4\% wt.).

(f) Many new WS compositions have been published in the last decade, mainly based on results obtained at laboratory scale. Long-term experimentation in different types of atmospheres will confirm or dismiss the good expectations generated in the laboratory. 


\section{References}

[1] T. Murata, Weathering steel, in: R.W. Revie (Ed.), Uhlig's Corrosion Handbook, J. Wiley \& Sons, New York, 2000, pp. 569-580.

[2] H.R. Copson, Long-time atmospheric corrosion tests on low-alloy steels, Proc. ASTM 60 (1960) 1-16.

[3] C.P. Larrabee, S.K. Coburn, The atmospheric corrosion of steels as influenced by changes in chemical composition, Proc. $1^{\text {st }}$ International Congress on Metallic Corrosion, London, 1961, pp. 279-285.

[4] S. Feliu, M. Morcillo, Corrosión y Protección de los Metales en la Atmósfera, Bellaterra, Barcelona, 1982.

[5] V. Kucera, E. Mattsson, Atmospheric corrosion, in: F. Mansfeld (Ed.), Corrosion Mechanisms, Marcel Dekker, New York, 1987, pp. 211-284.

[6] C. Leygraf, T. Graedel, Atmospheric Corrosion, Electrochemical Society Series, J. Wiley \& Sons, New York, USA, 2000.

[7] I. Matsushima, Y. Ishizu, T. Ueno, M. Kanasashi, K. Horikawa, Effect of structural and environmental factors on the practical use of low-alloy weathering steel, Corros. Eng. 23 (1974) 177-182.

[8] M. Morcillo, B. Chico, I. Díaz, H. Cano, D. De la Fuente, Atmospheric corrosion data of weathering steels. A review, Corros. Sci. 77 (2013) 6-24.

[9] P. Albrecht, T.T. Hall, Atmospheric corrosion resistance of structural steels, J. Mater. Civil Eng. 15 (2003) 2-24.

[10] D.M. Buck, Copper in steel - The influence on corrosion, J. Ind. Eng. Chem. 5 (1913) 447-452.

[11] D.M. Buck, The influence of very low percentages of copper in retarding the corrosion of steel, Proc. ASTM (1919) 224-235.

[12] C.P. Larrabee, Report of subcommittee XIV on inspection of black and galvanized sheets, Proc. ASTM 54 (1954) 110-122.

[13] V.V. Kendall, E.S. Taylerson, A critical study of the ASTM corrosion data on uncoated commercial iron and steel sheets, Proc. ASTM 29 Part II (1929) 204-219.

[14] H.R. Copson, Atmospheric corrosion of low alloy steels, Proc. ASTM 52 (1952) 10051026.

[15] J.W. Stewart, J.A. Charles, E.R. Wallach, Iron-phosphorus-carbon system: Part I Mechanical properties of low carbon iron-phosphorus alloys, Mater. Sci. Tech-Lond. 16 (2000) 275-282.

[16] V. Raghavan, C-Fe-P (Carbon - Iron - Phosphorus), J. Phase Equilib. Diff. 25 (2004) 541542.

[17] D.M. Buck, Recent progress in corrosion resistance, Iron Age (1915) 1231-1239.

[18] C.P. Larrabee, Corrosion resistance of high-strength low-alloy steels as influenced by composition and environment, Corrosion (NACE) 9 (1953) 259-271.

[19] D. Fyfe, C.E.A. Shanahan, L.L. Shreir, Atmospheric corrosion of Fe-Cu alloys and Cucontaining steels, Corros. Sci. 10 (1970) 817-830.

[20] J.B. Horton, The rusting of low-alloy steels in the atmosphere, Regional Technical Meeting of American Iron and Steel Institute, San Francisco, Nov. 1965, pp. 1-24. 
[21] C. Carius, Knowledge of the corrosion process of copper-bearing steels, Z. Metallkunde 22 (1930) 337-341.

[22] N.D. Tomashov, Atmospheric corrosion of metals, in: B.H. Tytell, I. Geld,H.S. Preiser (Eds.), Theory of Corrosion and Protection of Metals, The Macmillan Company, New York, 1966, pp. 367-398.

[23] H.R. Copson, A theory of the mechanism of rusting of low-alloy steels in the atmosphere, Proc. ASTM 45 (1945) 554-580.

[24] M. Herzog, Aciers faiblement alliés résistant à la corrosion, La Metallurgie 92 (1960) 915.

[25] W.K. Boyd, Corrosion of metals in the atmosphere, in: Metals and Ceramics Information Center, Columbus, 1974, pp. 1-18.

[26] ASTM A-242 / A-242M-04, Standard specification for high-strength low-alloy structural steel, American Society for Testing and Materials, Philadelphia, 2007.

[27] D. Knotkova, J. Vlckova, J. Honzak, Atmospheric corrosion of weathering steels, in: S.W. Dean Jr., E.C. Rhea (Eds.), Atmospheric Corrosion of Metals, ASTM STP 767, American Society for Testing and Materials, 1982, pp. 7-44.

[28] I. Diaz, H. Cano, B. Chico, D. De la Fuente, M. Morcillo, Some clarifications regarding literature on atmospheric corrosion of weathering steels, International Journal of Corrosion ID 812192 (2012) 1-9.

[29] J. Aramendia, L. Gomez-Nubla, I. Arrizabalaga, N. Prieto-Taboada, K. Castro, J.M. Madariaga, Multianalytical approach to study the dissolution process of weathering steel: the role of urban pollution, Corros. Sci. 76 (2013) 154-162.

[30] Technical Report: Guideline for designing and construction of bridges by weathering steel, Kozai Club (Ed.), Tokyo, 1993.

[31] Corrosion control, in: L.L. Shreir, R.A. Jarman, G.T. Burstein (Eds.), Corrosion, third ed. vol. 2, Butterworth-Heinemann, Oxford, 1994, pp. 19:53-19:57.

[32] K.A. Chandler, M.B. Kilcullen, Corrosion-resistant low-alloy steels: a review with particular reference to atmospheric conditions in the United Kingdom, Brit. Corros. J. 5 (1970) 24-32.

[33] ASTM G 60-01, Standard practice for conducting cyclic humidity - exposures, American Society for Testing and Materials, Philadelphia, 2007.

[34] ISO 16701, Corrosion of metals and alloys. Corrosion in artificial atmosphere. Accelerated corrosion test involving exposure under controlled conditions of humidity cycling and intermittent spraying of a salt solution, International Standard Organization, Geneve, 2003.

[35] F.L. LaQue, Corrosion testing, Proceedings ASTM 51 (1951) 495-582.

[36] Ch. Thee, L. Hao, J. Dong, X. Mu, X. Wei, X. Li, W. Ke, Atmospheric corrosion monitoring of a weathering steel under an electrolyte film in cyclic wet-dry condition, Corros. Sci. 78 (2014) 130-137.

[37] P. Montoya, I. Díaz, N. Granizo, D. De la Fuente, M. Morcillo, A study on accelerated corrosion testing of weathering steel, Mater. Chem. Phys. 142 (2013) 220-228.

[38] ISO 3231, Paint and Varnishes - Determination of resistance to humid atmospheres containing sulphur dioxide, International Standard Organization, Geneve,1993. 
[39] ISO 6988, Metallic and other non organic coatings e sulphur dioxide test with general condensation of moisture, International Standard Organization, Geneve, 1985.

[40] L.A. Roudabush, D.C. McCune, H.E. Townsend, Update on the development of an improved cosmetic corrosion test by automotive and steel industries, in: G.S. Haynes (Ed.), Cyclic Cabinet Corrosion Testing, ASTM STP 1238, ASTM International, West Conshohocken, PA, 1995, pp. 61-80.

[41] M. Pourbaix, Une method electrochimique rapide de predeterminatión de la corrosion atmospherique, CEBELCOR RT 160, Vol. 109, Brussels, 1969.

[42] M. Pourbaix, J. van Muylder, A. Pourbaix, J. Kissel, Application of an electrochemical wet and dry method for atmospheric corrosion testing, CEBELCOR RT 259, Brussels, 1980.

[43] M. Pourbaix, J. van Muylder, A. Pourbaix, J. Kissel, An electrochemical wet and dry method for atmospheric corrosion, in: W.H. Ailor (Ed.), Atmospheric Corrosion, John Wiley \& Sons, New York, 1982, pp. 167-177

[44] L.R. de Miranda, Les aspects electrochimiques de la corrosion atmospherique des acers patinables, CEBELCOR RT 221, Vol. 125, Brussels, 1974, pp. 1-147.

[45] F. Bolivar, A. Morales, C. Arroyave, Simulation of a long term atmospheric corrosion process on plain and weathering steels, Rev. Metal. Madrid, Vol. Extr. (2003) 265-269.

[46] L.M. Ocampo, I.C.P. Margarit, O.R. Mattos, Velocidad de corrosión de aceros de baja aleación en varios tipos de ensayos: de campo y de laboratorio, International Workshop on Atmospheric Corrosion and Weathering Steels, Cartagena de Indias, Colombia, 2004, pp. 58-59.

[47] K.F. Garcia, A.L. Morales, C.A. Barrero, C. Arroyave, J.M. Greneche, Rust formation in weathering and carbon steels exposed to chloride rich environments, International Workshop on Atmospheric Corrosion and Weathering Steels, Cartagena de Indias, Colombia, 2004, pp. 21-22.

[48] L. Ocampo, Influencia dos elementos do liga na corrosao de aços patinaveis, Ph. Thesis, Universidade Federal RJ, Rio de Janeiro, 2005.

[49] C. Arroyave, M. Morcillo, Atmospheric corrosion products in iron and steels, Trends in Corros. Res. 2 (1997) 1-16.

[50] R. M. Cornell and U. Schwertmann, Iron Oxides in the Laboratory: Preparation and Characterization, Wiley-VCH, Weinheim, 1991.

[51] M. Morcillo, D. de la Fuente, I. Díaz, H. Cano, Atmospheric corrosion of mild steel, Rev. Metal. Madrid 47 (2011) 426-444.

[52] J.E. Hiller, Phasenumwandlungen im rost, Werkst. Korros. 17 (1966) 943-951.

[53] H. Schwarz, Über die wirkung des magnetits beim atmosphärischen rosten und beim unterrosten von anstrichen, Werkst. Korros. 23 (1972) 648-663.

[54] A.K. Singh, T. Ericsson, L. Häggström, J. Gullman, Mössbauer and x-ray diffraction phase analysis of rusts from atmospheric test sites with different environments in Sweden, Corros. Sci. 25 (1985) 931-945.

[55] P. Keller, Occurrence, formation and phase transformation of $\beta-\mathrm{FeOOH}$ in rust, Werkst. Korros. 20 (1969) 102-108.

[56] R.A. Antunes, J. Costa, D.L Araujo, Characterization of atmospheric corrosion products formed on steels, Mater. Res. 6 (2003) 403. 
[57] S. Nasrazadani, A. Raman, Formation and transformation of magnetite $\left(\mathrm{Fe}_{3} \mathrm{O}_{4}\right)$ on steel surfaces under continuous and cyclic water fog test, Corrosion, 49 (1993) 294-300.

[58] D. de la Fuente, I. Díaz, J. Simancas, B. Chico, M. Morcillo, Long-term atmospheric corrosion of mild steel, Corros. Sci. 53 (2011) 604-617.

[59] H. Baum, U. Rasemann, K. Rössler, S. Böhmer, E. Kunze, Untersuchungen zum mechanismus der deckschichtbildu ng auf korrosionstraegen staehlen, Neue Hütte 19 (1974) 423-429.

[60] P. Dillmann, F. Mazaudier, S. Hoerlé, Advances in understanding atmospheric corrosion of iron. I. Rust characterization of ancient ferrous artefacts exposed to indoor atmospheric corrosion, Corros. Sci. 46 (2004) 1401-1429.

[61] J.F. Marco, M. Gracia, J.R. Gancedo, M.A. Martín-Luengo, G. Joseph, Characterization of the corrosion products formed on carbon steel after exposure to the open atmosphere in the Antartic and Easter Island, Corros. Sci. 42 (2000) 753-771.

[62] H. Leidheiser Jr., I. Czakó-Nagy, A Mössbauer spectroscopic study of rust formed during simulated atmospheric corrosion, Corros. Sci. 24 (1984) 569-577.

[63] T. Misawa, K. Asami, K. Hashimoto, S. Shimodaira, Mechanism of atmospheric rusting and protective amorphous rust on low-alloy steel, Corros. Sci. 14 (1974) 279-289.

[64] A. Raman, B. Kuban, Infrared spectroscopic analysis of phase transformation processes in rust layers formed on weathering steels in bridge spans, Corrosion 44 (1988) 483488.

[65] H. Antony, S. Perrin, P. Dillmann, L. Legranda, A. Chausse, Electrochemical study of indoor atmospheric corrosion layers formed on ancient iron artefacts, Electrochim. Acta 52 (2007) 7754-7759

[66] J.R. Gancedo, M. Gracia, J.F. Marco, Análisis de productos de corrosión atmosférica, in: M. Morcillo, S. Feliu (Eds.), Mapas de España de Corrosividad Atmosférica, CYTED, Madrid, 1993, pp. 343-361.

[67] D.C. Cook, Spectroscopic identification of protective and non-protective corrosion coatings on steel structures in marine environments, Corros. Sci. 47 (2005) 2550-2570.

[68] R.M. Cornell, U. Schwertmann, The Iron Oxides, VCH, Weinheim, 1996.

[69] M. Yamashita, H. Miyuki, Y. Matsuda, H. Nagano, The long term growth of the protective rust layer formed on weathering steel by atmospheric corrosion during a quarter of a century, Corros. Sci. 36 (1994) 283-299.

[70] S.J. Oh, D.C. Cook, H.E. Townsend, Atmospheric corrosion of different steels in marine, rural and industrial environments, Corros. Sci. 41 (1999) 1687-1702.

[71] J. Monnier, D. Neff, S. Reguer, P. Dillman, L. Bellot-Gurlet, E. Leroy, E. Foy, L. Legrand, J. Guillot, A corrosion study of the ferrous medieval reinforcement of the Amiens cathedral. Phase characterisation and localisation by various microprobes techniques, Corros. Sci. 52 (2010) 695-710.

[72] D.L.A. de Faria, S.V. Silva, M.T. de Oliveira, Raman microspectroscopy of some iron oxides and oxyhydroxides, J. Raman Spectrosc. 28(1997) 873-878.

[73] D. Neff, S. Reguer, L. Bellot-Gurlet, P. Dillmann, R. Bertholm, Structural characterization of corrosion products on archaeological iron: an integrated analytical approach to stablish corrosion forms, J. Raman Spectrosc. 35 (2004) 739-795. 
[74] D. Neff, L. Bellot-Gurlet, P. Dillmann, S. Reguer, L. Legrand, Raman imaging of ancient rust scales on archaeological iron artefacts for long-term atmospheric corrosion mechanisms study, J. Raman Spectrosc. 37 (2006) 1228-1237.

[75] B.R. de Meybaum, E. Ayllon, Urban-industrial corrosion of a weathering steel, in: W.H. Ailor (Ed.), Atmospheric Corrosion, The Electrochemical Society, John Wiley and Sons, New York, 1982, pp. 415-422.

[76] B.R. de Meybaum, E. Ayllon, Atmospheric marine corrosion of structural steels, in: W.H. Ailor (Ed.), Atmospheric Corrosion, The Electrochemical Society, John Wiley and Sons, New York, 1982, pp. 423-430.

[77] X. Chen, X. Wang, Q. Liu, F. Mi, Y. Chen, Y. Li, Effect of micro-area pH value on formation of different rust phases of weathering steel in initial corrosion period, J. Iron Steel Res. Int. 17 (2010) 69-72,78.

[78] W.H.J. Vernon, Second experimental report to the atmospheric corrosion research committee (British non-ferrous metal research association), Trans. Faraday Soc. 23 (1927) 113-183.

[79] W.H.J. Vernon, A laboratory study of the atmospheric corrosion of metals. Part I. - The corrosion of copper in certain synthetic atmospheres, with particular reference to the influence of sulphur dioxide in air of various relative humidities, Trans. Faraday Soc. 27 (1931) 255-277.

[80] W.H.J. Vernon, First experimental report to the atmospheric corrosion research committee (British non-ferrous metals research association), Trans. Faraday Soc. 19 (1924) 839-845.

[81] W.H.J. Vernon, A laboratory study of the atmospheric corrosion of metals. Part II. Iron: The primary oxide film. Part III. The secondary product or rust (Influence of sulphur dioxide, carbon dioxide, and suspended particles on the rusting of iron), Trans. Faraday Soc. 31 (1935) 1668-1700.

[82] K. Park, Corrosion resistance of weathering steels, Ph. Thesis, Department of Civil and Environmental Engineering, University of Maryland, USA, 2004.

[83] G. Schikorr, On the mechanism of atmospheric corrosion of iron, Werkst. Korros. 14 (1963) 63-80.

[84] K. Barton, Protection Againts Atmospheric Corrosion, Wiley and Sons, London, 1976.

[85] U.R. Evans, C.A.J. Taylor, Mechanism of atmospheric rusting, Corros. Sci. 12 (1972) 227-246.

[86] J.B. Horton, The mechanism of rusting of low alloy steels in the atmosphere, unpublished M.S. Thesis, Lehigh University, Bethlehem, 1957.

[87] J.B. Horton, The composition, structure and growth of the atmocpheric rust on various steels, Ph. Thesis, Lehigh University, Bethlehem, 1964.

[88] J.B. Horton, The rusting of low-alloy steels, Bethlehem Steel Publication 2385-A (1971) 13-16.

[89] U.R. Evans, The economic advantages of a sound painting scheme, T. I. Met. Finish. 37 (1960) 1-7.

[90] U.R. Evans, Electrochemical mechanism of atmospheric rusting, Nature 206 (1965) 980-982.

[91] U.R. Evans, Mechanism of rusting, Corros. Sci. 9 (1969) 813-821. 
[92] H. Okada, Y. Hosoi, K. Yukawa, H. Naito, Structure of the protective and decirative rust formed on low-alloy steels in the atmosphere, Trans. ASM 62 (1969) 278-281.

[93] H. Okada, Y. Hosoi, K. Yukawa, H. Naito, Structure of the rust formed on low alloy steels in atmospheric corrosion, J. Iron Steel Institute Japan 55 (1969) 355-365.

[94] H. Okada, Y. Hosoi, K. Yukawa, H. Naito, The protective rust layer formed on low alloy ateels in atmospheric corrosion, Proc. $4^{\text {th }}$ International Congress on Metallic Corrosion, Amsterdam, 1969, pp. 392-398.

[95] H. Okada, Y. Hosoi, H. Naito, Electrochemical reduction of thick rust layers formed on steel surfaces, Corrosion (NACE) 26 (1970) 429-430.

[96] I. Diaz, Corrosión atmosférica de aceros patinables de nueva generación, Ph. Thesis, Universidad Complutense, Madrid, 2012.

[97] I. Matsushima, T. Ueno, On the protective nature of atmospheric rust on low-alloy steel, Corros. Sci. 11 (1971) 129-140.

[98] T. Misawa, Y. Kyuno, W. Suëtaka, S. Shimodaira, The mechanism of atmospheric rusting and the effect of $\mathrm{Cu}$ and $\mathrm{P}$ on the rust formation of low-alloy steels, Corros. Sci. 11 (1971) 35-48.

[99] T. Misawa, The thermodynamic consideration for $\mathrm{Fe}^{-} \mathrm{H}_{2} \mathrm{O}$ system at 25 으, Corros. Sci. 13 (1973) 659-676.

[100] T. Misawa, K. Hashimoto, S. Shimodaira, The mechanism of formation of iron oxide and oxy-hydroxides in aqueous solutions at room temperature, Corros. Sci. 14 (1974) 131-149.

[101] M. Stratmann, K. Bohnenkamp, H.J. Engell, An electrochemical study of phasetransitions in rust layers, Corros. Sci. 23 (1983) 969-985.

[102] M. Stratmann, K. Bohnenkamp, T. Ramchandran, The influence of copper upon the atmospheric corrosion of iron, Corros. Sci. 27 (1987) 905-926.

[103] M. Stratmann, J. Müller, The mechanism of the oxygen reduction on rust-covered metal substrates, Corros. Sci. 36 (1994) 327-359.

[104] M. Stratmann, H. Streckel, On the atmospheric corrosion of metals which are covered with thin electrolyte layers-I. Verification of the experimental technique, Corros. Sci. 30 (1990) 681-696.

[105] M. Stratmann, H. Streckel, On the atmospheric corrosion of metals which are covered with thin electrolyte layers - II. Experimental results, Corros. Sci. 30 (1990) 697-714.

[106] M. Stratmann, H. Streckel, K.T. Kim, S. Crockett, On the atmospheric corrosion of metals which are covered with thin electrolyte layers - III. The measurement of polarisation curves on metal surfaces which are covered by thin electrolyte layers, Corros. Sci. 30 (1990) 715-734.

[107] M. Stratmann, The atmospheric corrosion of iron steel, Metal Odlew 16 (1990) 46-52.

[108] M. Stratmann, K. Hoffmann, In situ Mössbauer spectroscopy study of reactions within rust layers, Corros. Sci. 29 (1989) 1329-1352.

[109] H. Antony, S. Peulon, L. Legrand, A. Chausse, Electrochemical synthesis of lepidocrocite thin films on gold substrate - EQCM, IRRAS, SEM and XRD study, Electrochim. Acta 50 (2004) 1015-1021. 
[110] H. Antony, L. Legrand, L. Maréchal, S. Perrin, Ph. Dillmann, A. Chaussé, Study of lepidocrocite $\gamma$-FeOOH electrochemical reduction in neutral and slightly alkaline solutions at $25^{\circ} \mathrm{C}$, Electrochim. Acta 51 (2005) 745-753.

[111] V. Lair, H. Antony, L. Legrand, A. Chausse, Electrochemical reduction of ferric corrosion products and evaluation of galvanic coupling with ion, Corros. Sci. 48 (2006) 20502063.

[112] S. Hoerle, F. Mazaudier, Ph. Dillmann, G. Santarini, Advances in understanding atmospheric corrosion or iron. II. Mechanistic modeling of wet-dry cycle, Corros. Sci. 46 (2004) 1431-1465.

[113] E. Burger, M. Fenart, S. Perrin, D. Neff, P. Dillmann, Use of the gold markers method to predict the mechanisms of iron atmospheric corrosion, Corros. Sci. 53 (2011) 21222130.

[114] J. Monnier, E. Burger, P. Berger, D. Neft, I. Guillot, P. Dillmann, Localisation of oxygen reduction sites in the case of iron long term atmospheric corrosion, Corros. Sci. 53 (2011) 2468-2473.

[115] J. Monnier, S. Reguer, E. Foy, D. Testemale, F. Mirambet, M. Saheb, P. Dillmann, I. Guillot, XAS and XRD in situ characterisation of reduction and reoxidation processes of iron corrosion products involved in atmospheric corrosion, Corros. Sci. 78 (2014) 293303.

[116] H. Kihira, S. Ito, T. Murata, The behavior of phosphorus during passivation of weathering steel by protective patina formation, Corros. Sci. 31 (1990) 383-388.

[117] T. Misawa, Corrosion science in rusting of iron and weathering steel, Boshoku Gijutsu 37 (1988) 501-506.

[118] M. Yamashita, H. Miyuki, H. Nagano, T. Misawa, Compositional gradient and ion selectivity in $\mathrm{Cr}$ substituted goethite consisting the final stable protective rust layer on a weathering steel, Proc. $13^{\text {th }}$ International Corrosion Congress, Melbourne, 1996, Paper 020.

[119] M. Yamashita, H. Uchida, Recent research and development in solving atmospheric corrosion problems of steel industries in Japan, Hyperfine Interact. 139/140 (2002) 153-166.

[120] H.E. Townsend, T.C. Simpson, F.L. Johnson, Structure of rust on weathering steel in rural and industrial environments, Proc. $12^{\text {th }}$ International Corrosion Congress, Houston, NACE International, 1993, pp. 624-641.

[121] M. Yamashita, H. Nagano, T. Misawa, H.E. Townsend, Structure of protective rust layers formed on weathering steels by long-term exposure in the industrial atmospheres of Japan and North America, ISIJ Int. 38 (1998) 285-290.

[122] D.C. Cook, S.J. Oh, R. Balasubramanian, M. Yamashita, The role of goethite in the formation of the protective corrosion layer on steels, Hyperfine Interact. 122 (1999) 59-70.

[123] A-588 / A-588M, Standard specification for high-strength low alloy structural steel with $50 \mathrm{ksi}$ [345 MPa] minimum yield point to 4-in. [100 mm] thick, American Society for Testing and Materials, Philadelphia, 2005.

[124] M. Yamashita, T. Misawa, Recent progress in the study of protective rust-layer formation on weathering steel, Proc. Corrosion' 98, San Diego, 1998, Technical publication 357. 
[125] M. Yamashita, H. Konishi, J. Mizuki, H. Uchida, Nanostructure of protective rust layer on weathering steel exposed for 17 years examined by using synchrotron radiation, Proc. $15^{\text {th }}$ International Corrosion Congress, Granada, 2002.

[126] M. Yamashita, T. Shimizu, H. Konishi, J. Mizuki, H. Uchida, Structure and protective performance of atmospheric corrosion product of $\mathrm{Fe}-\mathrm{Cr}$ alloy film analyzed by Mössbauer spectroscopy and with synchrotron radiation X-rays, Corros. Sci. 45 (2003) 381-394.

[127] M. Kimura, T. Suzuki, G. Shigesato, H. Kihira, S. Suzuki, Characterization of nanostructure of rusts formed on weathering steel, ISIJ Int. 41 (2002) 1534-1540.

[128] S. Suzuki, M. Saito, M. Kimura, T. Suzuki, H. Kihira, Y. Waseda, A new method for describing the atomic-scale structure of rusts formed on the iron based alloy surfaces, ISIJ Int. 43 (2003) 366-372.

[129] K. Asami, M. Kikuchi, Characterization of rust layers on weathering steels air-exposed for a long period, Mater. Trans. 43 (2002) 2818-2825.

[130] K. Asami, M. Kikuchi, In-depth distribution of rusts on a plain carbon steel and weathering steels exposed to coastal-industrial atmosphere for 17 years, Corros. Sci. 45 (2003) 2671-2688.

[131] T. Kamimura, S. Hara, H. Miyuki, M. Yamashita, H. Uchida, Composition and protective ability of rust layer formed on weathering Steel exposed to various environments, Corros. Sci. 48 (2006) 2799-2812.

[132] S. Hara, T. Kamimura, H. Miyuki, M. Yamashita, Taxonomy for protective ability of rust layer using its composition formed on weathering steel bridge, Corros. Sci. 49 (2007) 1131-1142.

[133] J. Monnier, P. Dillmann, L. Legrand, I. Guillot, Corrosion of iron from heritage buildings: proposal for degradation indexes based on rust layer composition electrochemical reactivity, Corros. Eng. Sci. Technol. 45 (2010) 375-380.

[134] R. Balasubramanian, On the corrosion resistance of the Delhi iron pillar, Corros. Sci. 42 (2000) 2103-2129.

[135] R. Balasubramanian, A.V.R. Kumar, Characterization of Delhi iron pillar rust by X-ray diffraction, Fourier transform infrared spectroscopy and Mössbauer spectroscopy, Corros. Sci. 42 (2000) 2085-2101.

[136] R. Balasubramanian, A.V.R. Kumar, Corrosion resistance of the Dhar iron pillar, Corros. Sci. 45 (2003) 2451-2465.

[137] P. Dillmann, R. Balasubramanian, G. Beranger, Characterization of protective rust on ancient Indian iron using micropobe analyses, Corros. Sci. 44 (2002) 2451-2465.

[138] J. Monnier, D. Vantelon, S. Reguer, P. Dillmann, X-ray absorption spectroscopy study of the various forms of phosphorus in ancient iron samples, J. Anal. At. Spectrom. 26 (2011) 885-891.

[139] H. Schwitter, H. Bohni, Influence of accelerated weathering on the corrosion of lowalloy steels, J. Electrochem. Soc. 127 (1980) 15-20.

[140] I. Suzuki, Y. Hisamatsu, N. Masuko, Nature of atmospheric rust on iron, J. Electrochem. Soc. 127 (1980) 2210-2215.

[141] T. Kamimura, M. Stratmann, The influence of chromium on the atmospheric corrosion of steel, Corros. Sci. 43 (2001) 429-447. 
[142] M. Kimura, H. Kihira, N. Ohta, M. Hashimoto, T. Senuma, Control of Fe $(\mathrm{O}, \mathrm{OH})_{6}$ nano-network structures of rust for high atmospheric-corrosion resistance, Corros. Sci. 47 (2005) 2499-2509.

[143] X. Chen, J. Dong, E. Han, W. Ke, Effect of Ni on the ion-selectivity of rust layer on low alloy steel, Mater. Lett. 61 (2007) 4050-4053.

[144] Y. Paul Virmani, Improved corrosion-resistant steel for highway bridge construction knowledge-based design, U.S. Department of Transportation, Federal Highway Administration, Techbrief., 2009.

[145] W.T. Hou, C.F. Liang, Effects of alloying on atmospheric corrosion of steels, in: H.E. Townsend (Ed.), Outdoor Atmospheric Corrosion, ASTM STP 1421, American Society for Testing and Materials, West Conshohocken, 2002, pp. 368-377.

[146] L. Hao, S. Zhang, J. Dong, W. Ke, Atmospheric corrosion resistance of Mn Cu P weathering steel in simulated environments, Corros. Sci. 53 (2011) 4187-4192.

[147] G.P. Zhou, Z.Y. Liu, Y.Q. Qiu, G.D. Wang, The improvement of weathering resistance by increasing P contents in cast strips of low carbon steels, Mater. Design 30 (2009) $4342-4347$.

[148] J.A. Mejía Gómez, J. Antonissen, C.A. Palacio, E. de Grave, Effects of Si as alloying element on corrosion resistance of weathering Steel, Corros. Sci. 59 (2012) 198-203.

[149] J.A. Mejía Gómez, V.G. de Rosende, J. Antonissen, E. de Grave, Characterization of the effects of silicon on the formation of goethite, Corros. Sci. 53 (2011) 1756-1761.

[150] X. Chen, J. Dong, E. Han, W. Ke, Synergistic effect of $\mathrm{Cu}$ and Ni on atmospheric corrosion resistance for low alloying steel in wet/dry cyclic industrial environment, Proc. $17^{\text {th }}$ International Corrosion Congress, Las Vegas, 2009, Paper 3201.

[151] Y. Qian, C. Ma, D. Niu, J. Xu, M. Li, Influence of alloyed chromium on the atmospheric corrosion resistance of weathering steels, Corros. Sci. 74 (2013) 424-429.

[152] Y.H. Qian, D. Niu, J.J. Xu, M.S. Li, The influence of chromium content on the electrochemical behavior of weathering steels, Corros. Sci. 71 (2013) 72-77.

[153] T. Nakayama, T. Ishikawa, T.J. Konno, Structure of titanium-doped goethite rust, Corros. Sci. 47 (2005) 2521-2530.

[154] B. Wang, D. Wang, C. Liu, M. Jiang, Effect of nitrogen on electrochemical behaviour of weathering steel in corrosion solution simulated industrial atmosphere, Proc. SinoSwedish Structural Materials Symposium, Beijing, 2007, pp. 350-354.

[155] Y.T. Zhao, S.W. Yang, H. Guo, X.M. Wang, C.J. Shang, X.L. He, Rust layer structure and corrosion resistance of high strength microalloyed steels, Mater. Sci. Forum 539-543 (2007) 4774-4779.

[156] E.S. Ayllón, Special weathering steel, a contribution to environmental protection, WIT Trans. Eng. Sci. 54 (2007) 329-338.

[157] L. Yue, L. Wang, J. Han, Effects of rare earth on inclusion and corrosion resistance of 10PCURE weathering steel, J. Rare Earth. 28 (2010) 952-956.

[158] F. Mi, X. Wang, Z. Liu, B. Wang, Y. Peng, D. Tao, Industrial atmospheric corrosion resistance of P-RE weathering steel, J. Iron Steel Res. Int. 18 (2011) 67-73.

[159] Y.T. Zhao, S.W. Yang, C.J. Shang, X.M. Wang, W. Liu, X.L. He, The mechanical properties and corrosion behaviors of ultra-low carbon microalloying steel, Mater. Sci. Eng. A 454-455 (2007) 695-700. 
[160] Z.F. Wang, P.H. Li, Y. Guan, Q.F. Chen, S.K. Pu, The corrosion resistance of ultra-low carbon bainitic steel, Corros. Sci. 51 (2009) 954-961.

[161] J. Guo, C.J. Shang, S.W. Yang, H. Guo, X.M. Wang, X.L. He, Weather resistance of low carbon high performance bridge steel, Mater. Design 30 (2009) 129-134.

[162] K. Gao, D. Li, X. Pang, S. Yang, Corrosion behaviour of low-carbon bainitic steel under a constant elastic load, Corros. Sci. 52 (2010) 3428-3434.

[163] J. Guo, S. Yang, C. Shang, Y. Wang, X. He, Influence of carbon content and microstructure on corrosion behaviour of low alloy steels in a $\mathrm{Cl}^{-}$containing environment, Corros. Sci. 51 (2009) 242-251.

[164] M. Morcillo, B. Chico, E. Otero, L. Mariaca, Effect of marine aerosol on atmospheric corrosion, Mater. Performance april (1999) 72-77.

[165] T. Kamimura, S. Nasu, T. Segi, T. Tazaki, H. Miyuki, S. Morimoto, T. Kudo, Influence of cations and anions on the formation of $\beta-\mathrm{FeOOH}$, Corros. Sci. 47 (2005) 2531-2542.

[166] T. Nishimura, H. Katayama, K. Noda, T. Kodama, Electrochemical behavior of rust formed on carbon steel in a wet/dry environment containing chloride ions, Corrosion (NACE) 56 (2000) 935-941.

[167] A. Usami, T. Kusunoki, H. Kihira, 3\%-Ni weathering steel plate for uncoated bridges at high airborne salt environment, Nippon Steel Technical Report No. 87, 2003, 21-23.

[168] Z. Wang, J. Liu, L. Wu, R. Han, Y. Sun, Study of the corrosion behavior of weathering steels in atmospheric environments, Corros. Sci. 67 (2013) 1-10.

[169] Q.X. Li, Z.Y. Wang, W. Han, E.H. Han, Characterization of the rust formed on weathering steel exposed to Quinghai salt lake atmosphere, Corros. Sci. 20 (2008) 365371.

[170] S. Hara, M. Miura, Y. Uchiumi, T. Fujiwara, M. Yamamoto, Suppression of deicing salt corrosion of weathering steel bridges by washing, Corros. Sci. 47 (2005) 2419-2430.

[171] L. Hao, S. Zhang, J. Dong, W. Ke, Evolution of corrosion of MnCuP weathering steel submitted to wet/dry cyclic tests in a simulated coastal atmosphere, Corros. Sci. 58 (2012) 175-180.

[172] L. Hao, S. Zhang, J. Dong, W. Ke, Evolution of atmospheric corrosion of MnCuP weathering steel in a simulated coastal-industrial atmosphere, Corros. Sci. 59 (2012) 270-276.

[173] M. Itagaki, R. Nozue, K. Watanabe, H. Katayama, K. Noda, Electrochemical impedance of thin rust film of low-alloy steels, Corros. Sci. 46 (2004) 1301-1310.

[174] T. Nishimura, H. Qiu, K. Hiraoka, Characteristics of ultrafine weathering steel, Steel Research Centre, National Institute for Materials Science, Tsukuba, July 20-21, 2005.

[175] T. Nishimura, Rust formation and corrosion performance of Si- and Al-bearing ultrafine grained weathering steel, Corros. Sci. 50 (2008) 1306-1312.

[176] T. Nishimura, Structure of the rust on aluminum bearing steel after the exposure test, J. Jpn I. Met. 71 (2007) 905-915.

[177] Q. Zhang, J. Wu, W. Zheng, J. Wang, J. Chen, X. Yang, A. Li, Characterization of rust layer formed on low alloy steel exposed in marine atmosphere, J. Mater. Sci. Technol. 18 (2002) 455-458.

[178] Q.C. Zhang, J.S. Wu, J.J. Wang, W.L. Zheng, J.G. Chen, A.B. Li, Corrosion behavior of weathering steel in marine atmosphere, Mater. Chem. Phys. 77 (2002) 603-608. 
[179] M. Yamashita, H. Konishi, J. Mizuki, H. Uchida, Formation process and nanostrucuture of atmospheric rust layer on Fe-based binary alloys examined using Synchrotron Radiation X-Rays, Proc. $16^{\text {th }}$ International Corrosion Congress, Beijing, Chinese Society for Corrosion and Protection, 2005, paper 05-B-01.

[180] H. Kihira, S. Ito, S. Mizoguchi, T. Murata, A. Usami, K. Tanabe, Creation of alloy design concept for anti air-born salinity weathering steel, Zairyo- to -Kankyo 49 (2000) 30-40.

[181] Y. Ma, Y, Li, F. Wang, Weatherability of 09CuPCrNi steel in a tropical marine environment, Corros. Sci. 51 (2009) 1725-1732.

[182] A. Nishikata, Y. Yamashita, H. Katayama, T. Tsuru, A. Usami, K. Tanabe, H. Mabuchi, An electrochemical impedance study on atmospheric corrosion of steels in a cyclic wet-dry condition, Corros. Sci. 37 (1995) 2059-2069.

[183] M. Kimura, H. Kihira, M. Nomura, Y. Kitajima, Corrosion protection mechanism of the advanced weathering steel (Fe-3.0Ni-0.40Cu, mass\%) in a coastal area, Corrosion and Corrosion Control in Saltwater Environments II - Proc. International Symposium, Honolulu, PV 2004-14, 2005, pp. 133-142.

[184] H. Kihira, A. Usami, K. Tanabe, M. Ito, G. Shigesato, Y. Tomita, T. Kusunoki, T. Tsuzuki, S. Ito, T. Murata, Development of weathering steel for coastal atmosphere, International Symposium on Corrosion and Corrosion Control in Saltwater Environments, Honolulu, Hi, 99, 2000, pp. 127-136.

[185] H. Konishi, M. Yamashita, H. Uchida, J. Mizuki, X-ray absorption fine structure spectra of rust layers on Fe-based binary alloys exposed to $\mathrm{Cl}$-rich environment, Proc. $16^{\text {th }}$ International Corrosion Congress, Beijing, Chinese Society for Corrosion and Protection, 2005, paper 19-08.

[186] M. Yamashita, T. Yonezawa, H. Uchida, Corrosion current distributions in a low-alloy steel covered with a layer of rust formed under electrolyte thin films in a $\mathrm{NaCl}$ solution, J. Jpn I. Met. 63 (1999) 1332-1337.

[187] J.E. Post, V.F. Buchwald, Crystal-structure refinement of akaganeite, Am. Mineral. 76 (1991) 272-277.

[188] T. Mizoguchi, Y. Ishii, T. Okada, M. Kimura, H. Kihira, Magnetic property based characterization of rust on weathering steels, Corros. Sci. 47 (2005) 2477-2491.

[189] I. Sugimoto, K. Kito, Evaluation of applicability for Ni-advanced weathering steels and bridge high-performance steels to railway steel bridges, QR of RTRI 51 (2010) 33-37.

[190] R.F. Pasano, The harmony of outdoors weathering steels, Proc. Symposium on the Outdoor Weathering of Metals and Metallic Coatings, Washington Regional Meeting of ASTM, Philadelphia, 1934.

[191] I. Diaz, H. Cano, D. de la Fuente, B. Chico, J.M. Vega, M. Morcillo, Atmospheric corrosion of $\mathrm{Ni}$-advanced weathering steels in marine atmospheres of moderate salinity, Corrosion Science 76 (2013) 348-360. 


\section{FIGURE CAPTIONS}

Figure 1. Effect of the phosphorus and copper contents on atmospheric corrosion of steel exposed in the industrial atmospheres of Bayonne (left) and Kearny (right), during $9.1[2]$ and 15.5 [3] years respectively.

Figure 2. Effect of the copper content on corrosion of steel exposed during 15.5 years at different type of atmospheres [3].

Figure 3. Effect of the chromium and copper contents on corrosion of steel exposed during 18.1 years in an industrial atmosphere [2].

Figure 4. Effect of the chromium and copper contents on corrosion of steel exposed during 3.5 years in Kearny (industrial atmosphere) and Kure Beach (marine atmosphere) $[3,24]$.

Figure 5. Effect of the nickel content on corrosion of steel exposed during 15.5 years at the marine atmosphere of Kure Beach, $250 \mathrm{~m}$ [2].

Figure 6. Effect of the copper content in 1\% wt Ni weathering steel exposed during 15.5 years at Kearny (industrial atmosphere) and Kure Beach (marine atmosphere) [3].

Figure 7. Simplified diagram due to Park [82], showing the effect of relative humidity and pollution on the corrosion of mild steel [78-81].

Figure 8. Microscopic observation of cross section of 17-year old rust layer formed on Mayari-R (WS) at the industrial atmosphere of Rankin. Reproduced from a copy of the Fig. 19 in [87].

Figure 9. Simplified diagram of atmospheric rusting according to Horton's considerations [87].

Figure 10. Tentative suggestion for the electrochemical mechanism of atmospheric rusting according to Evans [91].

Figure 11. Schematic representation according to Okada et al. [92] of rust layers formed on plain carbon steel (left) and weathering steel (right) after exposure to atmosphere for long periods of time.

Figure 12. Schematic representation according to Misawa et al. [98] of rust layers formed on plain carbon steel (a) and weathering steel (b) after exposure to the atmosphere for long periods of time. 
Figure 13. Schematic representation according to Stratmann [107] of atmospheric rusting cyclic mechanism.

Figure 14. Schematic progress according to Yamashita [69] for a stable and protective rust layer formation on a weathering steel.

Figure 15. Raman spectra at several points with different distances from the rust/steel interface, $\Delta d$, both in the inner and outer rust layers formed on WS. The beam diameter was controlled to be approximately $2 \mu \mathrm{m}[118]$.

Figure 16. Mean values of the maximum crystal length of synthetic $\mathrm{Cr}$-substituted goethite as a function of $\mathrm{Cr}$ content. Data obtained by TEM observation [119].

Figure 17. The transport number of $\mathrm{Cl}^{-}, \mathrm{t}_{\mathrm{Cl}^{-}}$, as a function of $\mathrm{Cr}$ content in the synthetic $\mathrm{Cr}$ substituted goethite membrane. Data obtained by membrane potential measurements [118].

Figure 18. Schematic summary of the distribution of phases in WS protective rust. (a) Simple two layer structure, (b) irregular alternating band structure. $\mathrm{Cr}$ enrichment was found only in the goethite layer [121].

Figure 19. Long-term change in relative amounts of rust constituents on WS [119].

Figure 20. Relation between $\alpha / \gamma$ of the rust layer formed on weathering steel and exposure time (a) and corrosion rate (b). According to Yamashita and Misawa [124]

Figure 21. Corrosion versus time of $3 \% \mathrm{Ni}-0.4 \% \mathrm{Cu}$ advanced WS exposed in the marine atmosphere of Kimitsu and its comparison with conventional WS [142].

Figure 22. Influence of $\mathrm{Ni}$ addition amount in coastal weathering performance for $3 \% \mathrm{Ni}$ advanced WS after 9 years of exposure at Kimitsu ( $79 \mathrm{mg} \mathrm{Cl} / \mathrm{m}^{2}$ day) [142, 167, 183].

Figure 23. Guiding philosophy for design of protective rust layers having enhanced salt corrosion resistance (alkalization of rust interface by control of ion exchanging function of rust layers) [184]. 

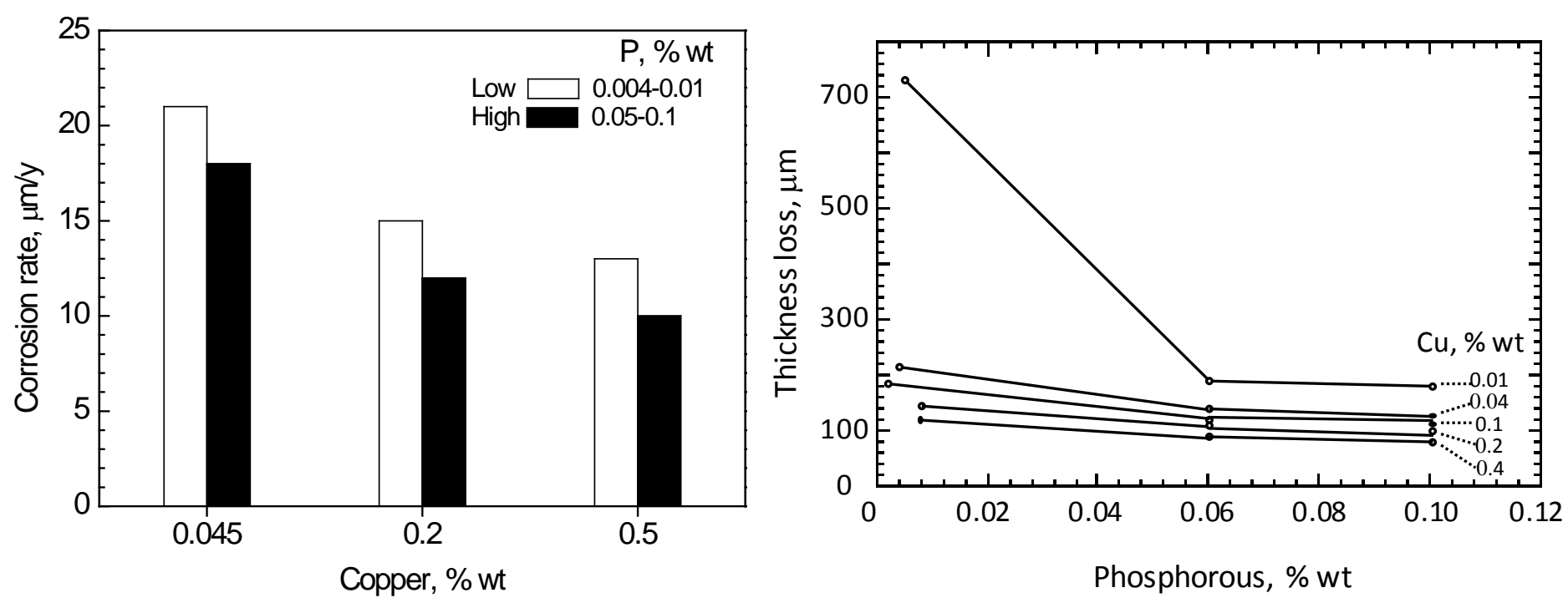

Figure 1 


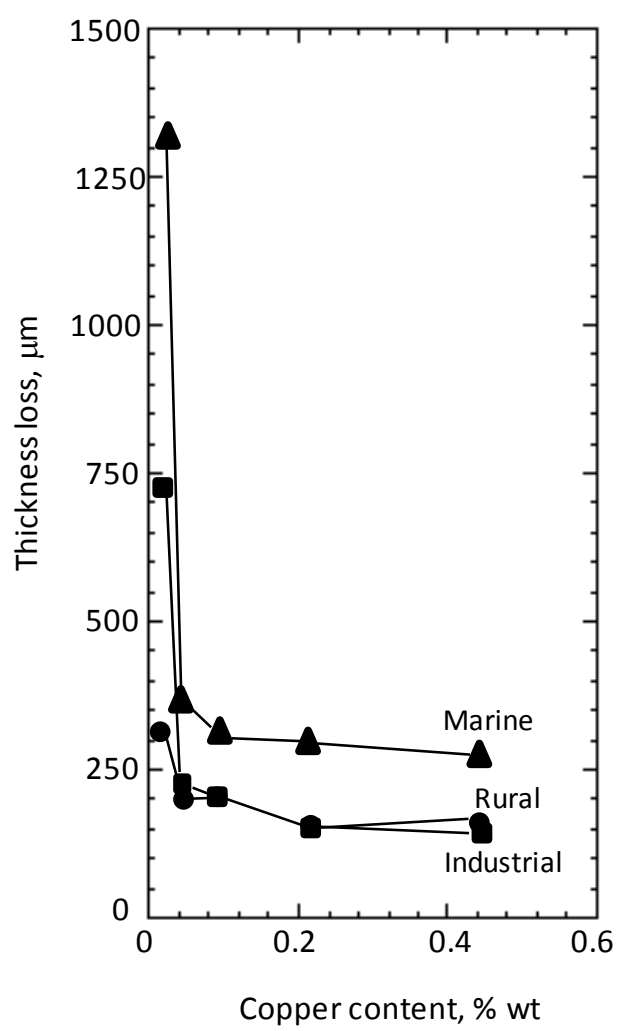

Figure 2 


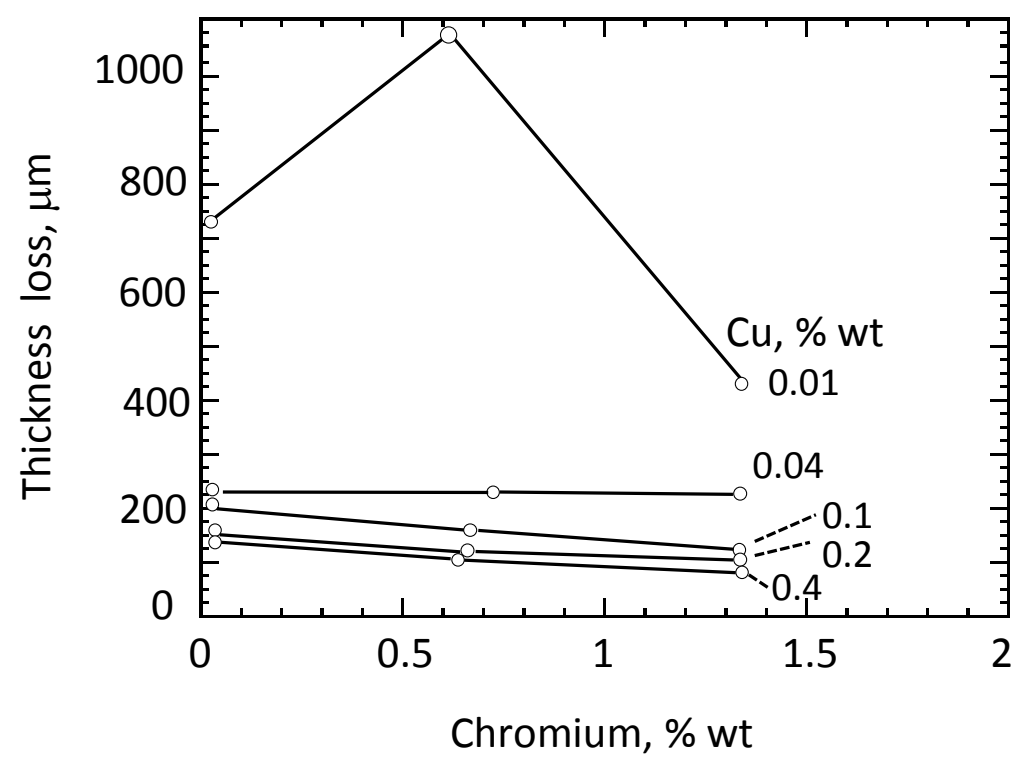

Figure 3 


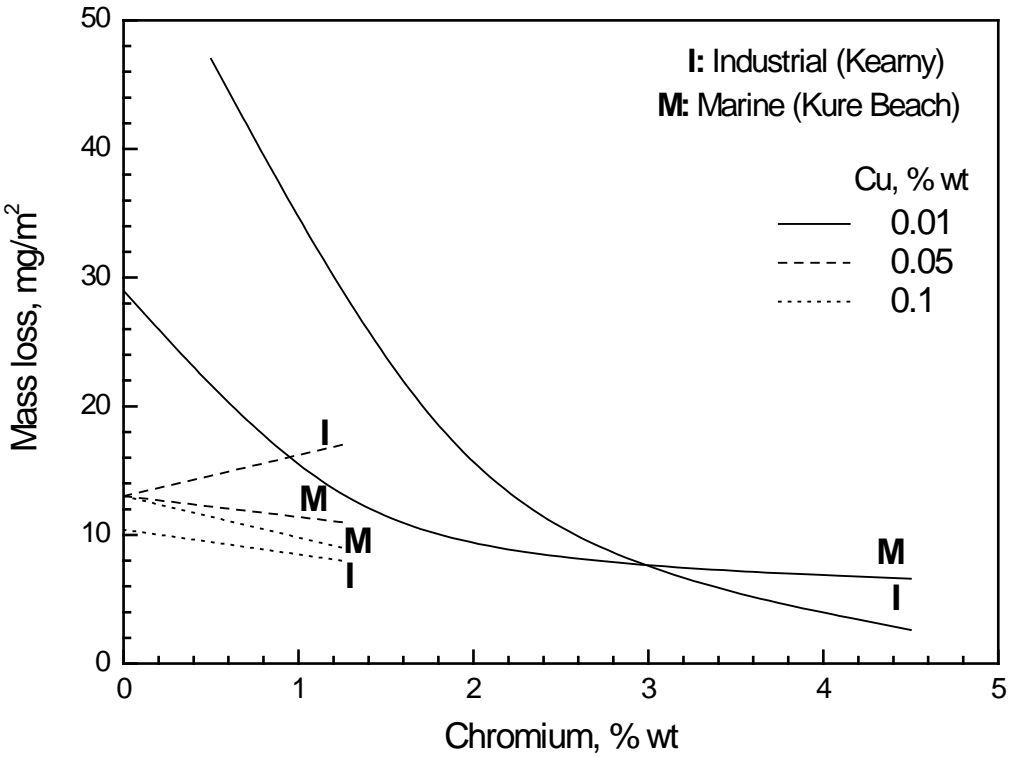

Figure 4 


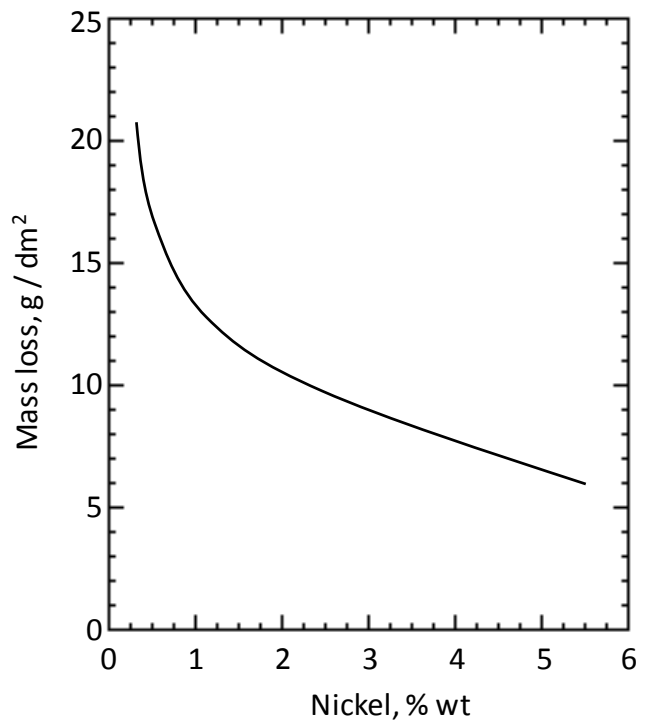

Figure 5 


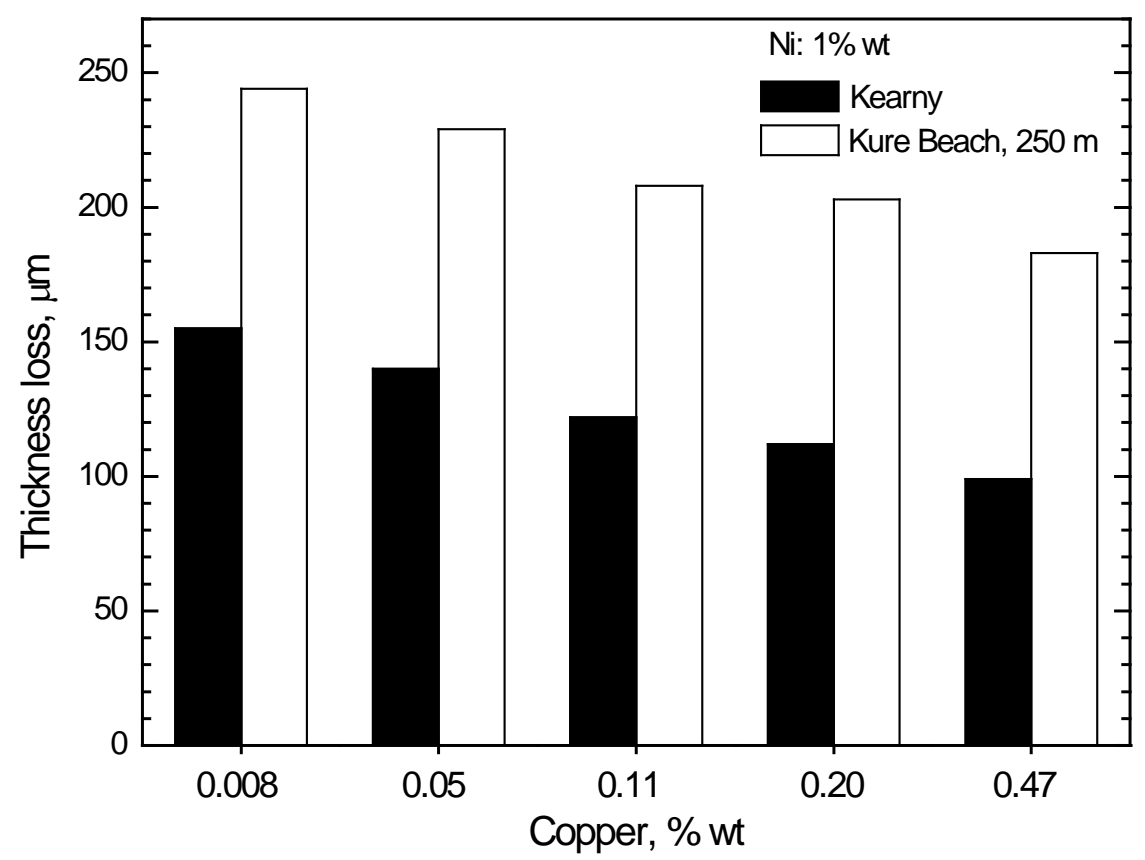

Figure 6 


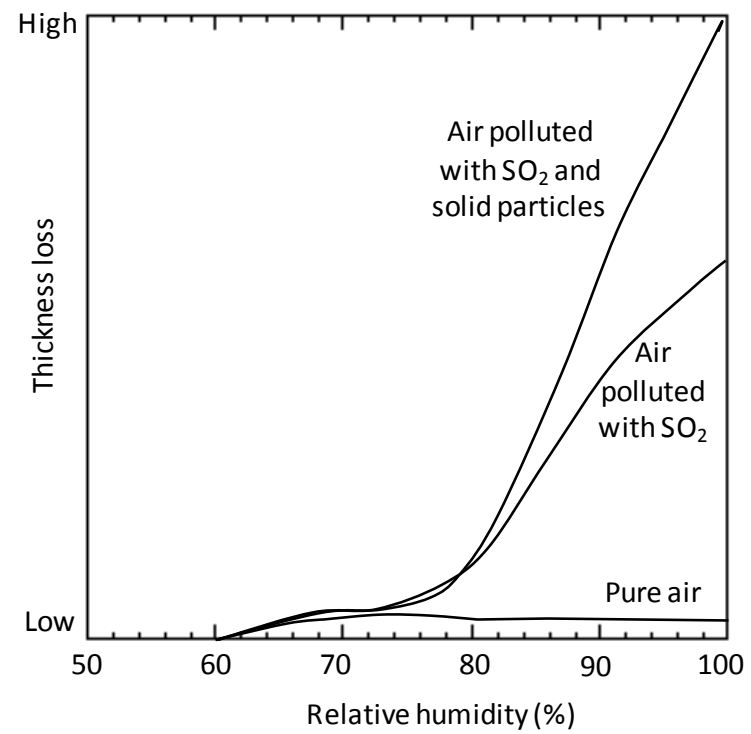

Figure 7 


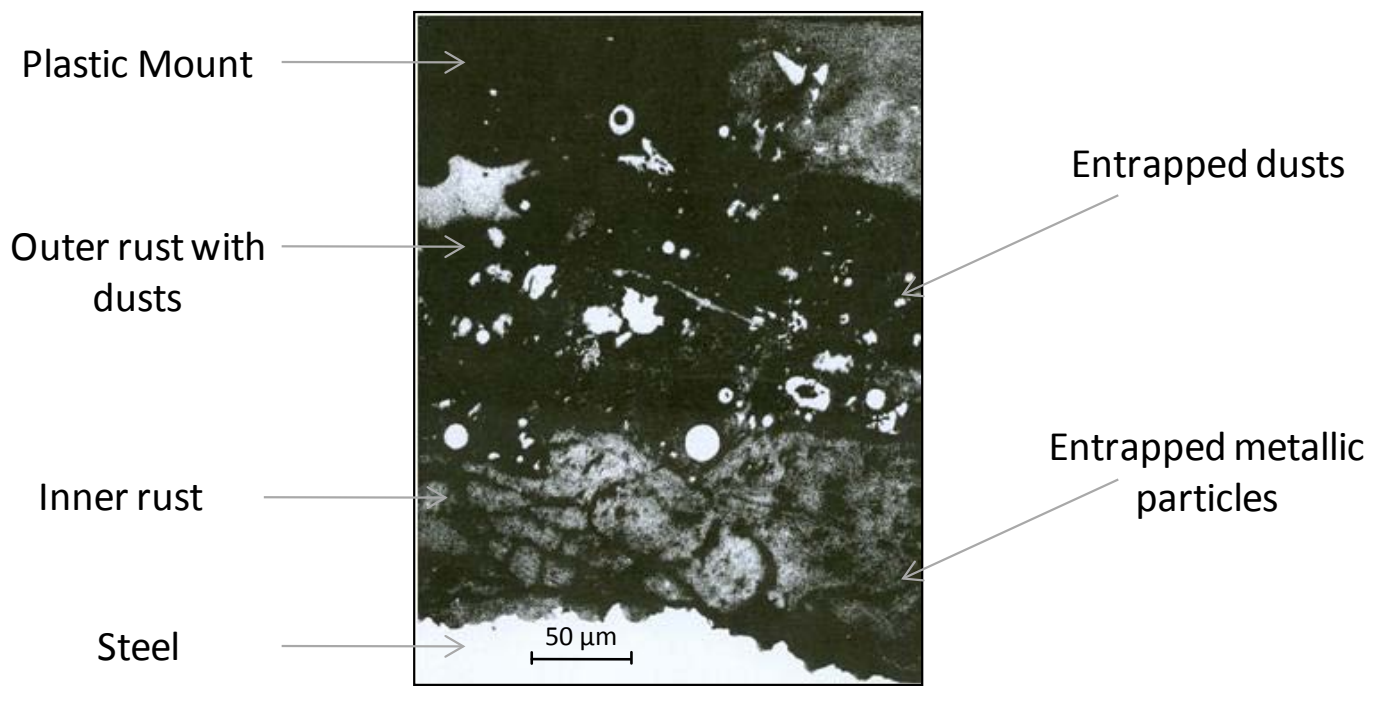

Figure 8 


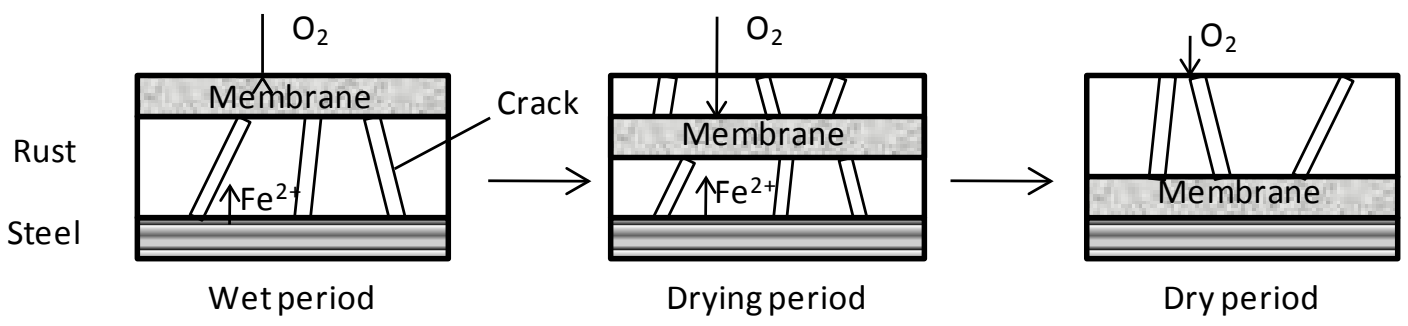

Figure 9 
Air

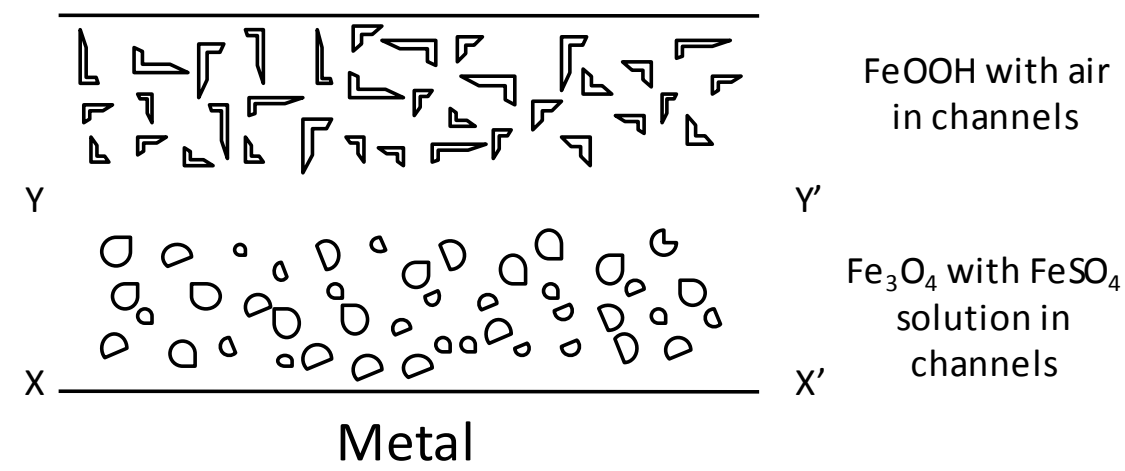

Figure 10 


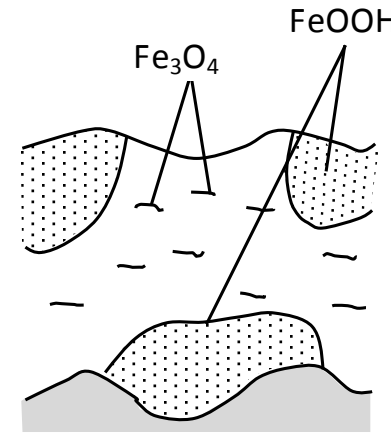

Plain Carbon Steel

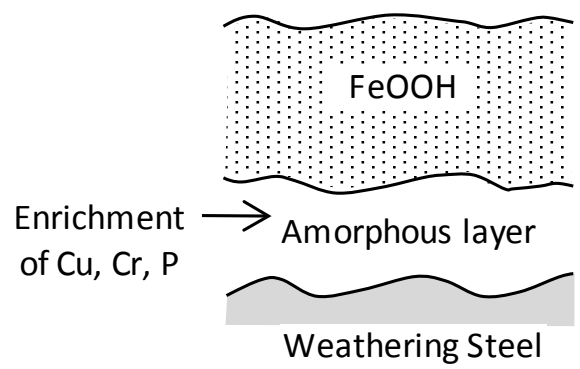

Figure 11 


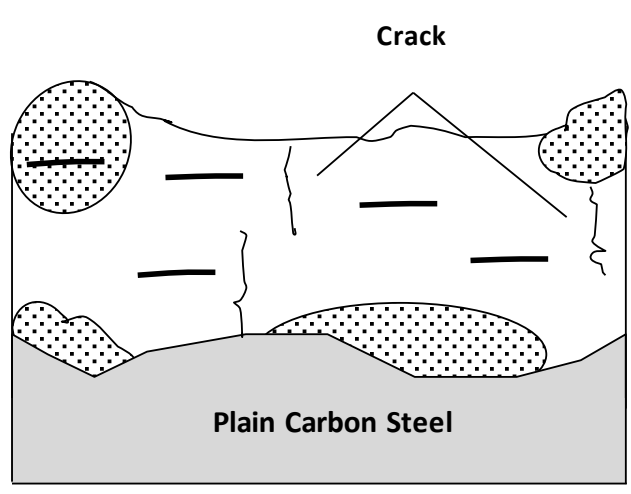

(a)

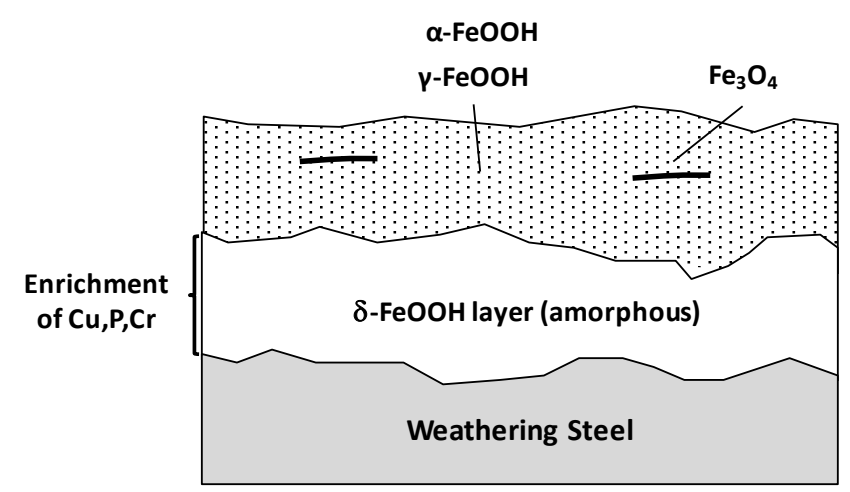

(b)

Figure 12 


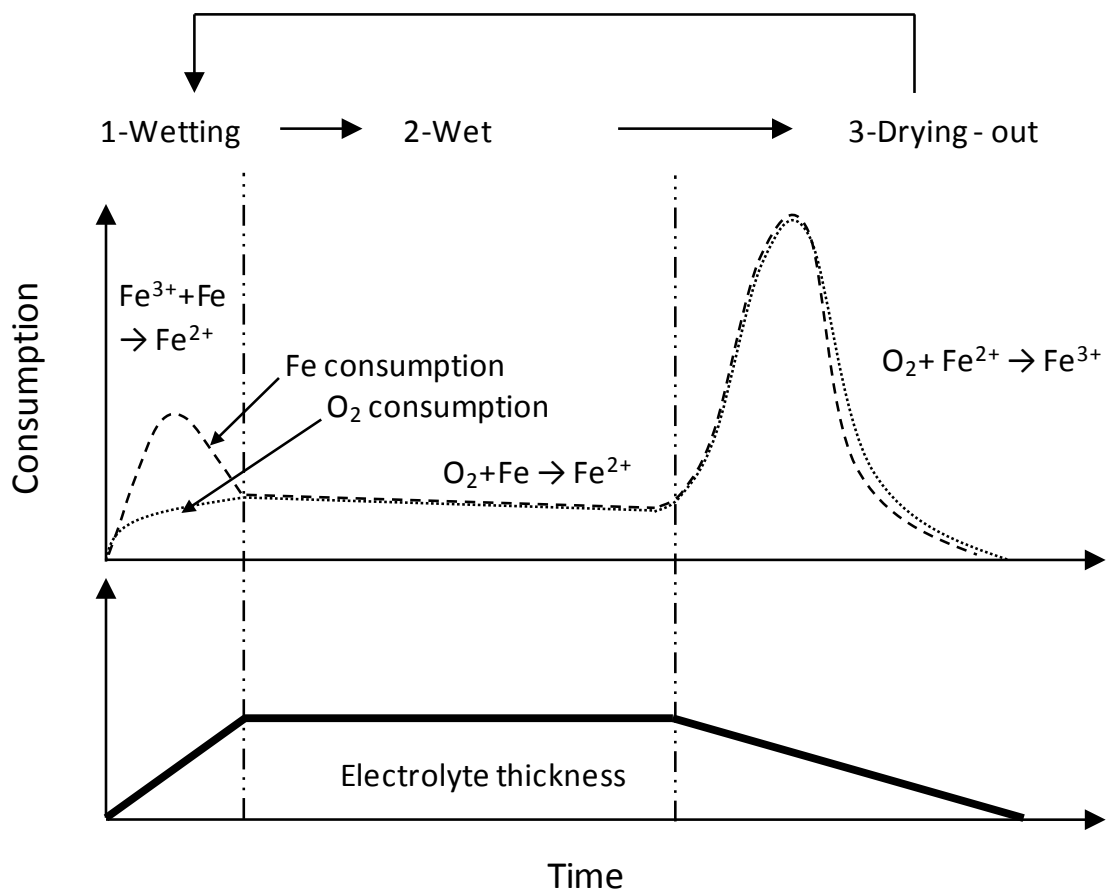

Figure 13 
Initial stage

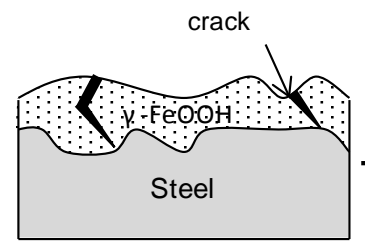

Less than a few years
Meta-stable stage

Final stage Precipitation

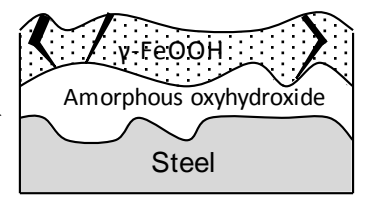

$\stackrel{\text { Solid state }}{\text { transformation }}$

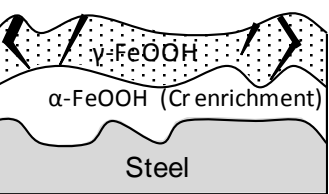

Several years

Decades

Figure 14 


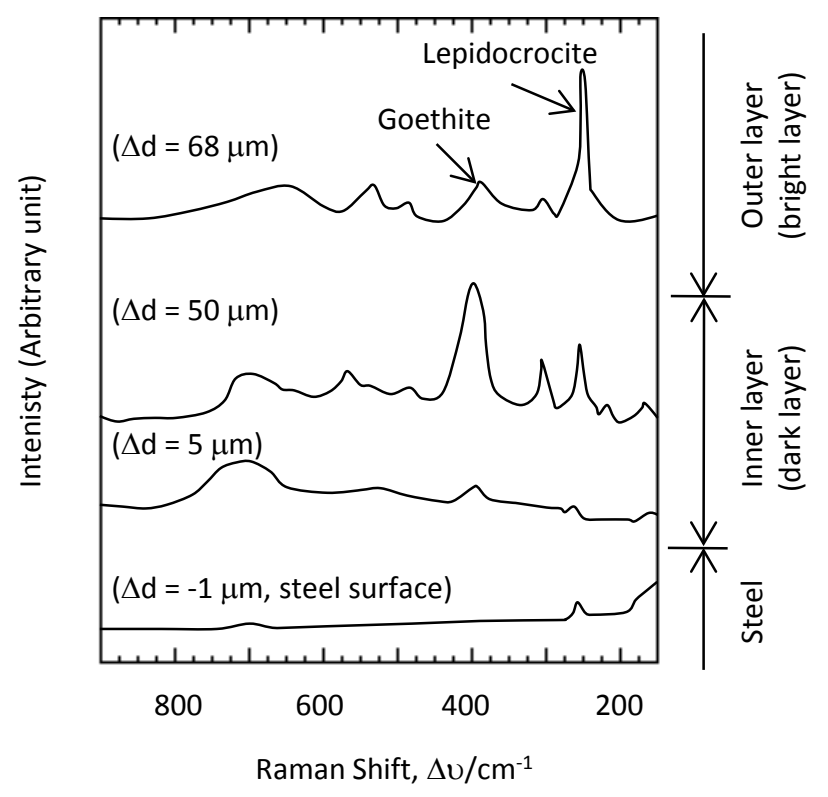

Figure 15 


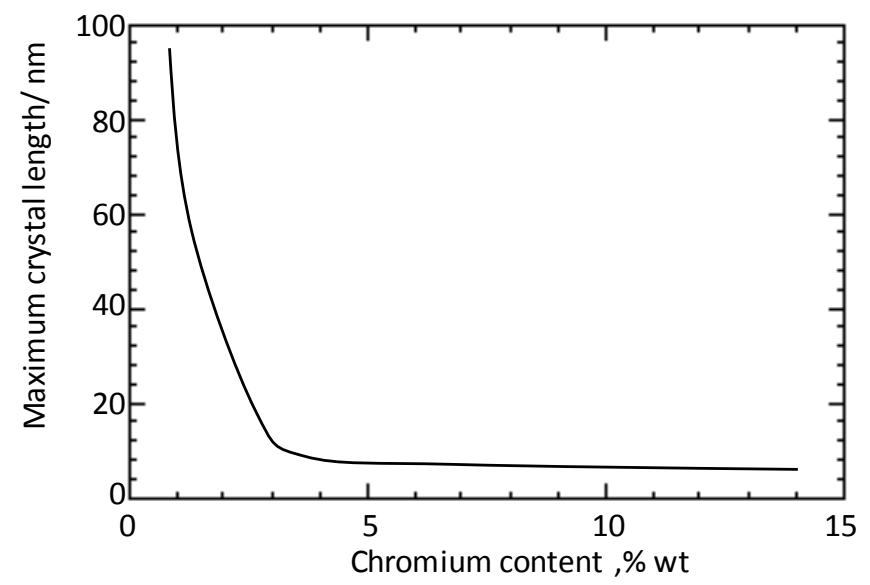

Figure 16 


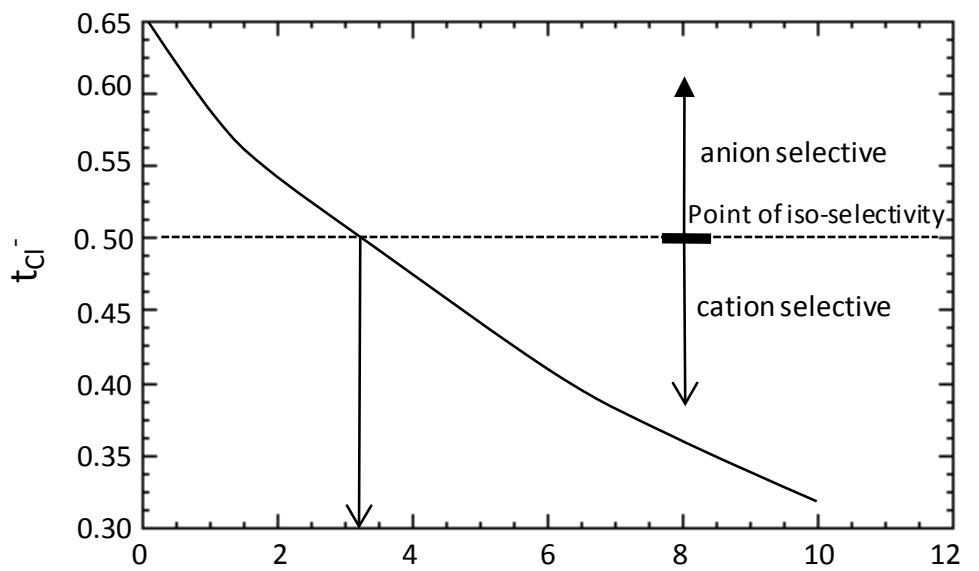

Chromium content in $\alpha-(\mathrm{Fe}, \mathrm{Cr}) \mathrm{OOH}, \%$ wt

Figure 17 


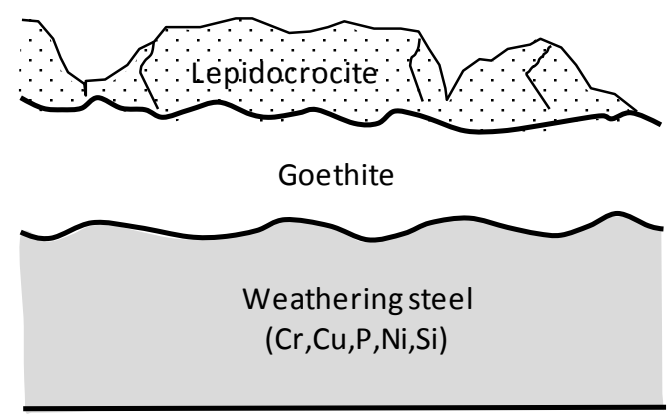

(a)

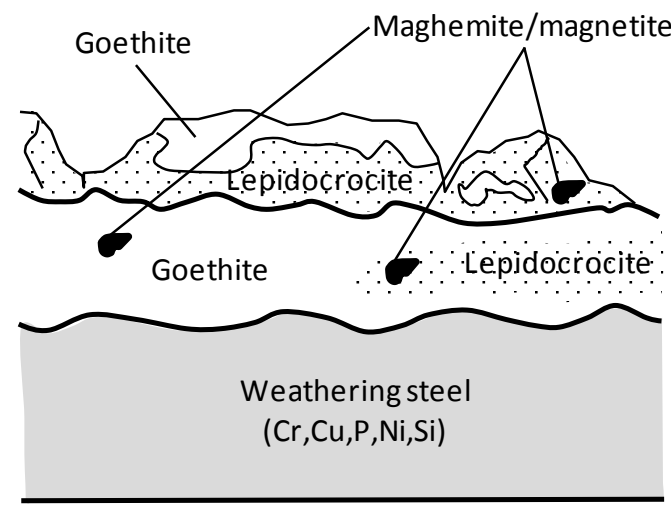

(b)

Figure 18 


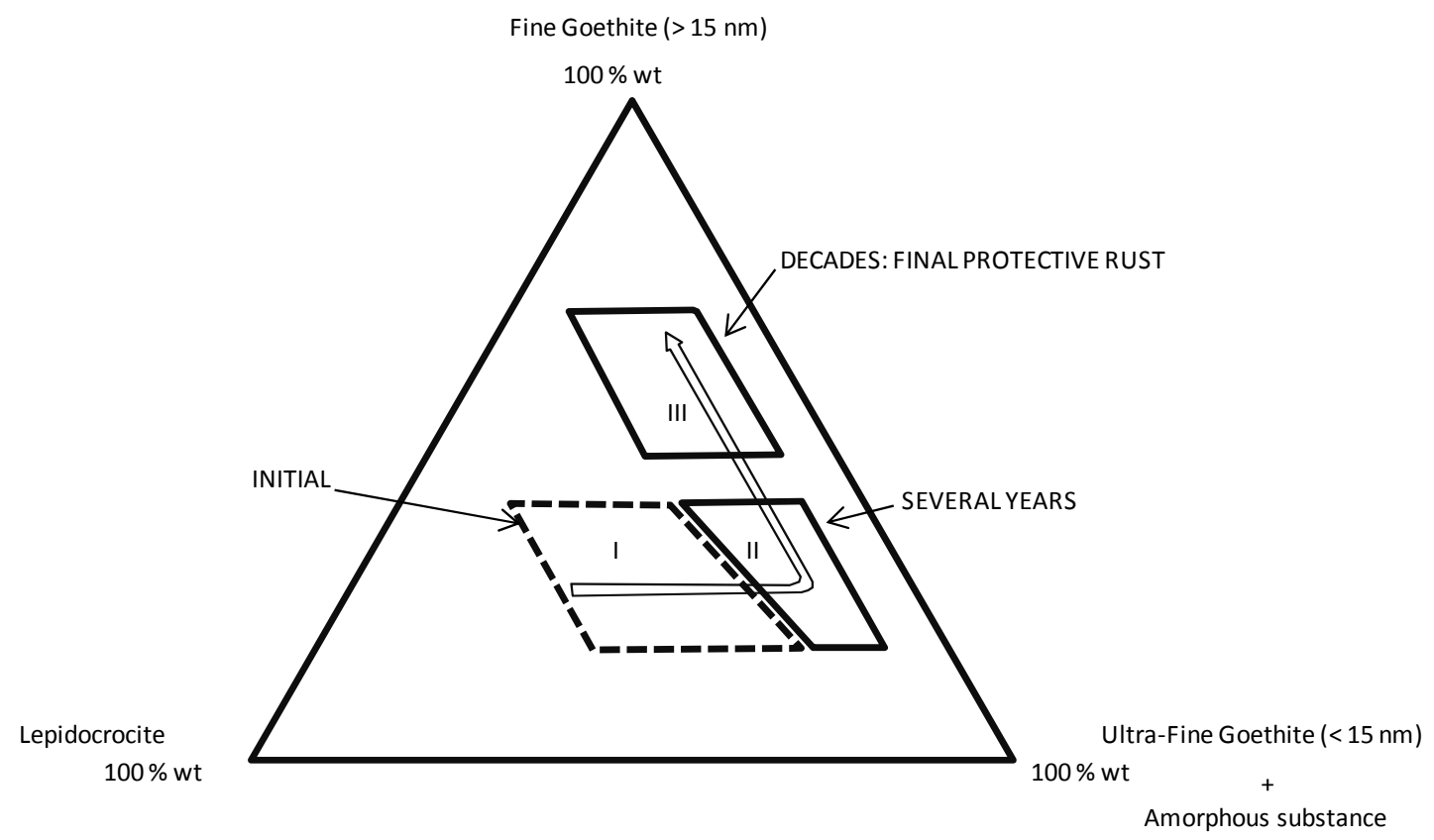

Figure 19 


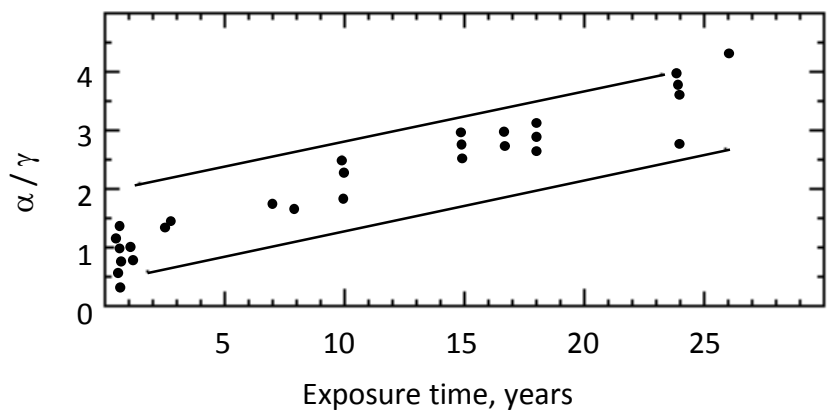

(a)

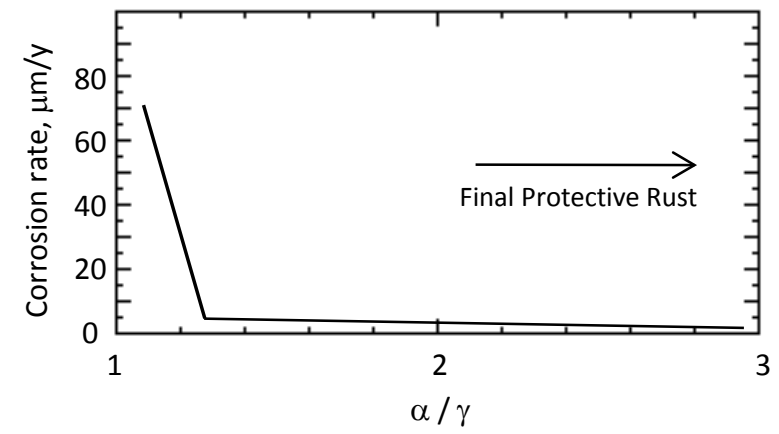

(b)

Figure 20 


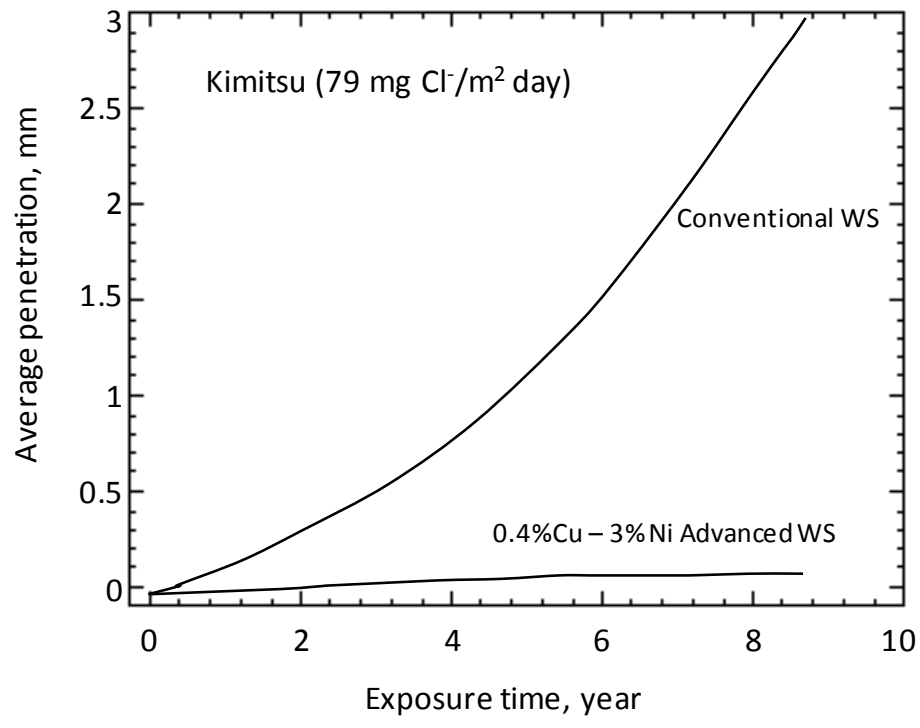

Figure 21 


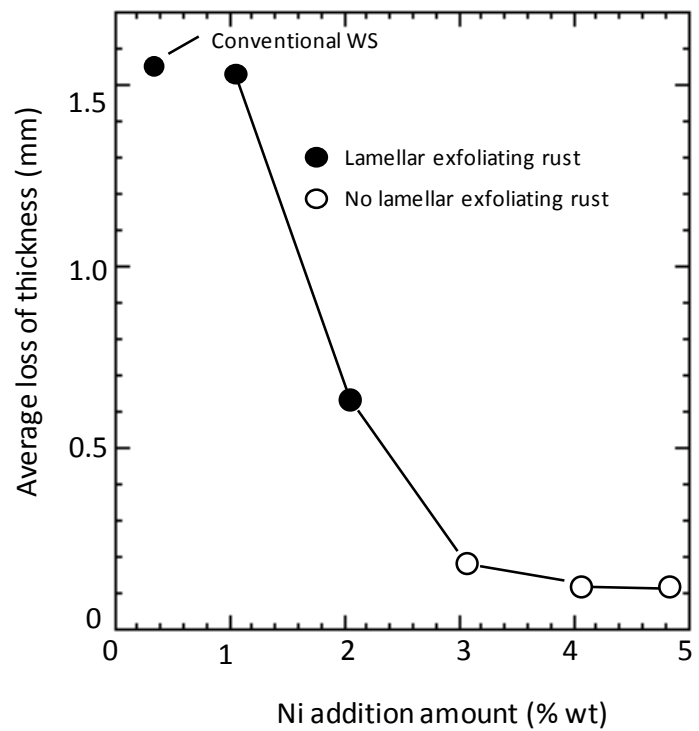

Conventional WS: C $0.05 \%$ wt - Si $0.05 \%$ wt $-\mathrm{Mn} 1.0 \%$ wt $-\mathrm{P} 0.008 \%$ wt $-\mathrm{Cu} 0.4 \%$ wt

Figure 22 
Guiding principle for alloy design

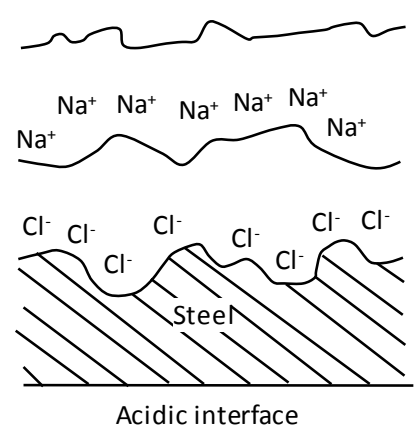

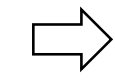

Outer rust

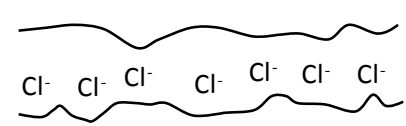

Inner rust

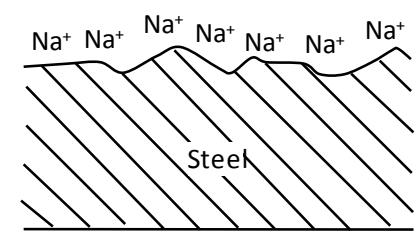

Alkali interface

Figure 23 
Table 1. Effect of the presence of sulphur and copper on corrosion of steel in an industrial atmosphere [18].

\begin{tabular}{cccc}
\hline Steel & $\% \mathrm{~S}$ & $\% \mathrm{Cu}$ & Corrosion \\
\hline $\mathrm{A}$ & 0.03 & 0.0004 & High \\
$\mathrm{B}$ & 0.03 & 0.2 & Low \\
$\mathrm{C}$ & 0.001 & 0.0004 & Low \\
$\mathrm{D}$ & 0.001 & 0.2 & Low \\
\hline
\end{tabular}


Table 2. Chemical compounds usually found in rust layers.

\begin{tabular}{cc}
\hline Name & Composition \\
\hline Oxides & \\
Hematite & $\alpha-\mathrm{Fe}_{2} \mathrm{O}_{3}$ \\
Maghemite & $\gamma-\mathrm{Fe}_{2} \mathrm{O}_{3}$ \\
Magnetite & $\mathrm{Fe}_{3} \mathrm{O}_{4}$ \\
Ferrihydrite & $\mathrm{Fe}_{5} \mathrm{HO}_{8} \cdot 4 \mathrm{H}_{2} \mathrm{O}$ \\
\hline Hydroxides & \\
Goethite & $\alpha-\mathrm{FeOOH}$ \\
Akaganeite & $\beta-\mathrm{FeOOH}$ \\
Lepidocrocite & $\gamma-\mathrm{FeOOH}$ \\
Feroxyhyte & $\delta-\mathrm{FeOOH}$ \\
\hline
\end{tabular}

